
This report was prepared as an account of work sponsored by the United States Government. Neither the United States nor the United States Atomic Energy Commission, nor any of their employees, nor ary of their contrar. tors, subcontractors, or their employees, makes any warranty, express or implied, or assumes any legal liability or responsibility for the accuracy, com. pleteness or usefulness of any information, apparatus, product or process dis. closed, or represents that its use would not infringe privately owned rights.

Printed in the United States of America. Available from National Technical Information Service

U. S. Department of Commerce 5285 Port Royai Road

Springfield, Virginia 22151

Price: Printed Cofy $\$ 3.00$; Microfiche $\$ 0.95$ 


\author{
LA-4875 \\ UC-48 \\ ISSUED: January 1973
}

10storemos

scientific laboratory

of the Universily of California

LOS ALAMOS, NEW MEXICO 87544

$\downarrow$

\title{
Plutonium in Autopsy Tissue
}

by

\author{
Evan E. Campbell \\ Morris F. Milligan \\ William D. Moss \\ Harry F. Schulte \\ James F. Mclnroy
}

Work partially supported by the US AEC Division of Biology and Medicine.

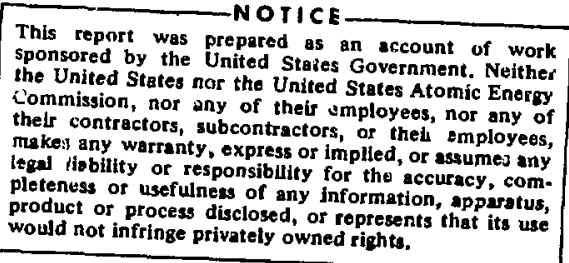




\title{
PLUTONIUM IN AUTOPSY TISSUE
}

\author{
by \\ Evan E. Campbell, Morris F. Milligan, \\ William D. Moss, Hany F. Schulte, and James F. Mcinroy
}

\begin{abstract}
Since 1959, selected tissues from deceased humans have been examined for the presence of plutonium. The original purpose was to correlate plutonism body burden calculated from urine assay and actual burden determinesl by analysis of autopsy materials. The tissues have provided data on plutonium deposition in man resulting from general distribution of plutonium in the environment through global faliout and that resulting from plutonium fabrication or researci and development operations.

Lung, liver, kidney, lymph, and skeletal tissue are the principal materials examined. The analytical data, the significance of the findings, and the considerable uncertainties in the radiochenical analysis and calculations are discussed. The data will be completely evaluated in other Los Alamos Scientific Iaboratory reports.

The results are contained in the appendixes to this report. Median concentrations in the organs and tissues of a general population (not occupationally exposed) were (each number represents dis/min Pu per $\mathrm{kg}$ ): liver,1.4; lung, 0.8 ; lymph nodes, 3.0; bone, 0.6 ; and kidney, 0.6. Plutonium concentration is generally higher in the tissues of those who have been occupationally exposed to plutonium; the concentration obviously depends upon the nature of the exposure and its severity anc luration.
\end{abstract}

\section{INTRODUCTION}

Since 1959, the Los Alamos Scientific Laboratory Industrial Hygiene Group has collected necropsy material for analysis. The analysis consists of plutonium measurement by variations of the methods routinely used in the bioassay program to determine plutonium in the urine of employees potentially exposed to plutonium.

The original intent of our tissue-analysis effort was to seek confirmation or denial of the validity of estimates of plutonium body burdens by urinalysis. In at least one notable case, ${ }^{1}$ confirmation of estimates of body burden made during life was obtained by analysis of tissues from the deceased. The ubiquity of plutonium in the environment has since led us to examine autopsy material from the general population, to learn whether plutonium exists in detectable amounts in the tissues of individuals from that population.

Harley ${ }^{2}$ has estimated that the testing of nuclear weapons distributed $\sim 300 \mathrm{kCi}$ of ${ }^{238} \mathrm{Pu}$ over the surface of the earth before the beginning of the moratorium. Tests by France and China have added about $5 \%$. More recently, ${ }^{238} \mathrm{Pu}$ became detectable in the environment because of the burnup of a SNAP generator. It is therefore expected that plutonium can be detected in the tissue of nonoccupationally exposed humans. Tissue data are limited because of the various tissue-analysis problem?s that will be discussed.

Magno $^{3}$ reported an average of 0.14 to $1.1 \mathrm{pCi}$ of ${ }^{239} \mathrm{Pu} / \mathrm{kg}$ wet weight in the lungs, with the bone 
concentrations ranging from 0.04 to $0.12 \mathrm{pCi} / \mathrm{kg}$. Tarasov et al." tried to correlare the measured air concentration in each year with the lung concentration of humans over the age of 50 who did not suffer from any pulmonary pathology. Their data suggest that pulmonary deposition is consistent with air concentration. They gave:

$0.15 \pm 0.1 \mathrm{pCi}$ of ${ }^{239} \mathrm{Pu} / \mathrm{kg}$ in the lung for 1965 , and

$0.1 \pm 0.2 \mathrm{pCi}$ of ${ }^{239} \mathrm{Pu} / \mathrm{kg}$ in the lurig for 1966 .

The concentrations in the tracheobronchial lymph nodes for the same period were $6.85 \pm 8.5$ and $9.6 \pm 7.6 \mathrm{pCi} / \mathrm{kg}$, respectively. Thkizawa ${ }^{5}$ aralyzed two to five cases per year from the Niigata District in Japan from 1960 to 1967; his analyses showed that the lung contained 0.012 to $0.038 \mathrm{pCi} / \mathrm{kg}$. Takizawa stated that he found $2.36 \mathrm{pCi}$ ${ }^{239} \mathrm{Pu} / \mathrm{kg}$ in the genital organs of a 70-yr-old woman and $6.3 \mathrm{pCi} / \mathrm{kg}$ in her bone. Krey et al. ${ }^{6}$ reported the following results for a group of cases.

\section{PLUTONIUM CONCENTRATION}

\begin{tabular}{lc} 
& (dis/ $/ \mathbf{m i n}) / \mathbf{k g}$ \\
\cline { 2 - 2 } Lung & $1.74 \pm 0.17$ \\
Lymph Node & $11: \pm 4$ \\
Kidney & $0.99 \pm 0.22$ \\
Gonad & $7.9 \pm 1.9$
\end{tabular}

They concluded that the lung and lymph-node deposition confirmed values that might be calculated from airborne contamination.

Because of the variable values reported above, the AEC provided a number of samples from metropolitan New York City so that we might confirm or deny the plutonium concent:ations previously reported.

\section{TISSUE SAMPLES}

\section{A. Sample Selection}

The local pathologist provides samples from as many autopsies as possible. No atrempt is made to exclude any cast. Therefore, $w:$ receive a number of samples from outside th.e geographical area as a result of traumatic accidents occurring wichin the jurisdiction of the pathologist. Most of the samples, however, are from residents of Los Alamos, New Mexico. This is a single-industry town, with a population of approximately 14.000 , containing a research laboratory. The industry includes a plutoniumresearch development laboratory. Studies of the plutonium in the environs of this laboratory have been documented. ${ }^{7-9}$
A special series of samples were collected in New York City through the cooperation of Dr. John Harley of the New York Operations Office of the AEC. These samples were from males and were received by the medical examiner's office. Generally only small weights of each organ were made available, but the gonads were included. The limited mass available for these analyses permitted detection of $\sim 0.03 \mathrm{dis} / \mathrm{min}$ of plutonium in the aliquot, or a lower limit of 1.5 (dis/min)/ $\mathrm{kg}$ if a $20 \mathrm{~g}$ sample was used.

Since June 1970, this program has been expanded to include a number of other areas, using a similar selection of cases.

\section{B. Sample Storage}

The pathologist selects the tissues and packages each separately in a plastic bag. These tissues are held in a freezer until released by the pathologist for chemical processing. A small sectior, of the lung, liver, kidney, and lymph node is preserved for analysis for other metals.

\section{Autopsy Samples}

Lung. Both lungs are nermally received and treated without special preparation. Small amounts of tissue other than lung normally accompany the sample. No attempt is made to separate the lower bronchial lymph nodes or other lymphatic tissue from the lung tissue itself. The weight recorded is the weight actually received at the time of preparation and represents both lungs. The amount of plutonium in the lung includes that in the pulmonary lymph tissue.

Liver. The whole organ is normally receiver and prepared for chemical analysis.

Kidney. At least one kidney has been used in each case. Every attempt is made to obtain both kidneys for analysis.

Gonads. The gonads were included in samples received from New York City and Denver, Colorado.

Lymph Nodes The lymphatic tissue of the tracheobronchial region is received for analysis. Usually it includes only the lymph nodes of that region and is only a small part of the total lymph-node mass. In a few cases, adnexal tissue is included.

Bone. Unless otherwise designated, all bone samples arc wedges from the 4 th and 5 th lumbar vertebrae. The bone weights include only a small amount of adnexal tissu'e. If other types of bones are available, they are analyzed separately. 
TABLE I

\section{A. Method}

FRACTIONS ANALYZED

1. Each tissue is placed in an appropriate vessel for dry ashing. The liver and lung are placed in porcelain evaporating dishes, and the other tissues are placed in Pyrex beakers of appropriate size. Since June of 1971 , all tissues have been air dried at 100 to $150^{\circ} \mathrm{C}$ to remove excess water.

2. The samples are placed on shelves in a muffle furnace to prevent direct heating of the vessel. The temperature-programed muffle furnace is operated from 200 to $500^{\circ} \mathrm{C}$, reaching maximum temperature in $24 \mathrm{~h}$. The samples are held an additional $24 \mathrm{~h}$ at $500^{\circ} \mathrm{C}$ partly to whiten them.

3. After the samples cool in the furnace, the liver and lung residues are transferred to $800-\mathrm{cm}^{3}$ beakers. The vessels are thoroughly washed with $2 N$ nitric acid, and the washing, combined with the residue, is evaporated to dryness.

4. Each residue is heated repeatidly with nitric and hydrofluoric acid until it remains white. From 1968 to 1971 , we used hydrogen peroxide in conjunction with nitric acid to speed the ashing process, but because of concentrated hydrogen peroxide's high metal content, we no longer use it. Excess HF is removed by repeated evaporation with nitric acid.

5. Each residue is finally dissolved in $2 N$ nitric acid and transferred to a volumetric flask. Except for the lung and bone samples, the procedure brings about complete dissolution of the residue. The following volumetric flasks are normally used for each sample.

$\begin{array}{lrlr}\text { Liver } & 1000-\mathrm{cm}^{3} & \text { Lymph Nodes } & 50-\mathrm{cm}^{3} \\ \text { Lung } & 1000-\mathrm{cm}^{3} & \text { Bone } & 250-\mathrm{cm}^{3} \\ \text { Kidney } & 100-\mathrm{cm}^{3} & \text { Gonads } & 50-\mathrm{cm}^{3}\end{array}$

6. Each sample is mixed well and stored pending analysis of groups of samples.

7. At the time of analysis, aliquots are taken from each sample as indicated in Table I. Each aliquot is "spiked" with ${ }^{236} \mathrm{Pu}$ at a level of $2 \mathrm{dis} / \mathrm{min}$ and evaporated to dryness, treated with concentrated nitric acid several times, and allowed to evaporate almost to dryness. The salts of the lung and liver are dissolved in $200 \mathrm{~cm}^{3}$ of $8 \mathrm{~N}$ nitric acid, sodium nitrite is added, and the mixture is allowed to stand overnight before anion-exchange separation.

\begin{tabular}{|c|c|c|c|c|}
\hline \multirow[b]{2}{*}{ Tissue } & \multicolumn{2}{|c|}{ Through 1969} & \multicolumn{2}{|c|}{ Since 1970 \& Repeats } \\
\hline & $\begin{array}{c}\text { Aliquot } \\
\left(\mathrm{cm}^{3}\right)\end{array}$ & $\begin{array}{l}\% \text { of } \\
\text { Total }\end{array}$ & $\begin{array}{c}\text { Aliquor } \\
\left(\mathrm{cm}^{3}\right)\end{array}$ & $\begin{array}{l}\text { \% of } \\
\text { Total }\end{array}$ \\
\hline Lung & 50 & 5 & 500 & 50 \\
\hline Liver & $\$ 0$ & 5 & 500 & 50 \\
\hline Kidney & 10 & 10 & 50 & 50 \\
\hline Lymph & & & & \\
\hline Node & 10 & 20 & 1.0 & 20 \\
\hline Bone & 10 & 4 & 50 & 20 \\
\hline
\end{tabular}

Normaily, all the salts except the lung and bone are in solution. These latter two suspensions are shaken before aliquoting as listed above. Most of the tissue salts are in solution after evaporation and redissolution in $8 \mathrm{~N} \mathrm{HNO}$. All the salts are treated with hydrofluoric acid, and the excess HF is removed by repeated nitric acid evaporation and treatment with boric acid.

8. Each aliquot is subjected to anion exchange on a Bio-Rad AG 1 × 2 anion-exchange resin, using a modification of the procedure of Campbell and Moss. ${ }^{\text {In }}$ The 6-mm by $10-\mathrm{cm}$ columns are eluted with dilute hydrochlori: acid, and the eluate is evaporated to dryness and prepared for electrodeposition using an acid oxalate electrolyte. The plutonium is electroplated on $1 / 2$-in.-diam stainless steel plates and counted by alpha spectrometry, using a $300-\mathrm{mm}^{2}$ silicon-surface barrier detector. The column effluents that do not contain plutonium are saved for possible future use. Each sa nple is counted for $1000 \mathrm{~min}$ with a counter efficiency of $30 \%$ and a counter background of $0.004 \pm 0.003$ counts $/ \mathrm{min}$. The ${ }^{239} \mathrm{Pu}$ reagent blank is $0.007 \pm 0.004$ cournts/min, including the ${ }^{236} \mathrm{Pu}$ internal standard.

Until 1967, we analyzed all samples by Schwendiman and Healy's ${ }^{11}$ method, using nuclear-track alpha counting, pfeceded by electrodeposition as stated above. We have reanalyzed many samples from that time which contained analytically significant amounts, using ${ }^{236} \mathbf{P u}$ tracer added when the aliquot is taken. Schwendiman and Healy's method cannot be used in the presence of added ${ }^{236} \mathrm{Pu}$ tracer. We have also reanalyzed a number of samples of analytical sigrificance using larger aliquots to demonstrate that the plutonium recovery was essentially complete. 


\section{B. Replicate Analyses}

Our former procedure was to select $50-\mathrm{cm}^{3}$ aliquots of a $1000-\mathrm{cm}^{3}$ solution of lung or liver tissue for analysis. This is $1 / 20$ th of the total weight, or $\sim 50 \mathrm{~g}$ of the lung or $\sim 60 \mathrm{~g}$ of liver, a quantity satisfactory for a surveillance of occupational-exposure cases. We reanalyzed 15 lung and liver tissue solutions containing measurable amounts of plutonium, using a $500-\mathrm{cm}^{3}$ aliquot.

Measurenents from analysis of large $\left(500-\mathrm{cm}^{3}\right)$ and small $\left(50-\mathrm{cm}^{3}\right)$ aliquots indicate that use of the large aliquot reduces the standard deviation of the individual analysis significantly, but also show no statistically significant difference in recults obtained from analyzing large or small aliquots of the same solution. Replicate analyses of various tissue-ash solutions analyzed at the same time by the same method indicate good agreement among aliquots. Table II indicates the typical degree of replication.

\section{Effect of Salts on Plutonium Recovery}

Becaluse our chosen procedure involves an isolation technique (ior exchange) without a preconcentration step, we investigated the effects of normally occurring salts in tissue-sample solutions. We used a solution of bone and lung from a case known to have a detectable plutonium burden for analysis. Each aliquot was evaporated to dryness and made to the same volume for ionexchange separation. The mass of salt in each solution wis determined by weighing an evaporated aliquot. The results are shown in Table III.

Because these results suggest that ancilysis of unnecessarily large aliquots can lead to low recoveries, we use no

\section{TABLE II}

TYPICAL REPLICATION OF VALUES (dis/min per aliquot)

\section{EFFECT OF SALTS ON PLUTONIUM RECOVERY}

\begin{tabular}{|c|c|c|c|c|}
\hline \multirow{2}{*}{$\begin{array}{c}\text { Tissue } \\
\text { Solution } \\
\text { Analyzed } \\
\left(\mathrm{cm}^{3}\right)\end{array}$} & \multicolumn{2}{|c|}{ Bone } & \multicolumn{2}{|c|}{ Lung } \\
\hline & $\begin{array}{c}\text { Measured } \\
\text { Activity } \\
\text { (dis/ } \mathrm{min} / \mathrm{cm}^{3} \text { ) }\end{array}$ & $\begin{array}{l}\text { Mass of } \\
\text { Solids } \\
\text { (g) }\end{array}$ & $\begin{array}{c}\text { Measured } \\
\text { Activity } \\
\left(\mathrm{dis} / \mathrm{min} / \mathrm{cm}^{3} \text { ) }\right.\end{array}$ & $\begin{array}{l}\text { Mass of } \\
\text { Solids } \\
\text { (g) }\end{array}$ \\
\hline 1 & 0.39 & 0.058 & 5.31 & 0.014 \\
\hline 2 & 0.39 & 0.117 & 4.16 & 0.027 \\
\hline 3 & 0.34 & 0.175 & 4.25 & 0.041 \\
\hline 5 & 0.37 & 0.292 & 3.75 & 0.068 \\
\hline 10 & 0.32 & 0.584 & 3.32 & 0.137 \\
\hline 15 & 0.25 & 0.876 & 3.42 & 0.206 \\
\hline 25 & 0.23 & 1.46 & 3.78 & 0.342 \\
\hline 50 & 0.15 & 2.92 & 3.34 & 0.685 \\
\hline
\end{tabular}

more than $50 \mathrm{~cm}^{3}$ in aliquoting highly concentrated solutions. Each aliquot is evaporated to dryness, treated with nitric acid, and made to $500 \mathrm{~cm}^{3}$ with $8 \mathrm{~N}$ nitric acid for ion-exchange isolation to reduce the salt concentration. By increasing the total volume of the tissue-salt solution and increasing the column size to $6 \mathrm{~mm}$ by $10 \mathrm{~cm}$, we have minimized the effects of high ionic strength noted above.

\section{Recovery of Plutonium During Analysis}

The use of ${ }^{236} \mathrm{Pu}$ to evaluate, the radiochemical se paration does not represent an atten $\mathrm{r}_{\mathrm{f}} \mathrm{t}^{t}$ to determine total yield of the overall procedure; accordingly, the tracer is added at the time of aliquotting, not at the time of ashing. The library of tissue solutions is still available for analysis for other nuclides. Examples of tracer recovery are given in Table IV.

TABLE IV

\section{RECOVERY OF ${ }^{236}$ Pu FROM TISSUE SOLUTIONS}

\begin{tabular}{|c|c|c|c|c|}
\hline Solution & 1 & 2 & 3 & Mean \\
\hline A & 0.38 & 0.62 & 0.36 & 0.45 \\
\hline B & 0.01 & 0.06 & 0.02 & 0.01 \\
\hline $\mathrm{C}$ & 0.33 & 0.39 & 0.53 & 0.42 \\
\hline D & 1.1 & $1 . '$ & 1.2 & 1.2 \\
\hline E & 0.07 & 0.03 & 0.11 & 0.07 \\
\hline$F$ & 5.9 & 7.8 & 5.3 & 6.3 \\
\hline$G$ & 28 & 25 & & 26.5 \\
\hline $\mathbf{H}$ & 38 & 35 & 40 & 38 \\
\hline I & 3.5 & 3.7 & & 3.6 \\
\hline $\mathrm{J}$ & 0.11 & 0.10 & & \\
\hline
\end{tabular}

\begin{tabular}{|c|c|c|c|c|}
\hline Tissue & Bone & Liver & Lung & Gonad \\
\hline \multicolumn{5}{|l|}{ No. of } \\
\hline Samples & 9 & 9 & 9 & 9 \\
\hline \multicolumn{5}{|l|}{ Mean } \\
\hline \multicolumn{5}{|l|}{ R.ecovery } \\
\hline$(\%)$ & 80.1 & 74.1 & 74.1 & 85.7 \\
\hline \multicolumn{5}{|l|}{ Standard } \\
\hline Deviation & 13.4 & 18.9 & 12.3 & 26.7 \\
\hline
\end{tabular}


The analytical losses after the tissue is ashed are low, and may be estimated from the percentages of recovery given above.

\section{E. Overall Recovery}

We spiked beef tissues of the same weight as human organs with ${ }^{239} \mathrm{Pu}$ and used the outlined procedure to ash and analyze the tissue for plutonium. The overall recovery was $87 \pm 8 \%$.

\section{F. Observed Losses}

Because some insoluble material normally defies dissolution in $2 N$ nitric acid, we conducted additional studies. The salts, probably silicates and phosphates, cannot be brought into compiete solution at this stage. We used solutions of tissue salts from individuals known to have been occupationally exposed to plutonium in the following study. We examined paired aliquots of the solution and of the insoluble residue in the following manner.

The suspension (in $2 N$ nitric acid) was well mixed during aliquoting to produce as homogeneous a mixture as possible. Small aliquots of the suspension were taken and centrifuged. The insoluble portion and the centrifugate were separated and spiked with ${ }^{236} \mathrm{Pu}$ as an internal tracer. Each portion was evaporated to dryness, treated repeatedly with hydrofiuoric acid and nitric acid, and finally evaporated repeatedly with nitric acid to remove the excess HF. Any fluoride surviving the evaporation was complexcd as she fluoborate, after which the solutions were carried through the ion-exchange procedure and the separated plutonium was counted by alpha spectrometry. The results indicate that the loss by incomplete dissolution of the pluionium from the salts in the procedure witbout repeated $\mathrm{HF}$ treatment may be as much as $20 \%$.

\section{RESULTS}

All of the results obtained under this program are reported in the appendixes:

Appendix A - Tables of Individual Cases

Appendix B - Cumulative Frequency Distributions

ippendix C - Summary Tables

The tables of individual cases contain the most tetailed, properly available information about each case examined. Included are case numbers, assigned by this laboratory and unrelated to any numbers assigned by pathologists or hospitals, ocrupation at time of death, age, sex, city of residence, and cause of death as described by the pathologist. The cause of death is also described by the HEW Code Number. ${ }^{12}$ Laboratory data included are: weight of organ (or tissue) as received; total volume of ash solution; aliquot of ash solution analyzed; disintegrations per minute of plutonium in the aliquot, of plutonium in the total sample, and of plutonium per gram of sample (concentration); and disintegrations per minus. per standard organ, calculated for convenience, weights of standard organs having been defined ' $-y$ ICRP Publication 2.13

The cumulative frequency distributions (Appendix B) are presented for convenience in viewing the results on a population basis rather than the individual basis used in Appendix A.

The summary tables (Appendix $C$ ) are the least detailed, and briefly present the median values (50th percentile) derived from Appendix B.

\section{EVALUATION OF RESULTS}

The plutonium concentrations in the analyzed tissues cannot be compared directly because the portions of the organs analyzed were never identical. To put the data on a common basis, therefore, we converted the results per aliquot to disintegrations per minute per kilogram and disintegrations per ninute per standard organ weight. We used these data to estimate thc concentration of plutonium in human tissues per unit of weight for each of the population groups listed in Appendix A.

Because of incomplete knowledge of sample selection, incomplete tissue collection, and uncertainties in the assav, we have not tried to evaluate statistical differences among groups of data, but have chosen to leave the testing to another study involving additional data with better controls.

Histograms of the frequency distribution of the data for each type of tissue from Appendix A were found to be skewed to the right. We therefore assumed that the data are distributed log-normally, and demonstrated the validity of that assumption by plotting the cumulative frequency of the number of samples against the plutonium concentration on logarithmic normal-probability graph paper. The data thus plotted gave acceptable straight-line fits, and these graphs are presented in Appen$\operatorname{dix} B$.

Every data point obtained experimentally is included in Appendix B. It is obvious that excluding all those results that were helow our detection limit would increase the median unrealistically; therefore, results that were, in $f_{d c t}$, below our detection limit are assigned an artificial value of $0.03(\mathrm{dis} / \mathrm{min}) / \mathrm{kg}$ simply to aid in the presentation of the data.

This assignment makes the plots flatten at the lower section, consistent with limitations of nueasurement sensitivity. Similar deviation from the straight-line fit at the upper end is associated with a selection against an upper 
limit of sample specification. From the logarithmicprobability plots, wic estimated the median, or 50th percentile, data points for each distribution expressed as disintegrations per minute per kilogram. The estimates are shown in Table C-I (Appendix C). The median values for each tissue type and population group suggest that there are no significant differences among the population groups except for the high-potential-exposure grcup.

Other aspects of the plutonium concentration in huma.i tissue may be obtained from the log-normal probability graphs. We combined the data from Tables A-I through A-III ? nd A-VII into a single unexposed population group and plotted the data for each tissue on lognormal probability graphs. These graphs provided estimates of the median, the 95 th percentile, and the 5 th percentile. These points include $90 \%$ of the results. These data are shown in Table C-II, along with similarly derived estimates of the occupationly exposed groups.

\section{ACKNOWLEDGMENTS}

We ackiowledge the assistance of the entire staff of the Laboratory Section of Group H-5 and all members of the Health Division who have helped collect supportive information, especially B. C. Eutsler, H. M. Ide, I. K. Kressin, and Jean McClelland. We are grateful to the late Thomas L. Shipman, M. D., Health Division Leader, for his encouragement in this program. The program continues ander the direction of George L. Voelz, M. D., with ine astistance of the Division of Biomedical and Environmental Kescasih of the Atomis rengy Commission and is a croporative effort among Battellc Noithosest Laboratories, LASL, "int the U. S. "Transuranium Registry." H/e thank various Divisions within the Liborarory, in particular P Division, for their assistance and preparation of efectronic ecuipment used to determine plintonium Many people have assisted in the preparation and anatysis of samples; these inchude Rita Bieri, Romualda Madrid, Komayne Owens, Sherry Step̧hens. Patricia Isham, and Iidena Royles. Doctors C. C. Lushibaugh and Michael $w$. Stcwart performed the autopsies and seiected many of the semples.

\section{REFERENCES}

1. T. L. Shipman et al., "Acate Radiation Death Resulting from An Accidenta! Nuclear Cricica! Excursion," J. Occ. Med. 3, 146-192 (1961), Special Supplement.

2. J. H. Harley, "Worldwide Fallou im Weapons Tests," pp. 4-5 in "Proceedings of Environmental Plutonium Symposium," Los Alamos Scientific Laboraotry report LA-4756 (1971).

3. P. I. Magno, P. E. Kauffman, and B. Shleien, "Plutonium in Environmental and Biological Media, "Health Phys. 13, 1325-30 (1957).

4. S. I, Tarasov et al., "The Extent of Aerogenic Introduction of ${ }^{239} \mathrm{Pu}$ Into The Human Body," Gig. Sanit., 4, 34-38 (1968).

5. Y. Takizawa, "Japanese Hygienist Points Out Increase in Plutoniuın in Human Body," Japan Society of Public Hygiene, Nagoya, Japan (October 28, 1970).

6. P. W. Krey, D. Bogen, and E. French, "Plutonium in Man and His Environment," Nature 195, 263-265 (1962).

7. H. S. Jordan and R. E. Black, "Evaluation of the Air Pollution Problem Resulting from Discharge of a Radioactive Effluent," J. Amer. Indust. Iyg. Assoc. 19, 20 (1958).

8. W. R. Kennedy and W. D. Purtymun, "Plutonium and Strontium in Soil in the Los Alamos, Espanola, and Santa Fe, New Mexico, Areas," Los Alamos Scientific Laboratory report LA-4562 (1971).

9. W. K. Kennedy and W. D. Purtymun, "Plutonium and Strontum in Soil Near Technical Area 21, Los Alamos Scicitific Laisoratory, Los Alamos, New Mexico," Los Alamos Scientific Laboratory report LA-4563 (1971).

10. E. E. Campbell and W. D. Moss, "Determination of Plutonium in Urine by Anion Exchange," Health Phys. 11, 737-742 (1965).

11. L. C. Schwendiman and J. W. Healy, "Nuclear-Track Technique for Low-Level ${ }^{k} u$ in Urine, Nucleonics 16, 78 (1958).

12. "International Classification of Diseases," U. S. Department of Health, Education, and Welfarc, 1 and 2, No. 719 (Dec. 1962).

13. "Report of Committee 11 on Permissible Dose for Internal Radiation," ICRP Publication 2 (Pergamon Press, New York, 1959).

14. E. E. Campbell, W. D. Moss, L. Johnson, M. F. Milligan, Jean MeClelland, and James F. Mc'nroy, "Plutonium Concentration in Tissue of Occupationally Exposed Workers," Los Alamos Scientific Laboratory report in preparacion. 


\section{APPENDIX A}

\section{TABLES OF INDIVIDUAL CASES}

The data tabulations are divided into convenient population categories based on residential area and occupational exposure.

TABLE A-I. Los Alamos residents with no occupational exposure to plutonium.

TABLE A-11. Nonresidents of Los Alamos with no known occupationai exposure to plutonium.

TABLE A-11l. Colorado cases analyzed for plutonium.

Former employees of the Los Alamos Scientific Laboratory were grouped according to their potential exposure to plutonium. If the work area or job assignment was directly related to plutonium handling, or known potential exposure of short duration, the case was considered as having a high prential exposure and placed in Table A-V or A-VI. Because of the nature of the Laboratory's work, all other former employess have a potential for exposure to plutonium; these cases are listed in Table A-IV.

TABLE A-IV. LASL employees known to have a potential exposure to plutoniusn.
TABLE A-V. LASL employees known to have a high plutonium-exposure potential.

TABLE A-VI. Special cases. Cases discussed in other reports $^{1}$ and for which other than the standard set of tissues were analyzed for plutonium.

TABI.E A-VII. New York City cases analyzed for plutonium. (These cases are listed separately because of the differences in weight of organs received and because the gonads were always included.)

The minimum reporting level (MRL) is based on the total counts, background, and recovery statistics. The MRL is $0.03 \mathrm{dis} / \mathrm{min}$ of plutonium found in the aliquot analyzed.

Uranium, mercury, and other elements have been determined and will be reported elsewhere. Tissues received during the past three years have been examined by gamma spectroscopy to determine ${ }^{40} \mathrm{~K},{ }^{137} \mathrm{Cs}$, and other radionuclides used therapeutically. Americium 241 and ${ }^{238} \mathrm{Pu}$ will be reported separately. A complete review of the occupationally exposed cases reported here has been published. $^{14}$ 
Table a-d hesidents of los alamos,

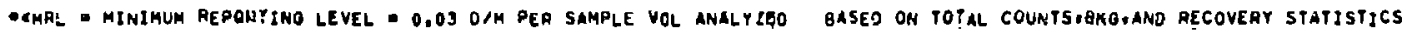

TISSUE

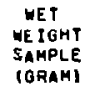

\begin{tabular}{|c|c|}
\hline $\begin{array}{l}\text { CASE NO. } \\
\text { OCCUPATION } \\
\text { AESIDENT } \\
\text { STATE } \\
\text { QAUSE OF DEATH } \\
\text { BEN CODE MO. }\end{array}$ & $\begin{array}{l}\text { I- GO } \\
\text { UNEMPLOYED } \\
\text { LOS ALAMOS } \\
\text { NEW MEXICO } \\
\text { PNEUMONIA } \\
\$ 91.8\end{array}$ \\
\hline $\begin{array}{l}\text { CASE NO, } \\
\text { OCCUPATION } \\
\text { RESIOENT } \\
\text { STATE } \\
\text { OAUSE OF DEATM } \\
\text { ME COOE NO. }\end{array}$ & $\begin{array}{l}\text { J- S4 } \\
\text { STUDENT } \\
\text { LOS ALAMOS } \\
\text { NEW HEXICO } \\
\text { OUNSHOT IN HEAD } \\
\text { EOT9.D }\end{array}$ \\
\hline $\begin{array}{l}\text { CASE NO. } \\
\text { UCCLPATION } \\
\text { RESIDENT }\end{array}$ & $\begin{array}{l}\text { I* } 70 \\
\text { CMILO } \\
\text { LOS ALAMOS }\end{array}$ \\
\hline $\begin{array}{l}\text { STATE } \\
\text { CAUSE OF DEATH } \\
\text { WEW CODE NO. }\end{array}$ & $\begin{array}{l}\text { NEW MEXICO } \\
\text { ENCEPHALITIS } \\
343.0^{\circ}\end{array}$ \\
\hline $\begin{array}{l}\text { CASE NO } \\
\text { OCCLPATION } \\
\text { KES COENT } \\
\text { STATE } \\
\text { CAUSE OF UEATH } \\
\text { GEW CODE NO. }\end{array}$ & $\begin{array}{l}\text { 1- } 76 \\
\text { CHILO } \\
\text { LOS ALAMOS } \\
\text { NEW MEXICO } \\
\text { ACUTE MENINOITIS } \\
340.9\end{array}$ \\
\hline
\end{tabular}
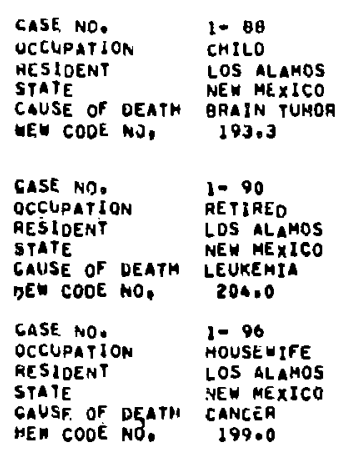$$
\begin{array}{ll}
\text { GASE NO. } & 1-100 \\
\text { OCCUPAYION } & \text { RESIDENT } \\
\text { HESLOENT } & \text { LOS ALAMOS } \\
\text { STATE } & \text { NEN MEXICD } \\
\text { GAUSE OF UEATH } & \text { CORONARY DCC } \\
\text { HEW CODE WO. } & \text { A2O.1 }
\end{array}
$$

CASE NO. $1-102$

$\begin{array}{ll}\text { CASE NOI } & 1-102 \\ \text { CCCUPATION } & \text { MOUSEWIFE } \\ \text { RESIDENT } & \text { LOS ALAMOS } \\ \text { STATE } & \text { NEW MEXICO } \\ \text { CAUSE OF DEATH } & \text { RHEUMATIC HEART } \\ \text { KS.11 CODE NO. } & 16.0\end{array}$

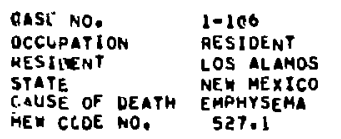

MEI CLOE NO. 527.1

\begin{tabular}{|c|c|}
\hline $\begin{array}{l}\text { CASE NO, } \\
\text { UCCUPATION } \\
\text { RESIOENT } \\
\text { STATE } \\
\text { GAUSE OF OEATH } \\
\text { MEY CODE NO. }\end{array}$ & $\begin{array}{l}1-116 \\
\text { RESIOENT } \\
\text { LOS ALAMOS } \\
\text { NEW REXICO } \\
\text { CORONARY OCC } \\
\text { QZO.I }\end{array}$ \\
\hline $\begin{array}{l}\text { GASE NO. } \\
\text { OCCUPATIOK }\end{array}$ & $\begin{array}{l}1=118 \\
\text { RESIOENT }\end{array}$ \\
\hline $\begin{array}{l}\text { RE\$LOENT } \\
\text { STATE } \\
\text { CALSE CF DEATH } \\
\text { DEY COOE HO. }\end{array}$ & $\begin{array}{l}\text { LOS ALAMOS } \\
\text { NEW MEXICO } \\
\text { VAOAL SMOCK } \\
\text { SSI.9 }\end{array}$ \\
\hline
\end{tabular}

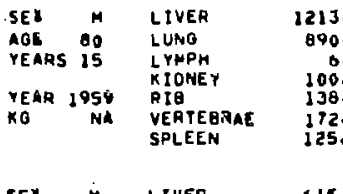

SEX M LIVER TOJ.0 $\begin{array}{ll}\text { AOE } & \text { O7 } \\ \text { YEARS Of }\end{array}$ YEAR 1960
KO NA KO NA

$\begin{array}{lll}\text { SEX F } & \text { LIVER } & 33000 \\ \text { AGE II } & \text { LUMG } & 70000 \\ \text { YEARS II } & \text { LYMPH } & 30.0 \\ \text { YEAP } 1900 & & 95.0\end{array}$
YEAP.
KG

sex $M$ $\begin{array}{lr}\text { SER } & M \\ \text { AEE } & 08 \\ \text { YEARS } & 08\end{array}$ YEAR 196O

SEX M YOE ODS NA YEAA 2960
nO NA nO NA $\begin{array}{lr}\text { SEX } & F \\ \text { AOE } & 59 \\ \text { YEARS } & \text { OS }\end{array}$ YEAR 1960
KO NA

SEX M LIVEA $\begin{array}{ll}\text { AGE } & 56 \\ \text { YEARS } & 02\end{array}$ YEAR 1960

LIVER
LUNG
LYMPH
KIONEY

\section{0} 307.0
12400

\section{LUER}

2520.0

LUNO

LYMPH
KIOHEY 10.0
270.0

LIVER

000.0

180.9

SEX F

$\begin{array}{ll}\text { SEK } & F 5 \\ \text { YEARS } & 05\end{array}$

YEAR 1960

LIVER 2400.0

LYMPH
KIONEY

SEX A LIVE

$\begin{array}{ll}\text { AGE } & 61 \\ \text { YEARS } 08\end{array}$

YEAP 1960

LIVEA
IUNG
LYMPH
KOONEY

1341.

1388.0
26.0
339.0

SEY it LUMO

759.0

KEAR 1960

SEX 4

AO5 35
YEARS OS

$\begin{array}{lr}\text { LIVER } & 1355.0 \\ \text { LUNG } & 617.0 \\ \text { LYMPM } & 16.0 \\ \text { KIDNEY } & 249.0\end{array}$

YEAR ISSI
KO

$\begin{array}{lllr}\text { SEX I } & \text { LIUER } & 615.0 \\ \text { MOE IS } & \text { LYYPM } & 0.5 \\ \text { YEARS IS } & \text { KIONEY } & 326.0 \\ \text { YEAR 1960 } & \text { SPLEEN } & 234.0 \\ \text { KG } & & \end{array}$
VOLUHE VOLUHE
OF
SAMALE ANALYELD
ICC) TCC) ACTIVITY
PER
VOL ANAL ACTIVITY ACTIVITY
PER OROAN PER KG cOLSIMINA IOISIM

DEIOMT ACTIVITY ST ANOARD OROAN IDIS/MIN]

$\begin{array}{rrr}13.0 & 250 & 100 \\ 90.0 & 2000 & 5 \\ 0.4 & 100 & 1 \\ 00.0 & 100 & 1 \\ 38.0 & 250 & 100 \\ 7200 & 200 & 10 \\ 25.0 & 250 & 100\end{array}$

100
50
10
10
100
100
100
50

$\begin{array}{rl}500 & 50 \\ 25 & 10 \\ 100 & 10 \\ 100 & 10\end{array}$

1.251
0.000
0.150
0.000
.022
.094
.700

3.13

3.13
SHRL.
1.50
IMNL.
TMAL.
19

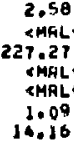

4.30

.040

.010

0.000

0.000

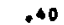

.40 TMAL: TMRL

.65

$\angle$ MAL

TMRL:

.060

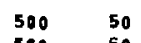

$\begin{array}{rl}500 & 50 \\ 25 & 10\end{array}$

.060
.020
.020

.60
YHRL:
YYQL:

.86

SMRL.

.010 SHRL.

.200

.490

$\begin{array}{rrr}2.00 & 6.06 & 10.30 \\ 4.90 & 7.00 & 7.00 \\ .13 & 4.17 & .04 \\ .00 & 4.21 & 1.26\end{array}$

100

50

.040

.100

.470

.040
.010

$$
\begin{array}{r}
1.00 \\
2.35 \\
\text { PMAL }
\end{array}
$$$$
\text { a }
$$

1000

5000500

50
500
10

.040

.332

.020

\begin{tabular}{lll}
.00 & .32 & .54 \\
.66 & .66 & .66 \\
\hline .MRL & CMALE &
\end{tabular}

$1000 \quad 50$

.030

.203
.020
.030

$\begin{array}{lll}.60 & .66 & 1.13 \\ 245 & .70 & .70 \\ \text { CMRLE } & \text { SMRL } & \\ .30 & 1.67 & .100\end{array}$

$\begin{array}{rl}50 & 10 \\ 100 & 10\end{array}$

.120

.360

.050

$\begin{array}{rrr}2.40 & 2.00 & 1.69 \\ 7.20 & 5.57 & 5.57 \\ .35 & 15.22 & .15 \\ .50 & 2.48 & .74\end{array}$

100050

$\begin{array}{rr}1000 & 50 \\ 50 & 10 \\ 100 & 10\end{array}$

.060

.100
0.000

1.20

$1.20 \quad 0.06 \quad 1.46$

100050

$\begin{array}{rr}1000 & 50 \\ 50 & 10 \\ 100 & 10\end{array}$

.060

.050
.030

.040

1,20

2.00
.15
.40

1.05

.72
.77

1.79

100050

$\begin{array}{llr}\text { AOE } 47 & \text { LYMPH } & 1000 \\ \text { YEARS.13 KIONEY } & 15.0 & 50 \\ \text { YY. } & & 100\end{array}$

.150
.030
0.000

1000
1000
50
100

50
50
10
10

.050
0.000
.010

1.00

CMRL"

SMRL:

74

SKRLE

SHAL:

2.27

7.65

1,11

2.46 


\begin{tabular}{|c|c|c|c|c|c|c|c|c|c|c|c|}
\hline & & & & TISSUE & $\begin{array}{l}\text { WET } \\
\text { WEICHT } \\
\text { SANPLE } \\
\text { IORANI }\end{array}$ & $\begin{array}{l}\text { YOLUHE } \\
\text { OF } \\
\text { SAMRLE } \\
\text { ICG) }\end{array}$ & $\begin{array}{l}\text { VOLUHE } \\
\text { SAMPLE } \\
\text { ANALYZED } \\
\text { ICC) }\end{array}$ & $\begin{array}{l}\text { ACTIVITY } \\
\text { PER } \\
\text { VOL ANAL } \\
\text { IDIS/MIND }\end{array}$ & $\begin{array}{l}\text { ACTIVITY } \\
\text { PER ORGAN } \\
\text { WE IGHT } \\
\text { (DIS/AIN) }\end{array}$ & $\begin{array}{l}\text { ACTIVITY } \\
\text { PEEA KO } \\
\text { (OLS/MIN) }\end{array}$ & $\begin{array}{l}\text { ACTIVITY } \\
\text { PER } \\
\text { STANDARO } \\
\text { ORGAN } \\
\text { (OIS/MIN) }\end{array}$ \\
\hline $\begin{array}{l}\text { GASE NO, } \\
\text { OCEUPAT LON } \\
\text { RESIOENT } \\
\text { STATE } \\
\text { CAUSE OF DEATH } \\
\text { DEW CODE NO, }\end{array}$ & $\begin{array}{l}\text { 1-134 } \\
\text { HOUSEWIFE } \\
\text { LOS ALAMOS } \\
\text { NEW MEXICO } \\
\text { NOSE CANCER } \\
\text { I } 60.0\end{array}$ & $\begin{array}{l}\text { SEX } \\
\text { ABE } \\
\text { YEARS } \\
\text { YEAR } \\
\text { KO }\end{array}$ & $\begin{array}{c}f \\
48 \\
01 \\
1961 \\
\text { NA }\end{array}$ & $\begin{array}{l}\text { LIVER } \\
\text { LUNG } \\
\text { LYMPH } \\
\text { KIDNEY }\end{array}$ & $\begin{array}{r}1734.0 \\
675.0 \\
5.0 \\
277.0\end{array}$ & $\begin{array}{r}1000 \\
1000 \\
50 \\
100\end{array}$ & $\begin{array}{l}30 \\
50 \\
10 \\
10\end{array}$ & $\begin{array}{r}.030 \\
.020 \\
.000 \\
.010\end{array}$ & $\begin{array}{l}.60 \\
\angle M R L= \\
\text { SMRLE } \\
\text { IMRLE }\end{array}$ & $\begin{array}{l}\text {.35 } \\
\text { \&MRLE } \\
\text { SMRLE } \\
\text { \&MRLE }\end{array}$ & .39 \\
\hline $\begin{array}{l}\text { CASE NOE } \\
\text { OCCLPATION } \\
\text { MESLOENT } \\
\text { STATE } \\
\text { GAUSE OF DEATH } \\
\text { HE CODE NO. }\end{array}$ & $\begin{array}{l}1-138 \\
\text { HOUSEWIFE } \\
\text { LOS ALAMOS } \\
\text { NEW HE, IICD } \\
\text { RUPTUAED HORTA } \\
\text { 451.9 }\end{array}$ & $\begin{array}{l}\text { SEX } \\
\text { AOK } \\
\text { YEAAS } \\
\text { YEAR } \\
\text { KO }\end{array}$ & $\begin{array}{r}5 \\
76 \\
502 \\
1901 \\
\text { NA }\end{array}$ & $\begin{array}{l}\text { LIUER } \\
\text { LUHO } \\
\text { LYHPH } \\
\text { KIOYEY }\end{array}$ & $\begin{array}{r}1317.9 \\
612.9 \\
16.1 \\
203.9\end{array}$ & $\begin{array}{r}1000 \\
2000 \\
50 \\
100\end{array}$ & $\begin{array}{r}50 \\
500 \\
10 \\
10\end{array}$ & $\begin{array}{r}.060 \\
.259 \\
.120 \\
.000\end{array}$ & $\begin{array}{r}1.20 \\
.52 \\
.60 \\
\text { AMRL. }\end{array}$ & $\begin{array}{r}.91 \\
.05 \\
37.50 \\
\text { PARL. }\end{array}$ & $\begin{array}{r}1.55 \\
.05 \\
.31\end{array}$ \\
\hline $\begin{array}{l}\text { CASE NO. } \\
\text { OCCUPATION } \\
\text { AESLOENT } \\
\text { STATE } \\
\text { CAUSE OF DEATH } \\
\text { GEU COOE NOD }\end{array}$ & $\begin{array}{l}2=\text { B } \\
\text { HOUSEWIFE } \\
\text { LOS ALAHOS } \\
\text { NEW HEXICO } \\
\text { CANCER } \\
199.0\end{array}$ & $\begin{array}{l}\text { SEX } \\
\text { GOE } \\
\text { YEARS } \\
\text { YEAR } \\
\text { KO }\end{array}$ & $\begin{array}{r}F \\
53 \\
14 \\
1961 \\
\mathrm{NA}\end{array}$ & $\begin{array}{l}\text { LIVEA } \\
\text { LUNO } \\
\text { LYHPM } \\
\text { KIONEY }\end{array}$ & $\begin{array}{r}1192.0 \\
720.0 \\
11.0 \\
200.0\end{array}$ & $\begin{array}{r}1000 \\
1000 \\
50 \\
100\end{array}$ & $\begin{array}{l}50 \\
50 \\
10 \\
10\end{array}$ & $\begin{array}{l}.005 \\
.230 \\
.005 \\
.002\end{array}$ & $\begin{array}{l}\text { CHAL" } \\
4,60 \\
\text { CMRLE } \\
\text { CHALE }\end{array}$ & $\begin{array}{l}\text { SMALE } \\
6.39 \\
\text { CMRLE } \\
\text { AMRLE }\end{array}$ & 6.39 \\
\hline $\begin{array}{l}\text { CASE NO. } \\
\text { OCCUPATION } \\
\text { RESIOENT } \\
\text { STATE } \\
\text { CAUSE OF DEATH } \\
\text { GEL CODE NO. }\end{array}$ & $\begin{array}{l}2-30 \\
\text { RETYREO } \\
\text { LOS ALAMOS } \\
\text { NE HEXICO } \\
\text { ARTERIOSCLEROSIS } \\
450.0\end{array}$ & $\begin{array}{l}\text { SEX } \\
\text { AGE } \\
\text { YEAAS } \\
\text { YEAR } \\
\text { KO }\end{array}$ & $\begin{array}{r}M \\
80 \\
507 \\
1961 \\
\text { NA }\end{array}$ & $\begin{array}{l}\text { LIVER } \\
\text { LUNG } \\
\text { LINPH } \\
\text { KIONEY }\end{array}$ & $\begin{array}{r}957.0 \\
345.0 \\
7.8 \\
170.0\end{array}$ & $\begin{array}{r}1000 \\
190 \\
50 \\
100\end{array}$ & $\begin{array}{l}50 \\
10 \\
10 \\
10\end{array}$ & $\begin{array}{l}.120 \\
.113 \\
.210 \\
.012\end{array}$ & $\begin{array}{l}2,40 \\
1.13 \\
1.05 \\
2 k 9 L\end{array}$ & $\begin{array}{r}2.31 \\
3.28 \\
150.00 \\
<\text { MAL }\end{array}$ & $\begin{array}{l}4.26 \\
3.28 \\
2.50\end{array}$ \\
\hline $\begin{array}{l}\text { CASE NO. } \\
\text { OCSUPATION } \\
\text { RESLOENT } \\
\text { STATE } \\
\text { CAUSE OF DEATH } \\
\text { WE COOE NO. }\end{array}$ & $\begin{array}{l}\text { 2- } 26 \\
\text { HOUSEWIFE } \\
\text { LOS ALAMOS } \\
\text { NEW MEXICO } \\
\text { UNKNOWN } \\
\text { NA }\end{array}$ & $\begin{array}{l}\text { SEY } \\
\text { AOE } \\
\text { YEAGS } \\
\text { YEAR } \\
\text { KO }\end{array}$ & $\begin{array}{c}f \\
62 \\
05 \\
1961 \\
N A\end{array}$ & $\begin{array}{l}\text { LIVER } \\
\text { LUNO } \\
\text { LYHPH } \\
\text { KIDNEY }\end{array}$ & $\begin{array}{r}1025.0 \\
705.6 \\
3.6 \\
295.0\end{array}$ & $\begin{array}{r}1000 \\
1000 \\
50 \\
100\end{array}$ & $\begin{array}{l}50 \\
50 \\
10 \\
10\end{array}$ & $\begin{array}{r}.042 \\
.000 \\
0,000 \\
0.000\end{array}$ & $\begin{array}{l}\text { ¿84 } \\
\text { SMRL: } \\
\text { SMRLE } \\
\text { SMRL" }\end{array}$ & 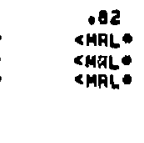 & 2.39 \\
\hline $\begin{array}{l}\text { SASE NDE } \\
\text { OCEUPAT KON } \\
\text { AESIOENY } \\
\text { STATE } \\
\text { GAUSE OF DEATH } \\
\text { MEW FOOE MO. }\end{array}$ & $\begin{array}{l}\text { 2- 34 } \\
\text { HOUSEWIFE } \\
\text { LOS ALAMOS } \\
\text { NEW MEXICO } \\
\text { PULMON EMBOLISM } \\
\text { \GS O }\end{array}$ & $\begin{array}{l}\text { SEd } \\
\text { AOE } \\
\text { YEARS } \\
\text { YEAR } \\
\text { YOO }\end{array}$ & $\begin{array}{c}F \\
71 \\
14 \\
1962 \\
\mathrm{Na}\end{array}$ & $\begin{array}{l}\text { LIYEA } \\
\text { LURA } \\
\text { LYMPH }\end{array}$ & $\begin{array}{r}1627.1 \\
075.1 \\
20.1\end{array}$ & $\begin{array}{r}1010 \\
1000 \\
50\end{array}$ & $\begin{array}{r}50 \\
100 \\
10\end{array}$ & $\begin{array}{r}.089 \\
.796 \\
0.000\end{array}$ & $\begin{array}{l}2,70 \\
1,59 \\
\text { SHAL }\end{array}$ & $\begin{array}{l}1.09 \\
\text { d.02 } \\
\text { CHRL. }\end{array}$ & $\begin{array}{l}3.86 \\
1.06\end{array}$ \\
\hline $\begin{array}{l}\text { GASE NO. } \\
\text { OCCUPATION } \\
\text { RESIOENT } \\
\text { STATE } \\
\text { GALSE OF DEATH } \\
\text { HEW CODE NOE }\end{array}$ & $\begin{array}{l}2 * 36 \\
\text { HOTEL MNOR } \\
\text { LOS ALAMOS } \\
\text { NE MEXICO } \\
\text { MYOCAROIAL INF } \\
\text { T2O.1 }\end{array}$ & $\begin{array}{l}\text { SEX } \\
\text { AQG } \\
\text { YEÄRS } \\
\text { YEAR I } \\
\text { KO }\end{array}$ & $\begin{array}{r}4 \\
60 \\
08 \\
1962 \\
\text { NA }\end{array}$ & $\begin{array}{l}\text { LIYER } \\
\text { LUHO } \\
\text { LYMPH } \\
\text { KIONEY }\end{array}$ & $\begin{array}{r}1505.0 \\
490.0 \\
13.0 \\
275.0\end{array}$ & $\begin{array}{r}1000 \\
1000 \\
30 \\
100\end{array}$ & $\begin{array}{l}250 \\
500 \\
10 \\
10\end{array}$ & $\begin{array}{l}1.003 \\
.482 \\
0.000 \\
.004\end{array}$ & $\begin{array}{l}6.41 \\
\text { SMA } \\
\text { CMRL: }\end{array}$ & $\begin{array}{l}1,26 \\
1.97 \\
\text { SMRL: }\end{array}$ & $\begin{array}{l}7.24 \\
1.97\end{array}$ \\
\hline CASE NO. & $2-60$ & SEX & $F$ & LIVER & 2759.0 & 1000 & 50 & .016 & $\angle M R L \bullet$ & SHRL - & \\
\hline $\begin{array}{l}\text { OCCUPATIDH } \\
\text { AESIOENT } \\
\text { STATE } \\
\text { GAUSE OF OEATH } \\
\text { WEI CODE WO. }\end{array}$ & $\begin{array}{l}\text { HOUSEWIFE } \\
\text { LOS ALIMOS } \\
\text { NEW MEXICO } \\
\text { CANCER } \\
100.0\end{array}$ & $\begin{array}{l}\text { MOS } \\
\text { YEARS } \\
\text { YEAR } \\
\text { MO }\end{array}$ & $\begin{array}{c}46 \\
12 \\
1962 \\
\text { MA }\end{array}$ & $\begin{array}{l}\text { LUNG } \\
\text { LYMPH } \\
\text { KIDNEY } \\
\text { VERTEBRAE }\end{array}$ & $\begin{array}{r}41.0 \\
3.0 \\
220.0 \\
154.0\end{array}$ & $\begin{array}{r}500 \\
50 \\
100 \\
250\end{array}$ & $\begin{array}{l}\mathbf{5 0} \\
10 \\
10 \\
10\end{array}$ & $\begin{array}{l}.302 \\
.003 \\
.003 \\
.007\end{array}$ & $\begin{array}{l}3.02 \\
\text { CMRL: } \\
\text { CMRLE } \\
\text { SMRL }\end{array}$ & $\begin{array}{l}6,05 \\
\text { CMAL: } \\
\text { CHRL: } \\
\text { CHRL: }\end{array}$ & 0.85 \\
\hline $\begin{array}{l}\text { CASE NOE } \\
\text { OCCUPATION } \\
\text { HESIOENT } \\
\text { STATE } \\
\text { GAUSE OF OEATH } \\
\text { HF COOE NO. }\end{array}$ & $\begin{array}{l}\text { 2- } 90 \\
\text { STUDENT } \\
\text { LOS ALAKOS } \\
\text { NEU MEXICO } \\
\text { HEAD INJUAIES } \\
\text { BS3.0 }\end{array}$ & $\begin{array}{l}\text { SEX } \\
\text { IOG } \\
\text { YEARS } \\
\text { YEAR } \\
\text { KO }\end{array}$ & $\begin{array}{c}4 \\
16 \\
15 \\
1962 \\
\mathrm{NA}\end{array}$ & $\begin{array}{l}\text { LIVEA } \\
\text { LUNO } \\
\text { LYMPH } \\
\text { KIONEY } \\
\text { VERTEGRAE }\end{array}$ & $\begin{array}{r}1203.0 \\
775.0 \\
5.0 \\
248.0 \\
182.0\end{array}$ & $\begin{array}{r}1000 \\
1000 \\
50 \\
100 \\
250\end{array}$ & $\begin{array}{l}50 \\
40 \\
10 \\
10 \\
10\end{array}$ & $\begin{array}{l}.150 \\
.200 \\
.040 \\
.010 \\
.030\end{array}$ & $\begin{array}{l}3.00 \\
4.00 \\
.20 \\
\text { QHRL } \\
.75\end{array}$ & $\begin{array}{r}2.49 \\
5.16 \\
0.00 \\
\text { EMRL } \\
4.12\end{array}$ & $\begin{array}{r}4.24 \\
5.16 \\
0.00 \\
28.05\end{array}$ \\
\hline $\begin{array}{l}\text { GASE NO. } \\
\text { OCCUPATION } \\
\text { FESIDENT } \\
\text { STATE } \\
\text { CAUSE OF DEATH } \\
\text { HE CODE NO. }\end{array}$ & $\begin{array}{l}\text { 2- P2 } \\
\text { HOUSEWIFE } \\
\text { LOS ALAMOS } \\
\text { NE MEXICO } \\
\text { UNKNOWN } \\
\text { NA }\end{array}$ & $\begin{array}{l}\text { SEX } \\
\text { AGE } \\
\text { YEARS } \\
\text { YEAR I } \\
\text { KO }\end{array}$ & $\begin{array}{r}7 \\
72 \\
03 \\
1962 \\
\text { Na }\end{array}$ & $\begin{array}{l}\text { LIVEA } \\
\text { LUNO } \\
\text { LYIPN } \\
\text { KIONEY }\end{array}$ & $\begin{array}{r}1333.0 \\
669.0 \\
4.0 \\
255.0\end{array}$ & $\begin{array}{r}1080 \\
1000 \\
50 \\
100\end{array}$ & $\begin{array}{l}50 \\
50 \\
10 \\
10\end{array}$ & $\begin{array}{l}.040 \\
.060 \\
.010 \\
.034\end{array}$ & $\begin{array}{l}.80 \\
1.20 \\
\text { CMRL } \\
.30\end{array}$ & $\begin{array}{l}.60 \\
1.19 \\
\text { SMRL } \\
1.10\end{array}$ & $\begin{array}{r}1.02 \\
3.79 \\
.35\end{array}$ \\
\hline GASE NO. & $2-102$ & SEK & $f$ & LIVER & 1615.0 & 1090 & 50 & .106 & 2.12 & 1.31 & 2.23 \\
\hline $\begin{array}{l}\text { OCCUPATIOH } \\
\text { PESIDENT } \\
\text { STATE } \\
\text { CAUSE OF DEATH } \\
\text { HEL CODE NO. }\end{array}$ & $\begin{array}{l}\text { CLERK } \\
\text { LOS ALAMOS } \\
\text { NEW NEXICO } \\
\text { DRUGS } \\
\text { P7Z.0 }\end{array}$ & $\begin{array}{l}\text { AGE } \\
\text { YEARS } \\
\text { YEAR I } \\
\text { KO }\end{array}$ & $\begin{array}{l}14 \\
16 \\
1962 \\
\text { NA }\end{array}$ & $\begin{array}{l}\text { LUNO } \\
\text { LYMPH } \\
\text { KIONEY } \\
\text { VERTEGRAE }\end{array}$ & $\begin{array}{r}1190.0 \\
3.0 \\
237.0 \\
267.0\end{array}$ & $\begin{array}{r}\log 0 \\
50 \\
100 \\
250\end{array}$ & $\begin{array}{l}50 \\
10 \\
10 \\
10\end{array}$ & $\begin{array}{l}.421 \\
.110 \\
.002 \\
.224\end{array}$ & $\begin{array}{l}8.42 \\
.55 \\
549 L \\
5.60\end{array}$ & $\begin{array}{r}7.08 \\
293.33 \\
6 \mathrm{MAL} \\
20.97\end{array}$ & $\begin{array}{r}7.06 \\
1.03 \\
140.02\end{array}$ \\
\hline $\begin{array}{l}\text { CASE NO, } \\
\text { OCCUPATION } \\
\text { RESIOENT } \\
\text { STATE } \\
\text { CIUSF OF DEATM } \\
\text { WEU CODE ND. }\end{array}$ & $\begin{array}{l}2-122 \\
\text { CLERK } \\
\text { LOS ALAMOS } \\
\text { NEW ME } 4 \text { ICO } \\
\text { CANCER OF OREAST } \\
170.0\end{array}$ & $\begin{array}{l}\text { SEA } \\
\text { LOE } \\
\text { YEARS } \\
\text { YEAR I } \\
\text { RO }\end{array}$ & $\begin{array}{l}5 \\
51 \\
10 \\
1962 \\
\text { NA }\end{array}$ & $\begin{array}{l}\text { LIVER } \\
\text { LUNG } \\
\text { LYMPH } \\
\text { KIDNEY } \\
\text { RIA }\end{array}$ & $\begin{array}{r}1200.0 \\
549.0 \\
11.0 \\
120.0 \\
135.0\end{array}$ & $\begin{array}{r}1000 \\
1000 \\
50 \\
200 \\
200\end{array}$ & $\begin{array}{l}50 \\
50 \\
10 \\
10 \\
10\end{array}$ & $\begin{array}{l}0.000 \\
0.000 \\
0.000 \\
0.000 \\
0.000\end{array}$ & $\begin{array}{l}\text { SHRL: } \\
\text { SHRL: } \\
\text { CMRL: } \\
\text { CMRL: } \\
\text { CMRL: }\end{array}$ & $\begin{array}{l}\text { SHAL: } \\
\text { CHRL: } \\
\text { SMRLE } \\
\text { CHHL: } \\
\text { SMRL: }\end{array}$ & \\
\hline
\end{tabular}




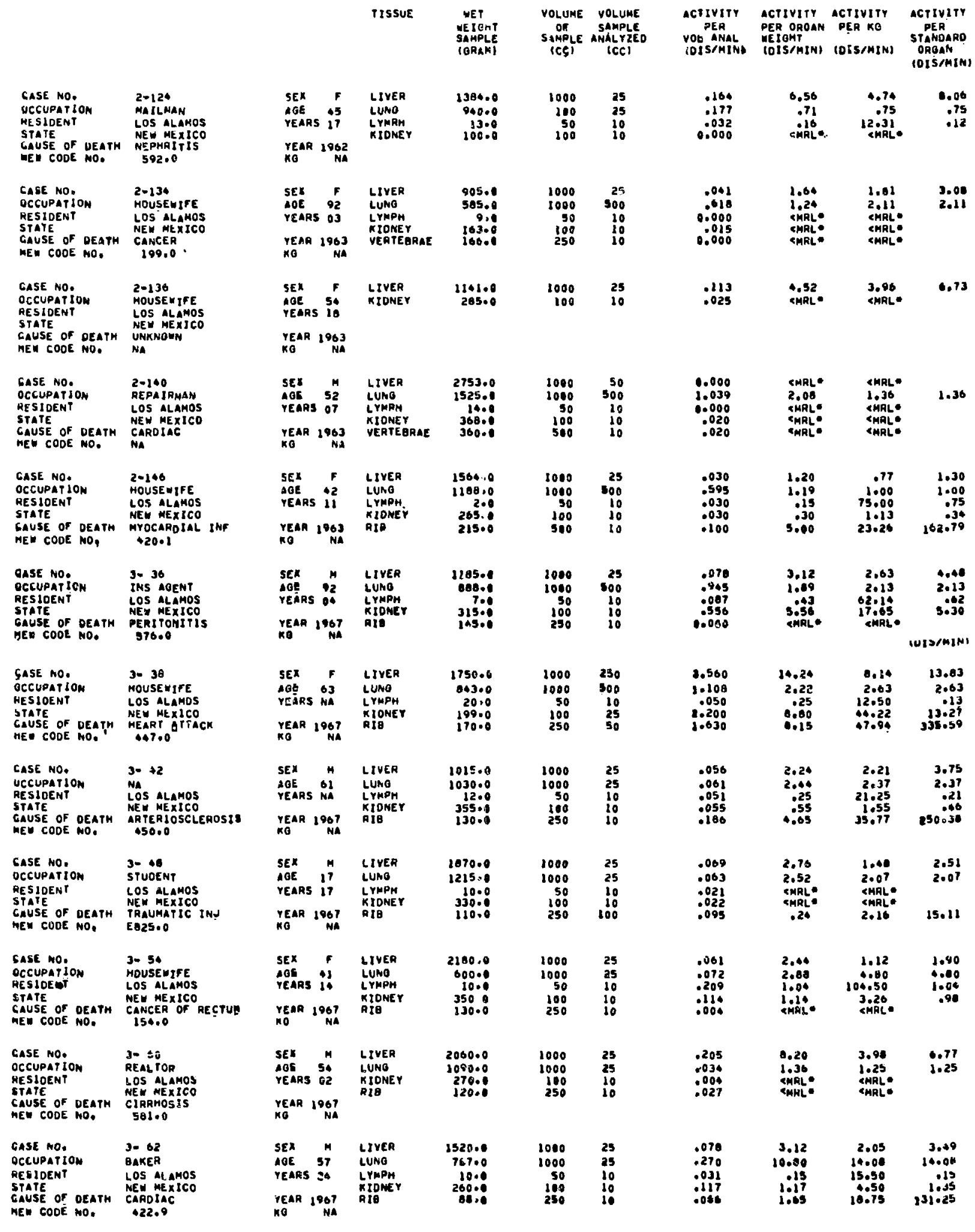




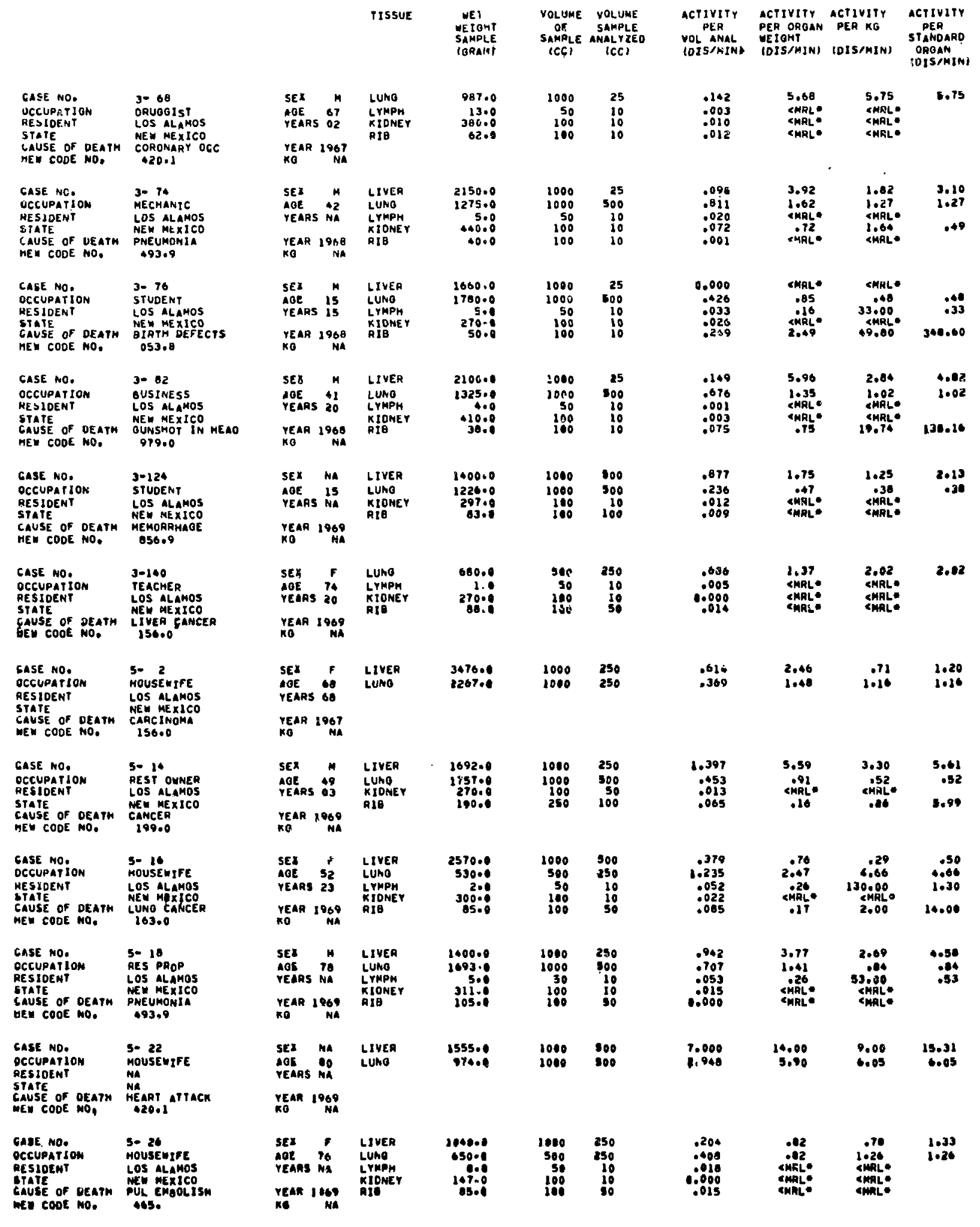




\begin{tabular}{|c|c|c|c|c|c|c|c|c|c|c|c|}
\hline $\begin{array}{l}\text { GASE NO. } \\
\text { PCCUPATION } \\
\text { RESIOENT } \\
\text { STATE } \\
\text { GAUSE OF UEATH } \\
\text { DEU CODE NO, }\end{array}$ & $\begin{array}{l}\text { S- 36 } \\
\text { HOUSEWIFE } \\
\text { LOS ALAMDS } \\
\text { NEU MEXICO } \\
\text { GURSHT WNO } \\
\text { EOT9.0 }\end{array}$ & $\begin{array}{l}\text { SEX } \\
\text { AGE } \\
\text { YEARS } \\
\text { TEAR I } \\
\text { RG }\end{array}$ & $\begin{array}{r}r \\
35 \\
N_{A} \\
8969 \\
\text { NA }\end{array}$ & $\begin{array}{l}\text { LIVEA } \\
\text { LUNO } \\
\text { LYMPH } \\
\text { KIDNEY } \\
\text { RJB }\end{array}$ & $\begin{array}{r}1270.0 \\
563.0 \\
3.0 \\
213.0 \\
78.0\end{array}$ & $\begin{array}{r}1000 \\
1000 \\
50 \\
100 \\
100\end{array}$ & $\begin{array}{l}500 \\
250 \\
10 \\
10 \\
50\end{array}$ & $\begin{array}{r}.019 \\
.171 \\
.005 \\
.010 \\
0.000\end{array}$ & $\begin{array}{l}\text { SMRL" } \\
\text { MGR } \\
\text { CMRL: } \\
\text { CMRLE }\end{array}$ & $\begin{array}{l}\text { CMAL } \\
2,21 \\
\text { CHRL: } \\
\text { CMRL: } \\
\text { CMRL }\end{array}$ & 1.21 \\
\hline $\begin{array}{l}\text { CASE NO. } \\
\text { OCCUPATION } \\
\text { AESIOENT } \\
\text { STATE } \\
\text { CAUSE OF DEATH } \\
\text { WE COOE HO. }\end{array}$ & $\begin{array}{l}5=38 \\
\text { NA } \\
\text { LOS ALAMOS } \\
\text { NEW HEXICS } \\
\text { PULMONARY INF } \\
\text { G5.0 }\end{array}$ & $\begin{array}{l}\text { SEX } \\
\text { AGE } \\
\text { YEARS } \\
\text { YEAR I } \\
\text { TE }\end{array}$ & $\begin{array}{c}\mathrm{M} \\
\mathrm{85} \\
\mathrm{NA} \\
1969 \\
\mathrm{NA}\end{array}$ & $\begin{array}{l}\text { LIVER } \\
\text { LUKG } \\
\text { LYMPN } \\
\text { KIONEY } \\
\text { PIB }\end{array}$ & $\begin{array}{r}16560 \\
1010.0 \\
10.8 \\
250.0 \\
170.0\end{array}$ & $\begin{array}{r}1000 \\
2000 \\
50 \\
100 \\
250\end{array}$ & $\begin{array}{r}500 \\
500 \\
10 \\
10 \\
100\end{array}$ & $\begin{array}{l}.192 \\
.112 \\
.014 \\
.023 \\
.067\end{array}$ & $\begin{array}{l}.30 \\
\text { SMRL } \\
\text { SMRL } \\
\text { \&MRL } \\
.12\end{array}$ & $\begin{array}{c}.26 \\
.22 \\
\text { KMRLE } \\
\text { \&MRL } \\
.69\end{array}$ & $\begin{array}{r}.05 \\
.22 \\
4.64\end{array}$ \\
\hline $\begin{array}{l}\text { GASE NOD } \\
\text { OCC:IPATION } \\
\text { RESIUENT } \\
\text { STATE } \\
\text { CAUSE OF DEATH } \\
\text { HFU COOE NO, }\end{array}$ & $\begin{array}{l}\text { 5- 50 } \\
\text { HOUSEWJFE } \\
\text { LOS ALANOS } \\
\text { NEW MEXICO } \\
\text { HEART ITIACK } \\
\text { Q2O.1 }\end{array}$ & $\begin{array}{l}\text { SEX } \\
\text { LOE } \\
\text { YEARS } \\
\text { YEAR I } \\
\text { MO }\end{array}$ & $\begin{array}{c}F \\
73 \\
72 \\
190 \\
\text { Na }\end{array}$ & $\begin{array}{l}\text { LIVER } \\
\text { LUNO } \\
\text { LYMPH } \\
\text { KIDNEY } \\
\text { YERTEBRAE }\end{array}$ & $\begin{array}{r}1434.0 \\
1050.0 \\
3.0 \\
264.8 \\
70.0\end{array}$ & $\begin{array}{r}1000 \\
1000 \\
50 \\
100 \\
100\end{array}$ & $\begin{array}{r}250 \\
250 \\
20 \\
10 \\
10\end{array}$ & $\begin{array}{l}.067 \\
.212 \\
.006 \\
.044 \\
.058\end{array}$ & $\begin{array}{l}.27 \\
\text { :A5 } \\
\text { MRL } \\
158\end{array}$ & $\begin{array}{l}.19 \\
.81 \\
\text { 19KL } \\
1.67 \\
8.20\end{array}$ & $\begin{array}{r}.32 \\
.01 \\
.50 \\
50.00\end{array}$ \\
\hline $\begin{array}{l}\text { CASE NO. } \\
\text { OCCUPATION } \\
\text { OESTOENT } \\
\text { STATE } \\
\text { CAUSE OF DEATM } \\
\text { WEU COOE NO. }\end{array}$ & $\begin{array}{l}\text { S- } 50 \\
\text { BNK CLERK } \\
\text { WHITE ROCK } \\
\text { NEU MEXICO } \\
\text { CANCER } \\
199.0\end{array}$ & $\begin{array}{l}\text { SEX } \\
\text { AOS } \\
\text { YeAAS } \\
\text { YEAA I } \\
\text { KO }\end{array}$ & $\begin{array}{r}37 \\
37 \\
19\end{array}$ & $\begin{array}{l}\text { LIVER } \\
\text { LUNO } \\
\text { LYMPH } \\
\text { KIOMEY } \\
\text { VERTEBALE }\end{array}$ & $\begin{array}{r}900 \cdot 0 \\
67500 \\
200 \\
293.0 \\
75.0\end{array}$ & $\begin{array}{l}250 \\
500 \\
50 \\
200 \\
250\end{array}$ & $\begin{array}{l}100 \\
250 \\
10 \\
10 \\
100\end{array}$ & $\begin{array}{r}.718 \\
.794 \\
.004 \\
.018 \\
0.013\end{array}$ & $\begin{array}{l}2.79 \\
1.59 \\
.22 \\
\text { CHRL. } \\
\text { SMRL. }\end{array}$ & $\begin{array}{r}1.99 \\
2.34 \\
110.00 \\
\text { EMRLO } \\
\text { CMRL }\end{array}$ & $\begin{array}{l}3.39 \\
2.34 \\
1.10\end{array}$ \\
\hline $\begin{array}{l}\text { CASE NO. } \\
\text { OCCUPAPION } \\
\text { RES SOENT } \\
\text { STATE } \\
\text { CAUSE OF DEATH } \\
\text { WE CODE NO. }\end{array}$ & $\begin{array}{l}\text { 5- 60 } \\
\text { MOUSE JFE } \\
\text { LOS ALANOS } \\
\text { NEU MEXICO } \\
\text { WEART ATTACK } \\
\text { \2O.1 }\end{array}$ & $\begin{array}{l}\text { SEX } \\
\text { MUR } \\
\text { YEAAS } \\
\text { YEAR } \\
\text { KO }\end{array}$ & $\begin{array}{c}5 \\
67 \\
67 \\
20\end{array}$ & $\begin{array}{l}\text { LIVER } \\
\text { LUAO } \\
\text { LYMPH } \\
\text { KIOMEY } \\
\text { VERTEGHAE }\end{array}$ & $\begin{array}{r}1571.4 \\
430.9 \\
50.9 \\
255.0 \\
106.8\end{array}$ & $\begin{array}{l}500 \\
590 \\
50 \\
200 \\
500\end{array}$ & $\begin{array}{r}250 \\
250 \\
10 \\
10 \\
100\end{array}$ & $\begin{array}{l}.233 \\
.132 \\
.044 \\
.013 \\
.030\end{array}$ & $\begin{array}{r}.27 \\
.26 \\
.22 \\
<H R L \\
.00\end{array}$ & $\begin{array}{r}.17 \\
.61 \\
4.00 \\
\times 1.00 \\
.78\end{array}$ & $\begin{array}{l}.29 \\
.61 \\
.44 \\
5.45\end{array}$ \\
\hline $\begin{array}{l}\text { CASE NO. } \\
\text { OCCUPATION } \\
\text { AESLOENT } \\
\text { STATE } \\
\text { GAUSE OF DEATH } \\
\text { WEU CODE HO. }\end{array}$ & $\begin{array}{l}\text { S- P4 } \\
\text { HOUSEMIFE } \\
\text { LOS ALAMOS } \\
\text { NE MEXICO } \\
\text { COR PULABHALE } \\
\text { O34.7 }\end{array}$ & $\begin{array}{l}\text { SEX } \\
\text { AGE } \\
\text { YEAGS } \\
\text { YEAR } \\
\text { XO }\end{array}$ & $\begin{array}{c}\mathrm{F} \\
1970 \\
\mathrm{MA}\end{array}$ & $\begin{array}{l}\text { LUNO } \\
\text { LYYPN } \\
\text { KIONEY } \\
\text { AIO }\end{array}$ & $\begin{array}{r}1214.0 \\
2 \pi .0 \\
11 \% .6 \\
90.0\end{array}$ & $\begin{array}{r}500 \\
25 \\
100 \\
200\end{array}$ & $\begin{array}{r}250 \\
10 \\
10 \\
100\end{array}$ & $\begin{array}{l}.306 \\
.026 \\
.019 \\
.205\end{array}$ & $\begin{array}{c}.61 \\
\text { CMAL: } \\
.37\end{array}$ & $\begin{array}{l}.50 \\
\text { SAAL } \\
\text { CHRL } \\
5.82\end{array}$ & $\begin{array}{r}.50 \\
40.71\end{array}$ \\
\hline $\begin{array}{l}\text { CASE NO. } \\
\text { OCCUPATIOH } \\
\text { RESIOENT } \\
\text { STATF. } \\
\text { CAUSE OF DEATM } \\
\text { ME COOE WO. }\end{array}$ & $\begin{array}{l}\text { S- B6 } \\
\text { STUOENT } \\
\text { LOS ALAMOS } \\
\text { NEE MLXJCO } \\
\text { MEAO INJURT } \\
\text { OS6.L }\end{array}$ & $\begin{array}{l}\text { SEX } \\
\text { AGE } \\
\text { YEARS } \\
\text { YEAR } \\
\text { MO }\end{array}$ & $\begin{array}{r}5 \\
17 \\
17 \\
1970 \\
\text { MA }\end{array}$ & $\begin{array}{l}\text { LIUER } \\
\text { LURO } \\
\text { LYPPM } \\
\text { KIOAEY } \\
\text { RIB }\end{array}$ & $\begin{array}{r}1785.0 \\
543.0 \\
5.0 \\
222.0 \\
50.6\end{array}$ & $\begin{array}{l}500 \\
500 \\
25 \\
100 \\
200\end{array}$ & $\begin{array}{r}250 \\
250 \\
10 \\
10 \\
100\end{array}$ & $\begin{array}{l}1.024 \\
.156 \\
.018 \\
.105 \\
.036\end{array}$ & $\begin{array}{l}3.25 \\
.31 \\
\text { CMRL. } \\
1.05 \\
.07\end{array}$ & $\begin{array}{l}1.02 \\
.57 \\
\text { EMAL } \\
0.73 \\
1.40\end{array}$ & $\begin{array}{r}3.09 \\
.57 \\
1.02 \\
10.06\end{array}$ \\
\hline $\begin{array}{l}\text { GASE NO. } \\
\text { OCCUPATION } \\
\text { HESIOENT } \\
\text { STATE } \\
\text { GAUSE OF DEATH } \\
\text { ME CODE NO. }\end{array}$ & 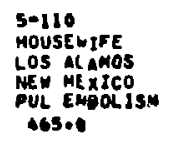 & $\begin{array}{l}\text { SEX } \\
\text { MOE } \\
\text { YEARS } \\
\text { YEAA I } \\
\text { KB }\end{array}$ & $\begin{array}{c}\text { F } \\
67 \\
1971 \\
\text { NA }\end{array}$ & $\begin{array}{l}\text { CIYEA } \\
\text { CUNO } \\
\text { LYMPH } \\
\text { KIONEY } \\
\text { RIE }\end{array}$ & $\begin{array}{r}951.0 \\
601.0 \\
10.0 \\
299.8 \\
61.0\end{array}$ & $\begin{array}{r}500 \\
1000 \\
25 \\
100 \\
200\end{array}$ & $\begin{array}{l}100 \\
150 \\
10 \\
10 \\
100\end{array}$ & $\begin{array}{r}.502 \\
.241 \\
.000 \\
0.000 \\
.064\end{array}$ & $\begin{array}{l}2.51 \\
\text { 995 } \\
\text { SHRL: } \\
\text { <MAL4 } \\
.13\end{array}$ & $\begin{array}{l}2.62 \\
1.20 \\
\text { CMRLE } \\
\text { CMRL- } \\
1.58\end{array}$ & $\begin{array}{l}4.46 \\
1,20 \\
11.06\end{array}$ \\
\hline $\begin{array}{l}\text { CASE NO. } \\
\text { OCCUPATION } \\
\text { RESLOENT } \\
\text { STATE } \\
\text { CAUSE OF DEATH } \\
\text { MEU COOE NO. }\end{array}$ & $\begin{array}{l}\text { 7- } 2 \\
\text { MOUSEWIFE } \\
\text { LOS ALAMOS } \\
\text { MEW MERICO } \\
\text { HEART ETFACK } \\
\text { A34.1 }\end{array}$ & $\begin{array}{l}\text { SEX } \\
\text { MEL } \\
\text { YEARS } \\
\text { YEAR I } \\
\text { KO }\end{array}$ & $\begin{array}{l}\text { 6e } \\
\text { NA } \\
\text { HEI }\end{array}$ & $\begin{array}{l}\text { LIVER } \\
\text { LUHO } \\
\text { LYMPH } \\
\text { RIONEY }\end{array}$ & $\begin{array}{r}1140.0 \\
640.9 \\
4.1 \\
170.0\end{array}$ & $\begin{array}{r}1000 \\
1000 \\
25 \\
100\end{array}$ & $\begin{array}{l}150 \\
250 \\
10 \\
10\end{array}$ & $\begin{array}{r}.920 \\
.060 \\
.606 \\
.0000\end{array}$ & $\begin{array}{l}3.60 \\
.24 \\
1.52 \\
\text { CHRL }\end{array}$ & $\begin{array}{r}3.23 \\
.37 \\
3+5.51 \\
\text { SHAL }\end{array}$ & $\begin{array}{r}5.48 \\
.37 \\
3.70\end{array}$ \\
\hline $\begin{array}{l}\text { GASE NO. } \\
\text { OCCUPAT DON } \\
\text { AESPOENT } \\
\text { BTATE } \\
\text { CAUSE OF OEATH } \\
\text { HEV COOE HO. }\end{array}$ & $\begin{array}{l}\text { 70 IA } \\
\text { HOUSEWIFe } \\
\text { LOS ALAMOS } \\
\text { ME MEXICE } \\
\text { STHOKE } \\
394.0\end{array}$ & $\begin{array}{l}\text { SEx } \\
\text { Aot } \\
\text { reans } \\
\text { rean I } \\
\text { Ro }\end{array}$ & $\begin{array}{c}6 \\
69 \\
107\end{array}$ & $\begin{array}{l}\text { Livea } \\
\text { Lung }\end{array}$ & $\begin{array}{r}1275 \cdot 4 \\
067.8\end{array}$ & $\begin{array}{l}2000 \\
1000\end{array}$ & $\begin{array}{l}250 \\
\text { aso }\end{array}$ & $\begin{array}{r}1.300 \\
.05\end{array}$ & $\begin{array}{l}5.20 \\
2.42\end{array}$ & $\begin{array}{l}4.00 \\
2.30\end{array}$ & $\begin{array}{l}6.93 \\
2.50\end{array}$ \\
\hline
\end{tabular}


TABLE AOII NON-RESIOENTS OF SOS ALAMOS. ho OCCUPATLONAL EXPOSURE TO PLUTONIUM

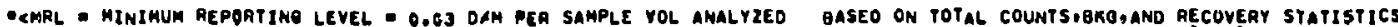

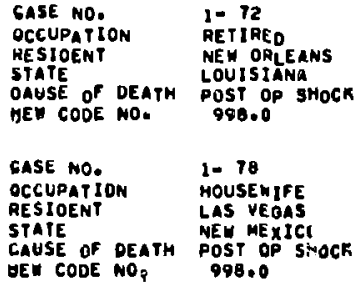

CASE NO.

OCEUPATION 1- 82

RESIDENT

STATE

CRUSE OF DEATH CAADIAC

HEN CUDE NO.

CASE NO.

OCCUPATION

AESIOENT

STATE of

HEU COOE NO. 998.0

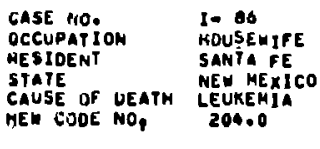

CASE no.

OCCUPATIO

AESIOENT

itate

CAUSE OF DEATM MRTERLOSCLEROSIS

HEU CODE NO.

GASE nO.

OCGUPATION

AESIOENT

STATE

OFITISH COA

MEO CODE MO.

CASE NO.

oct.upation

RESIOENT

Gause of OEATH ALC

HEU COOE NO. ALCOHOLISA

CASE NO.

occupation

RESICEN

STAlE

CAUSE OF DEATH MYOCAROIAL HYFER

MFE CODE NO!

GASE Mo.

occupation

AESIOENT

STAIE OF DEATH PNEUHONTA

MEW CCOE NO, $\$ 90.0$

Gase No.
OCCUPATION MOUSEIJE

AESIOCNT

STATE

CAUSE OF JEATM GAEAST CAMCER

MEU COOE MO. ITQOO

case mo.

occupation FORST SEMY

AES JOENT

FOAST SEMY
SANTA FE

Mey Mexjco

caube of vearm nuprengo aonta

bet coof wo.

WET
WE JOMT
SAMPLG
IORAMI

YOLUME VOLUME
OF SAMPLE
SAMGLE ANALYTEO

SAMGLE ANALYZEO

IGRAMI

\begin{tabular}{|c|c|c|}
\hline $\begin{array}{l}\text { SEX } \\
\text { AOS } \\
\text { YEARS }\end{array}$ & 5 MA & $\begin{array}{l}\text { LIYER } \\
\text { LUNO } \\
\text { LYMPH }\end{array}$ \\
\hline $\begin{array}{l}\text { YEAR } \\
\text { KO }\end{array}$ & $\begin{array}{r}1960 \\
\mathrm{NA}\end{array}$ & \\
\hline $\begin{array}{l}\text { SEX } \\
\text { AOE } \\
\text { YEARS }\end{array}$ & $\begin{array}{r}F \\
12 \\
N A\end{array}$ & $\begin{array}{l}\text { LIUEA } \\
\text { LUMG } \\
\text { LYMPH } \\
\text { RIONEY }\end{array}$ \\
\hline
\end{tabular}

1705.6

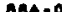

$804=0$
20.9
300.8

1010050

$2000 \quad 100$

$100 \quad 10$

1361.0
475.1

15.4
12.9

100050

$\begin{array}{rr}1000 & 500 \\ 25 & 10\end{array}$

YeAR 1960

MOE 75

LUNO

LYWPH
KIONEY

1000

500

16.9
320.9

10

YEAR 1960

YOE

LUNG

LYMPH
XIDNEY

1060.0

1000

23409

1000
100

YEAR 1960

SEL F
MEE AO
YEARS NA

YEAR 1960

\section{LIVER}

LUNG

2220.0
556.0
2.0
450.0

$\begin{array}{rr}2000 & 50 \\ 1000 & 500 \\ 50 & 10 \\ 100 & 10\end{array}$

.000

.000
1.101
010

.010
.010

2.60

$3.20 \quad 3.98$

AMRL:

SEX F
AGE II
YEARS MA

YEAR 1060

LIYER

$10^{2}$

$\begin{array}{rr}1000 & 50 \\ 10.4 & 500 \\ 50 & 10 \\ 100 & 10\end{array}$

.050

0.010

$\begin{array}{lll}2.00 & .05 & 2.44 \\ 2.80 & 3.49 & 3.49\end{array}$

TEAR IVGO

KIONEY 2AB.

SEX $F$ LIVEA

YEA BAS $B$

YEAP 1960

LUNO

KIONEY

as4.0

0.09
14.09

2000

1000
$50 \quad 100$

100

.030

.339
.090

.090

$\begin{array}{rrr}.60 & .70 & 1.19 \\ .60 & .11 & .61 \\ .45 & 32.14 & .32 \\ .40 & 2.00 & .64\end{array}$

SOE 3H
YEARS NA

YEAR 1960

LIVEA

21200

1000

.060

146000
375.0

100

50
500
10

KIONEY

1

2.249

.640

$\begin{array}{rrr}1.20 & .57 & .90 \\ 2.50 & 1.71 & 1.71 \\ 1.60 & 145.45 & 1.45 \\ 1.40 & 3.73 & 1.12\end{array}$

SEX
MOE

YEARS NA

YEAR 1961

$\begin{array}{lr}\text { LIYER } & 1400.0 \\ \text { LUNO } & 646.0 \\ \text { LYMPN } & 20.0 \\ \text { KIONEY } & 17000\end{array}$

$\begin{array}{rr}1000 & 50 \\ 1000 & 500 \\ 50 & 10\end{array}$

.140

.590

100
.130

$\begin{array}{lll}2.00 & 1.09 & 3.22 \\ 1.20 & 1.05 & 1.43 \\ 1.50 & 17.06 & 2.18 \\ 3.30 & 7.65 & 2.29\end{array}$

SEX F

YOE AS

YEAT ITH

LIVCA

LUNO

LYMPH
R IONEY

2070.0

1415.8
7.8
267.8

$\begin{array}{rr}1000 & 50 \\ 1000 & 500 \\ 50 & 10 \\ 100 & 10\end{array}$

.040

.630
.100
.000

.80
2.26
.10
.40

.39
$100 \% 09$
1.90

.66
.09
1.00
.05

SEL 5

TEARS HA

YEAF IOEL

LIVER

1249.0

$1000 \quad 50$

LUMO

775.0

1000

10

1210
0.200

3.00

\&HAL

$3.13 \quad 5.33$

KIONEY

241.0

100

10

.060

.60

2.06

.62

SeI

LIVEA 1292.

AOE 7

YEAR ITSI

$\begin{array}{rr}1010 & 50 \\ 1090 & 500 \\ 50 & 100\end{array}$

.040

.593

$.00 \quad 2.02 \quad 1.05$

1.19020 .33

$2 \cdot 33$ 


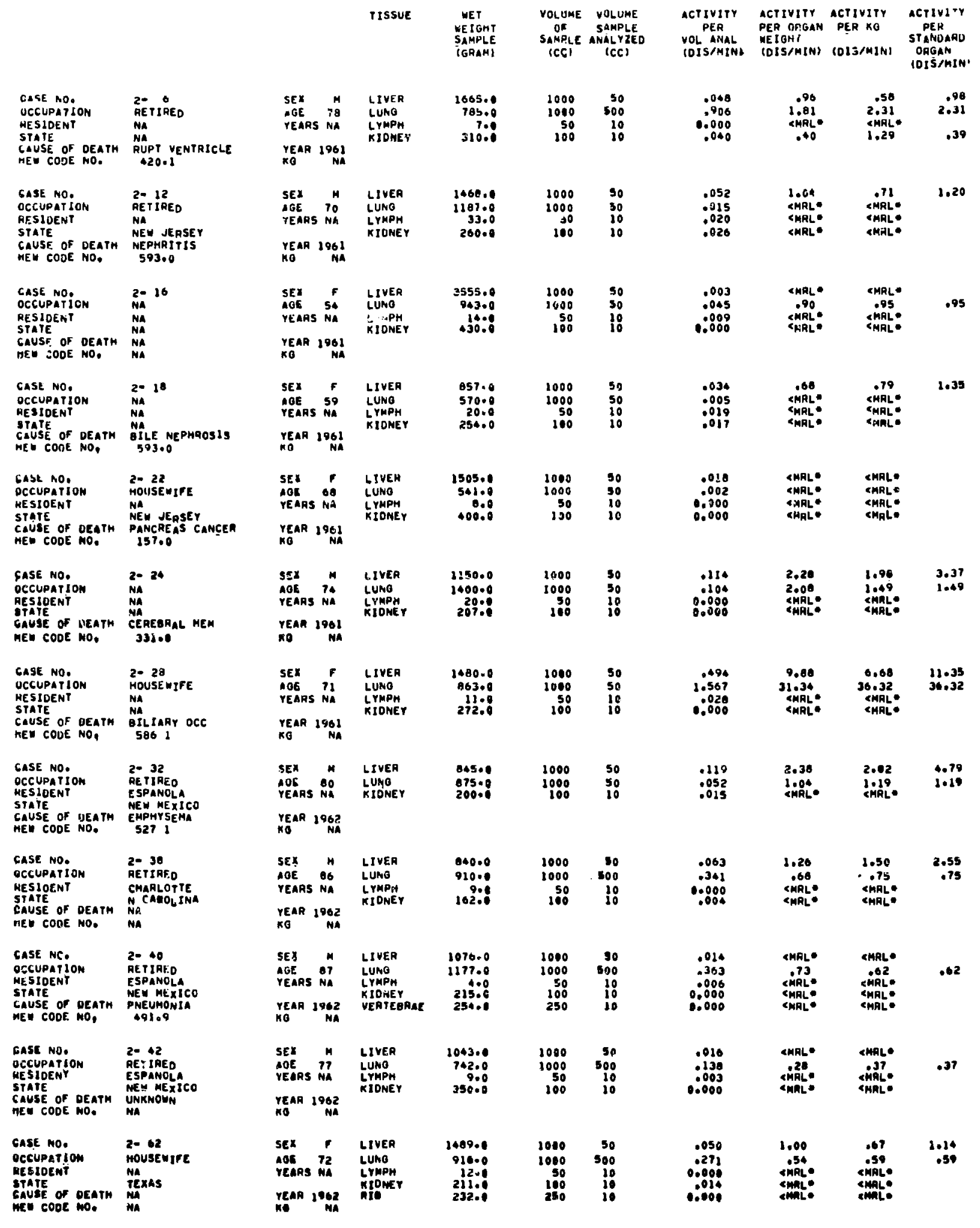




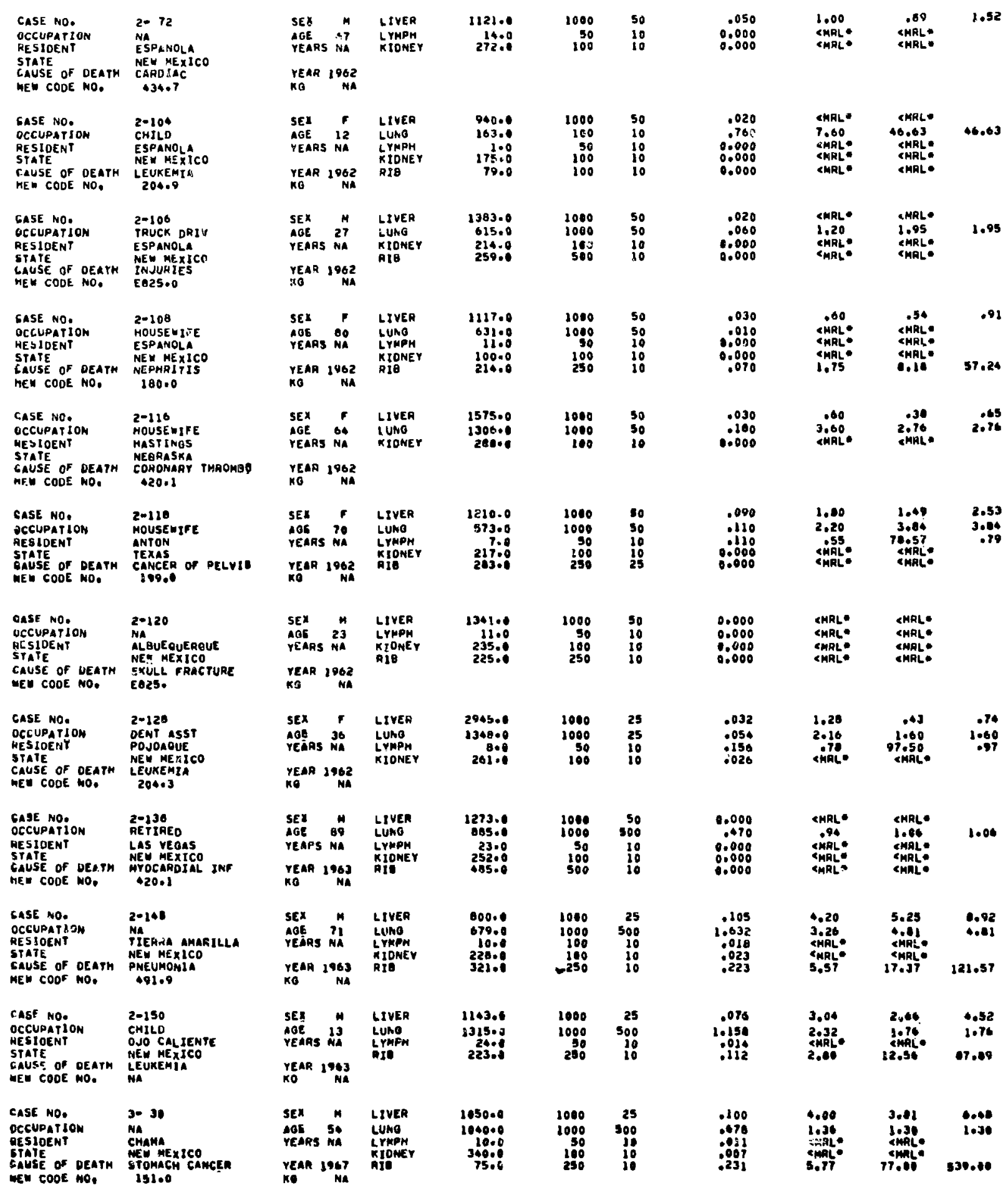




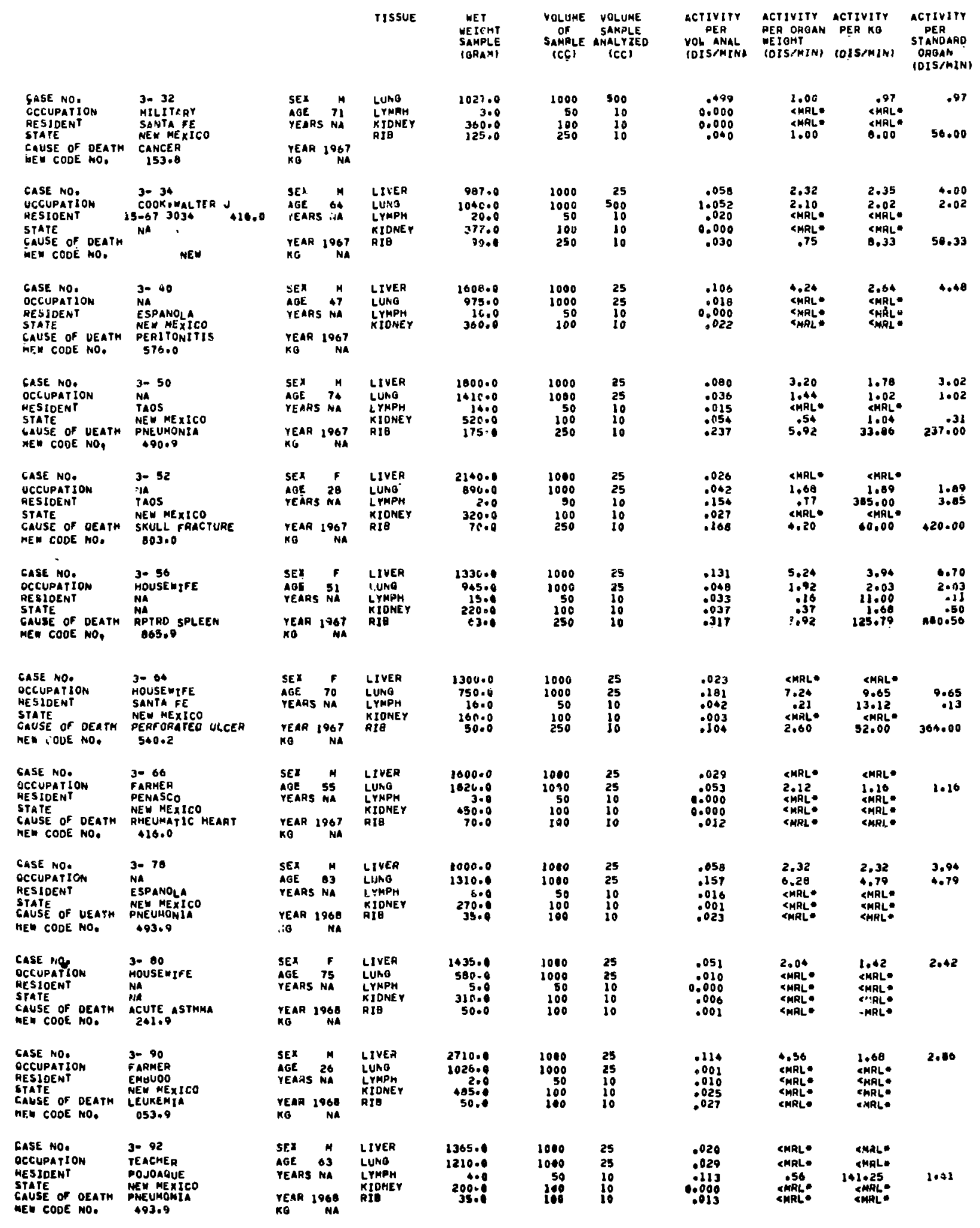




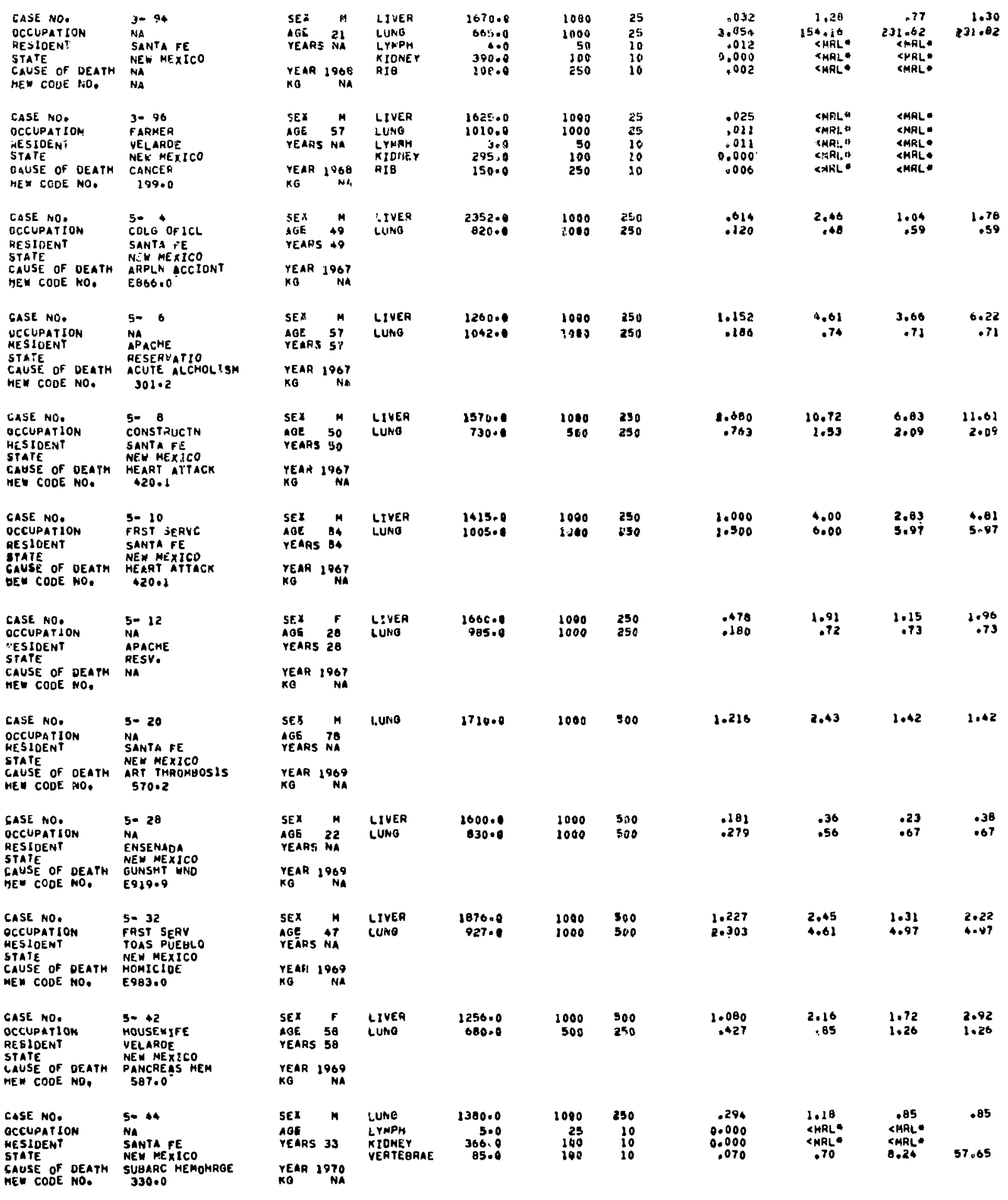




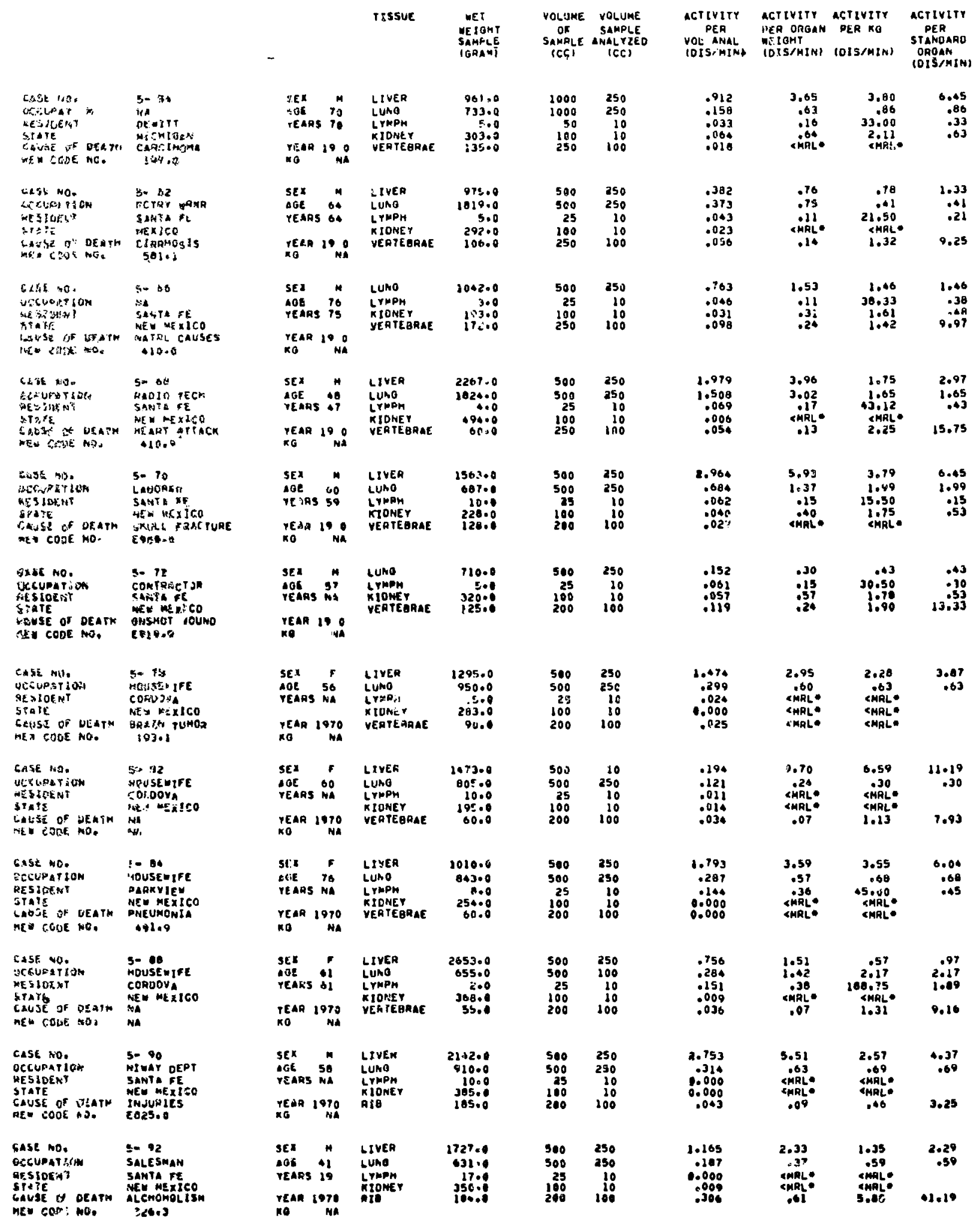




\begin{tabular}{|c|c|c|c|c|c|c|c|c|c|c|c|}
\hline $\begin{array}{l}\text { CASE NO, } \\
\text { UCCUPATION } \\
\text { RESIDENT } \\
\text { STATE } \\
\text { CAUSE OF DEATH } \\
\text { ME COOE NO. }\end{array}$ & $\begin{array}{l}\text { 5- } 96 \\
\text { T CAT MNOA } \\
\text { SANTA RE } \\
\text { NEW AEXICO } \\
\text { HEART GTTACK } \\
\text { 42O-1 }\end{array}$ & $\begin{array}{l}\text { SEX } \\
\text { IOE } \\
\text { YEARS } \\
\text { YEAR I } \\
\text { KO }\end{array}$ & $\begin{array}{r}\text { M } \\
52 \\
5 \text { NA } \\
1970 \\
\text { NA }\end{array}$ & $\begin{array}{l}\text { LIVEA } \\
\text { LUNO } \\
\text { LYHAH } \\
\text { KIONEY } \\
\text { RIB }\end{array}$ & $\begin{array}{r}1070.0 \\
024.0 \\
7.00 \\
310.0 \\
106.0\end{array}$ & $\begin{array}{r}500 \\
500 \\
25 \\
100 \\
200\end{array}$ & $\begin{array}{r}250 \\
250 \\
10 \\
10 \\
100\end{array}$ & $\begin{array}{l}2.179 \\
.227 \\
.008 \\
.045 \\
.035\end{array}$ & $\begin{array}{l}+.36 \\
.45 \\
\text { CMRL: } \\
\text { CMRL: } \\
.07\end{array}$ & $\begin{array}{l}2.33 \\
.55 \\
\text { CMAL. } \\
\text { CMRLE } \\
.65\end{array}$ & $\begin{array}{r}3.96 \\
.55 \\
4.54\end{array}$ \\
\hline $\begin{array}{l}\text { CASE NO. } \\
\text { UGCUPATION } \\
\text { HESTUENT } \\
\text { STATE } \\
\text { GAUSE OF DEATH } \\
\text { MEW COSE NO. }\end{array}$ & $\begin{array}{l}\text { 5- DO } \\
\text { NA } \\
\text { SANTA FE } \\
\text { NEW MEXICO } \\
\text { ASPIRATION } \\
\text { 933.0 }\end{array}$ & $\begin{array}{l}\text { SEX } \\
\text { AGE } \\
\text { YEAFS } \\
\text { YEAR I } \\
\text { KO }\end{array}$ & $\begin{array}{r}\text { N } \\
30 \\
\text { NA } \\
1970 \\
\text { NA }\end{array}$ & $\begin{array}{l}\text { LIVER } \\
\text { LUNG } \\
\text { LYAPH } \\
\text { KIDNEY } \\
\text { RIB }\end{array}$ & $\begin{array}{r}2075.0 \\
1572.0 \\
10.0 \\
466.0 \\
93.0\end{array}$ & $\begin{array}{r}500 \\
500 \\
25 \\
100 \\
200\end{array}$ & $\begin{array}{r}250 \\
250 \\
10 \\
10 \\
100\end{array}$ & $\begin{array}{r}.211 \\
.205 \\
0.000 \\
.006 \\
.059\end{array}$ & $\begin{array}{l}.42 \\
\text { \&41 } \\
\text { SMRL } \\
\text { CHRLE } \\
.12\end{array}$ & $\begin{array}{l}.20 \\
.26 \\
\text { QHRLE } \\
\text { SHRL } \\
1.27\end{array}$ & $\begin{array}{r}.35 \\
.26 \\
.040\end{array}$ \\
\hline $\begin{array}{l}\text { GASE NO. } \\
\text { OCCUPATIOH } \\
\text { MESIDENT } \\
\text { STAIE } \\
\text { CAUSE OF DEATH } \\
\text { HEW CODE MO. }\end{array}$ & $\begin{array}{l}\text { 5-106 } \\
\text { MNTNCE MAN } \\
\text { SANTA FE } \\
\text { NEW MEXICO } \\
\text { ONSST? JOUND } \\
\text { E91D.9 }\end{array}$ & $\begin{array}{l}\text { SEX } \\
\text { AGE } \\
\text { YEARS } \\
\text { YEAR I } \\
\text { MB }\end{array}$ & $\begin{array}{r}M \\
27 \\
27 \\
1970 \\
\text { MA }\end{array}$ & $\begin{array}{l}\text { LUNO } \\
\text { LYRPH } \\
\text { KIDNEY }\end{array}$ & $\begin{array}{r}650.0 \\
3.0 \\
263.0\end{array}$ & $\begin{array}{r}500 \\
25 \\
100\end{array}$ & $\begin{array}{l}950 \\
10 \\
10\end{array}$ & $\begin{array}{r}.270 \\
0.000 \\
.009\end{array}$ & $\underset{\text { SMRL: }}{\text { SMFL }}$ & SMRL: & .05 \\
\hline $\begin{array}{l}\text { CASE NO. } \\
\text { OCCUPATIOH } \\
\text { RESIDENT } \\
\text { STATE } \\
\text { CAUSE OF DEATM } \\
\text { hEM COOE HO. }\end{array}$ & $\begin{array}{l}\text { 5WIII } \\
\text { PHYSICIAN } \\
\text { ESPANOLLA } \\
\text { NEW MEXICO } \\
\text { ORUOS } \\
\text { NA }\end{array}$ & $\begin{array}{l}\text { SE: } \\
\text { AOE } \\
\text { YEÄAS } \\
\text { YEAR I } \\
\text { KO }\end{array}$ & $\begin{array}{r}\text { H } \\
57 \\
1070 \\
\text { NA }\end{array}$ & $\begin{array}{l}\text { LIVER } \\
\text { LUAO } \\
\text { LYHPH } \\
\text { KIONEY } \\
\text { RIB }\end{array}$ & $\begin{array}{r}1625.9 \\
1000.0 \\
707.0 \\
9.08\end{array}$ & $\begin{array}{r}500 \\
1000 \\
25 \\
100 \\
200\end{array}$ & $\begin{array}{l}100 \\
250 \\
10 \\
100 \\
100\end{array}$ & $\begin{array}{l}.756 \\
.136 \\
.015 \\
.005 \\
.018\end{array}$ & $\begin{array}{l}3,70 \\
.54 \\
\text { QMAL: } \\
\text { \&MRL: } \\
\text { QMRL: }\end{array}$ & $\begin{array}{l}2.33 \\
\text {.54 } \\
\text { SAAL: } \\
\text { SMAL: } \\
\text { SMALE }\end{array}$ & $\begin{array}{r}3.95 \\
.54\end{array}$ \\
\hline $\begin{array}{l}\text { GASE NO. } \\
\text { OCCUPATION } \\
\text { WESJOENT } \\
\text { STATE } \\
\text { GAUSE OF DEATH } \\
\text { HEW COOE NO. }\end{array}$ & $\begin{array}{l}5=1+0 \\
\text { EVRL DOER } \\
\text { ANTON GHICO } \\
\text { NEY MEXICO } \\
\text { BULLEIS } \\
\text { EQIO.0 }\end{array}$ & $\begin{array}{l}\text { SEX } \\
\text { AGE } \\
\text { YEAAS } \\
\text { YEAR I } \\
\text { KO }\end{array}$ & $\begin{array}{l}\text { M } \\
\text { NA } \\
\text { I9T2 } \\
\text { NA }\end{array}$ & $\begin{array}{l}\text { LIVEA } \\
\text { LUMG } \\
\text { LYMPH } \\
\text { KIONEY } \\
\text { VERTEBRAE }\end{array}$ & $\begin{array}{r}2350.0 \\
760.0 \\
2.0 \\
286.0 \\
98.0\end{array}$ & $\begin{array}{r}1000 \\
1000 \\
25 \\
100 \\
200\end{array}$ & $\begin{array}{r}250 \\
250 \\
10 \\
10 \\
100\end{array}$ & $\begin{array}{l}.649 \\
.043 \\
.007 \\
.011 \\
.074\end{array}$ & $\begin{array}{l}2.60 \\
.17 \\
\text { CHRLE } \\
\text { EMRLE } \\
.15\end{array}$ & $\begin{array}{l}1.92 \\
.23 \\
\text { SARL } \\
\text { CHALE } \\
1.56\end{array}$ & $\begin{array}{r}3.27 \\
.23 \\
10.91\end{array}$ \\
\hline $\begin{array}{l}\text { GASE NO. } \\
\text { DCCUPATIOH } \\
\text { RESIDENT } \\
\text { STATE } \\
\text { GAUSE OF DEATH } \\
\text { TEL CODE NO. }\end{array}$ & $\begin{array}{l}\text { 7. } 10 \\
\text { NA } \\
\text { OULEE } \\
\text { NE MEXICO } \\
\text { SEPSIS } \\
\text { S53.6 }\end{array}$ & $\begin{array}{l}\text { SEX } \\
\text { AOQ } \\
\text { YEARS } \\
\text { YEAR I } \\
\text { KO }\end{array}$ & 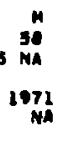 & $\begin{array}{l}\text { LIVER } \\
\text { LUAO } \\
\text { LYMPH } \\
\text { KJONEY } \\
\text { VERTEBRAE }\end{array}$ & $\begin{array}{r}1726.9 \\
1017.0 \\
9.5 \\
225.9 \\
76.0\end{array}$ & $\begin{array}{r}1000 \\
1000 \\
25 \\
100 \\
200\end{array}$ & $\begin{array}{l}250 \\
250 \\
10 \\
10 \\
100\end{array}$ & $\begin{array}{l}.930 \\
.169 \\
0004 \\
0012 \\
0019\end{array}$ & $\begin{array}{l}3.72 \\
\text { A76 } \\
\text { RMRLE } \\
\text { SMRLE } \\
\text { SMALE }\end{array}$ & 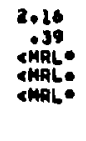 & $\begin{array}{r}3.66 \\
.39\end{array}$ \\
\hline $\begin{array}{l}\text { GASE NO. } \\
\text { OCCUPATION } \\
\text { RESIDENT } \\
\text { STATE } \\
\text { CAUSE OF DEATM } \\
\text { MEU CODE NO. }\end{array}$ & $\begin{array}{l}\text { 7- } 22 \\
\text { NA } \\
\text { SANTA FE } \\
\text { MEN MEXICO } \\
\text { DHUS OVEROOS } \\
\text { OSS.S }\end{array}$ & $\begin{array}{l}\text { SEX } \\
\text { AOS } \\
\text { YEARS } \\
\text { YEAR I } \\
\text { KS }\end{array}$ & $\begin{array}{l}\text { No } \\
\text { Nat } \\
\text { NA }\end{array}$ & $\begin{array}{l}\text { LIVER } \\
\text { LUMG } \\
\text { LYMPH } \\
\text { KIOMEY } \\
\text { VERTEQHAE }\end{array}$ & $\begin{array}{r}1474.0 \\
1025.0 \\
3.9 \\
337.9 \\
102.0\end{array}$ & $\begin{array}{r}1000 \\
1000 \\
25 \\
100 \\
200\end{array}$ & $\begin{array}{r}250 \\
290 \\
10 \\
10 \\
100\end{array}$ & $\begin{array}{r}.240 \\
.141 \\
0.040 \\
.006 \\
.030\end{array}$ & 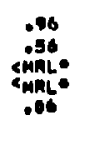 & 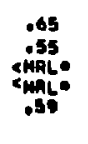 & $\begin{array}{r}1.11 \\
.58 \\
4.12\end{array}$ \\
\hline
\end{tabular}


TARLE A-III COLORADO CAGES ANALVZEO FOA PLUTONIUM

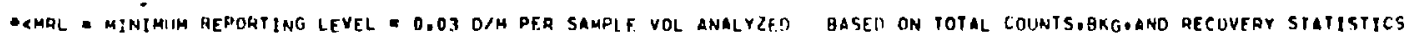

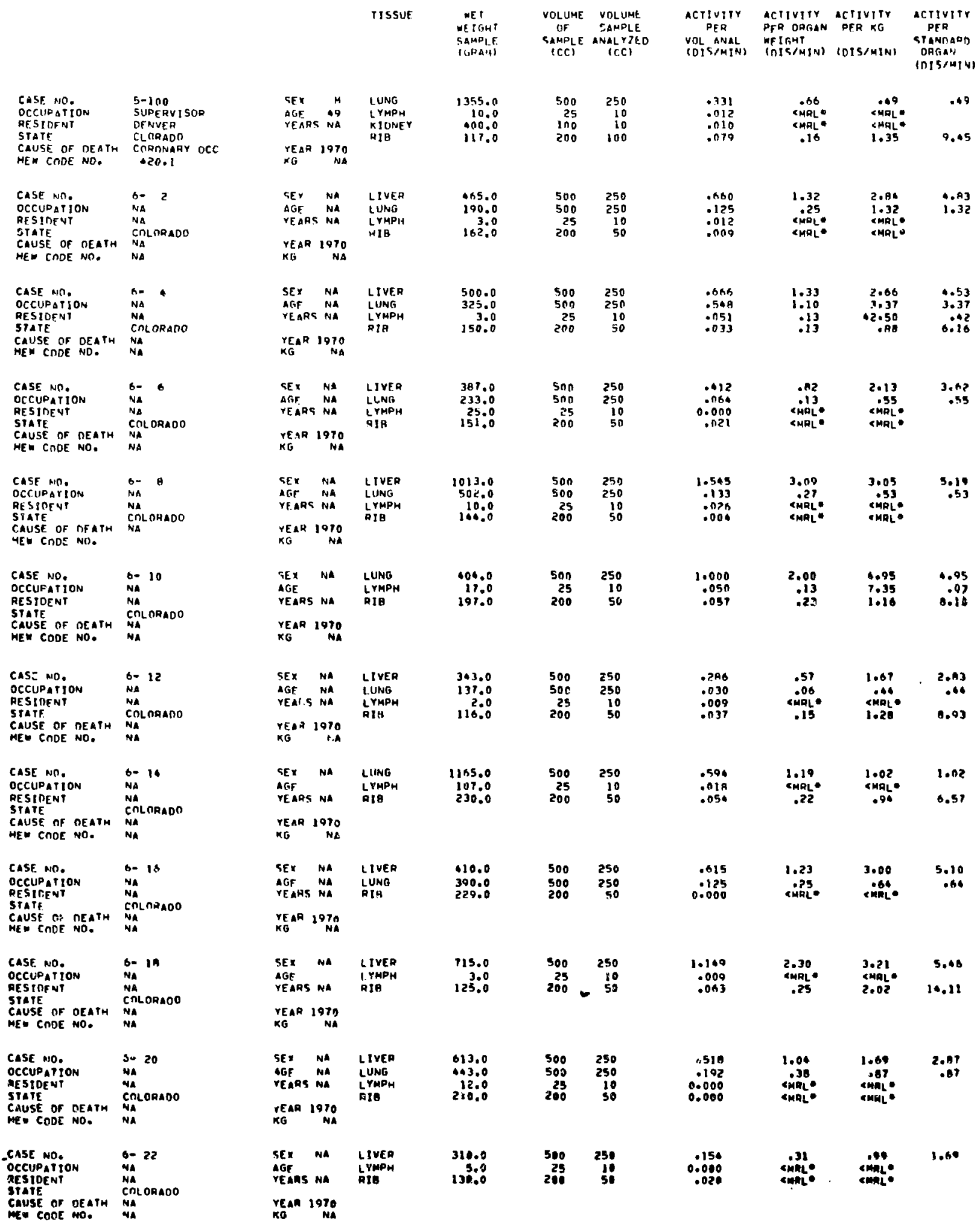




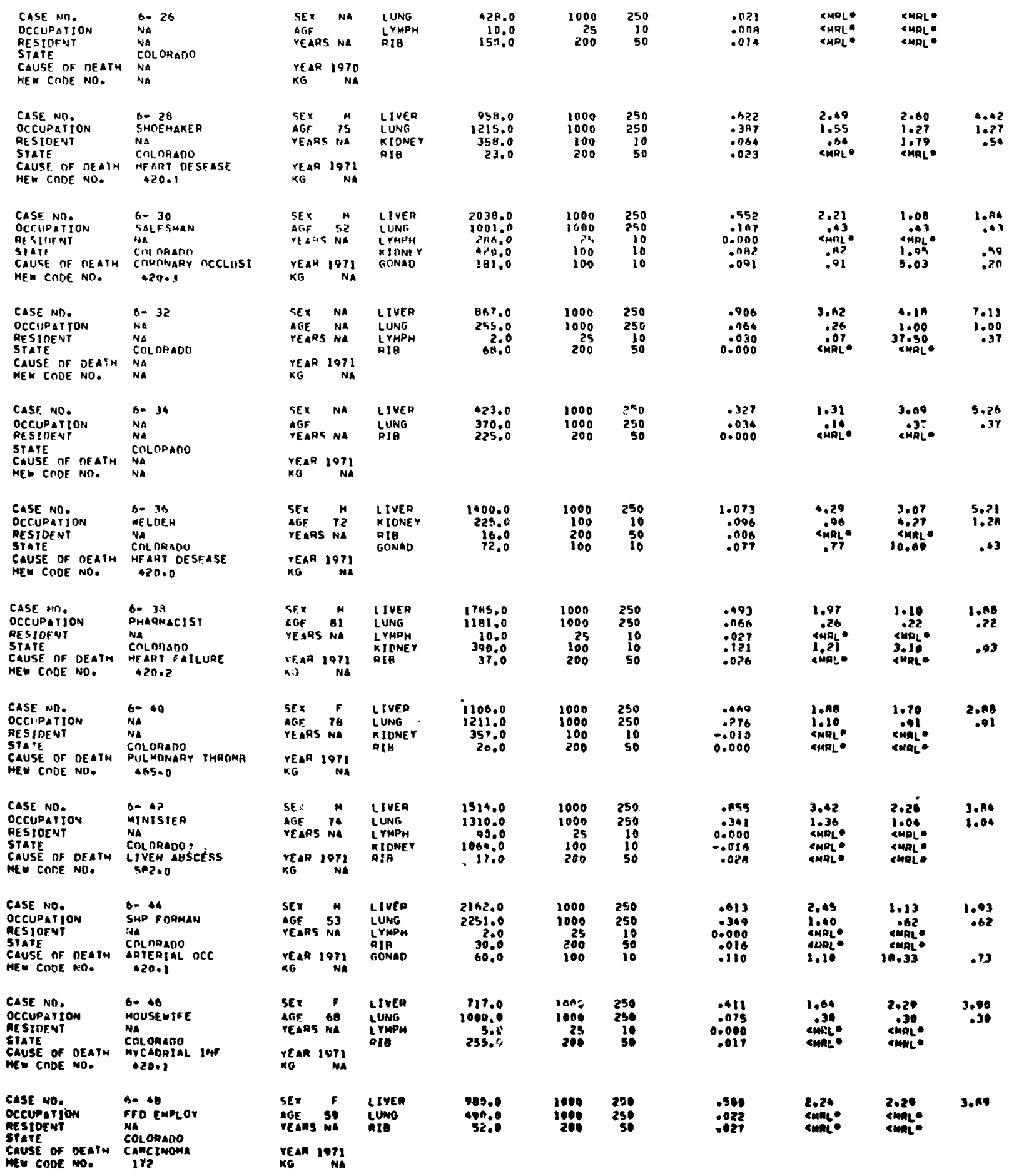


IISSUE

$$
\begin{aligned}
& \text { EET } \\
& \text { WEIGHT } \\
& \text { SAMPLE } \\
& \text { (GRIM) }
\end{aligned}
$$

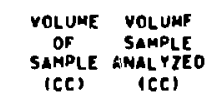$$
\begin{aligned}
& \text { ACTIYITY } \\
& \text { PEA } \\
& \text { YOL ANAL } \\
& \text { COISIMIN) }
\end{aligned}
$$

actiniti activiti PER ORGAN PEA KG (DISIMIN) COISIMINI IDISIMIN)

activity PED STANDARO IDISFIVI

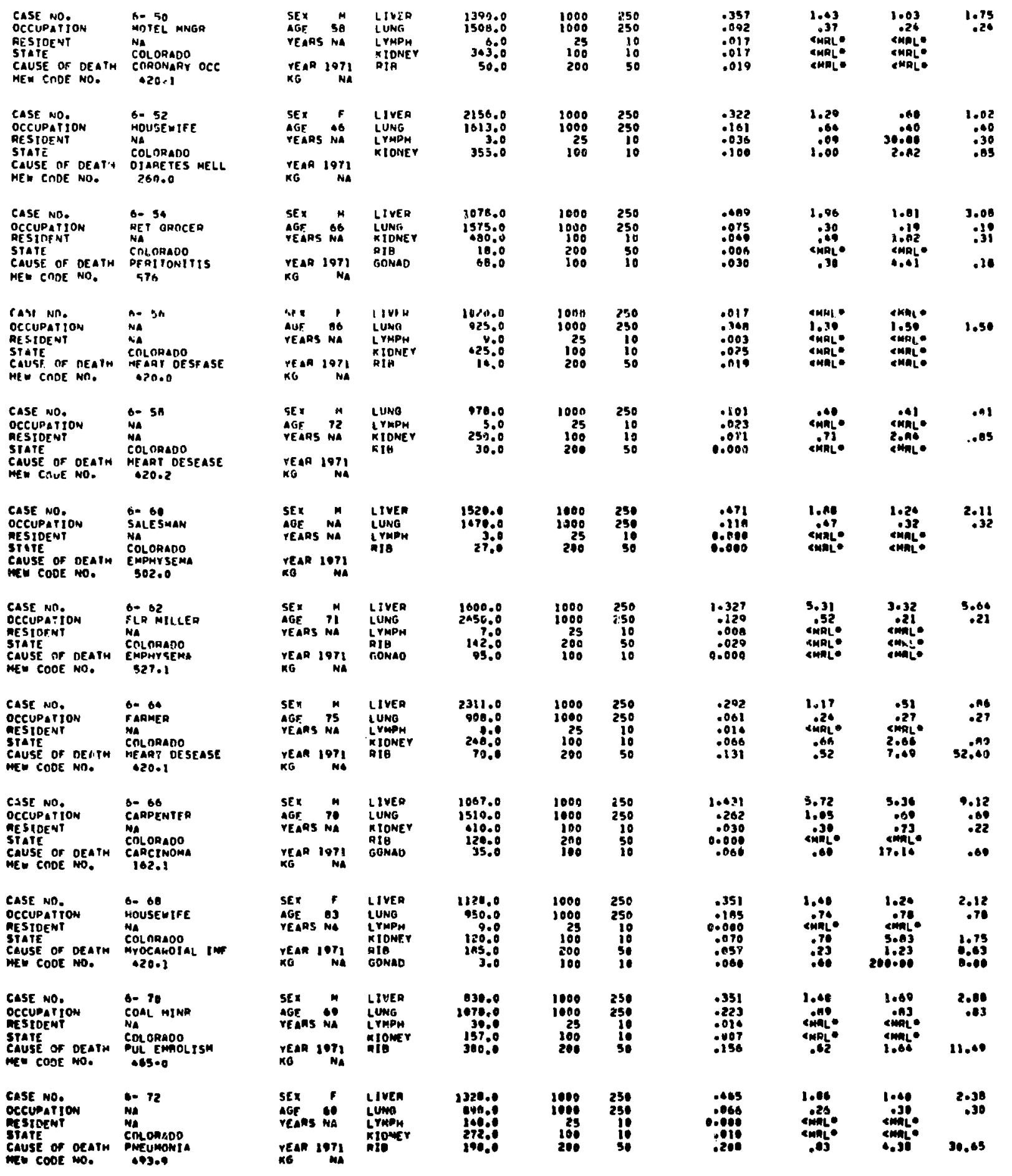




\begin{tabular}{|c|c|c|c|c|c|c|c|c|c|c|}
\hline & & & IISSUE & 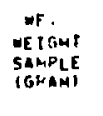 & $\begin{array}{l}\text { YOLUHE } \\
\text { SAF } \\
\text { SAMPLE } \\
\text { CCCI }\end{array}$ & $\begin{array}{l}\text { VOLIJEE } \\
\text { SAMLEE } \\
\text { ANALIRED } \\
\text { ICE) }\end{array}$ & $\begin{array}{l}\text { Acrsvity } \\
\text { DED } \\
\text { VoL ANAL } \\
\text { COISIMINI }\end{array}$ & 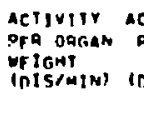 & 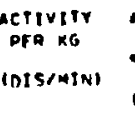 & 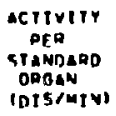 \\
\hline 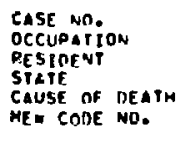 & $\begin{array}{l}\text { 6- } 76 \\
\text { NA } \\
\text { NA } \\
\text { COLOAASO } \\
\text { ATEMIOSCLEROSIS } \\
\text { AZO. }\end{array}$ & $\begin{array}{l}\text { SEX N } \\
\text { AGT BS } \\
\text { YEAAS NA } \\
\text { REAR } 1971 \\
\text { RG NA NE }\end{array}$ & $\begin{array}{l}\text { LIVER } \\
\text { LUNF, } \\
\text { LYWPA } \\
\text { KIDNFY } \\
\text { RIR } \\
\text { GONAD }\end{array}$ & $\begin{aligned} 906.0 \\
705 \% 0 \\
20.0 \\
20200 \\
72.0 \\
93.0\end{aligned}$ & $\begin{array}{l}1000 \\
1000 \\
25 \\
100 \\
200 \\
100\end{array}$ & $\begin{array}{r}250 \\
250 \\
10 \\
10 \\
50 \\
10\end{array}$ & $\begin{array}{l}0.000 \\
0.000 \\
0.019 \\
0.035 \\
0.55 \\
.025 \\
025\end{array}$ & 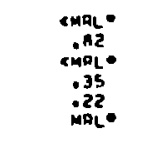 & 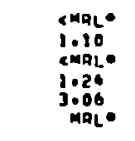 & $\begin{array}{r}1.10 \\
21.37\end{array}$ \\
\hline 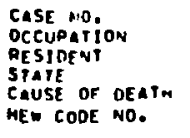 & $\begin{array}{l}\text { O- } 70^{\circ} \\
\text { OFTIPEO } \\
\text { NA } \\
\text { COLDARDE } \\
\text { EMPHYSEMA } \\
\text { S27.1 }\end{array}$ & $\begin{array}{l}\text { SEX N } \\
\text { AGF } 26 \\
\text { YEARS NA } \\
\text { YEAR 1971 } \\
\text { XG NAA }\end{array}$ & 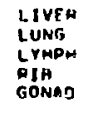 & $\begin{array}{r}1116.0 \\
5 B 5.0 \\
20.0 \\
1000 \\
36.0\end{array}$ & $\begin{array}{l}1000 \\
1000 \\
25 \\
200 \\
100\end{array}$ & $\begin{array}{r}250 \\
250 \\
10 \\
50 \\
10\end{array}$ & $\begin{array}{l}1.011 \\
0.317 \\
0.05 \\
0.050 \\
.015\end{array}$ & 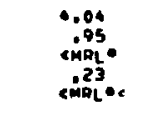 & 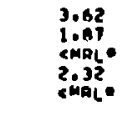 & $\begin{array}{r}6.16 \\
1.87 \\
16.24\end{array}$ \\
\hline 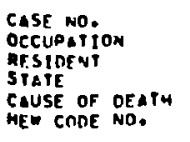 & 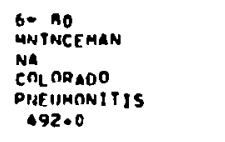 & $\begin{array}{l}\text { CEN M M } \\
\text { AGE BO } \\
\text { YEARS NA } \\
\text { YEAA IOYY } \\
\text { KG NA }\end{array}$ & $\begin{array}{l}\text { LULS: } \\
\text { LYMPH } \\
\text { KIONEY } \\
\text { HIB }\end{array}$ & $\begin{array}{r}1550.0 \\
280 \\
280 \\
77.0\end{array}$ & $\begin{array}{r}1000 \\
25 \\
200 \\
200\end{array}$ & $\begin{array}{r}250 \\
30 \\
16 \\
50\end{array}$ & $\begin{array}{l}.07 h \\
0.000 \\
0.034 \\
0100\end{array}$ & 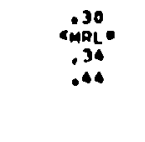 & $\begin{array}{l}.20 \\
\substack{240 \\
1.21 \\
1.21 \\
3.06}\end{array}$ & $\begin{array}{r}.20 \\
39.04\end{array}$ \\
\hline 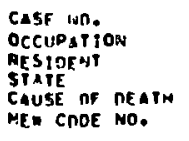 & 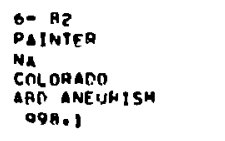 & $\begin{array}{l}\text { SEX NA } \\
\text { AGE } \\
\text { YEARS NA } \\
\text { YEAR } 1971 \\
\text { XG NG NA }\end{array}$ & $\begin{array}{l}\text { LUVEA } \\
\text { LUNG } \\
\text { LYMPM } \\
\text { KIONEY } \\
\text { RIA }\end{array}$ & 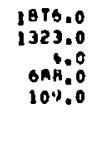 & $\begin{array}{l}1000 \\
1000 \\
25 \\
100 \\
200\end{array}$ & $\begin{array}{l}250 \\
250 \\
10 \\
10 \\
50\end{array}$ & $\begin{array}{l}.453 \\
.080 \\
0.000 \\
.013 \\
.067\end{array}$ & 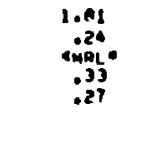 & 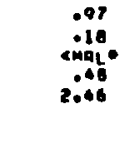 & $\begin{array}{l}1.64 \\
.10 \\
17.93\end{array}$ \\
\hline 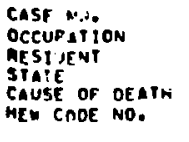 & 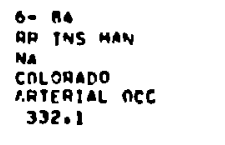 & $\begin{array}{l}\text { SEX SA } \\
\text { GEF SB } \\
\text { YEARS } \\
\text { YEAA 107I } \\
\text { KG NA }\end{array}$ & $\begin{array}{l}\text { LIVEA } \\
\text { LUNG } \\
\text { LYMOM } \\
\text { KIONEY } \\
\text { RYGEY }\end{array}$ & 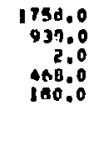 & $\begin{array}{l}1000 \\
1000 \\
23 \\
100 \\
200\end{array}$ & $\begin{array}{r}250 \\
250 \\
10 \\
10 \\
50\end{array}$ & $\begin{array}{l}.008 \\
.2 n 6 \\
0.001 \\
0.047 \\
.004\end{array}$ & 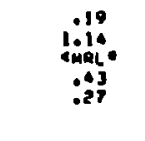 & 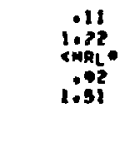 & $\begin{array}{r}10 \\
1.82 \\
10.25\end{array}$ \\
\hline 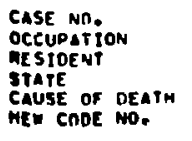 & 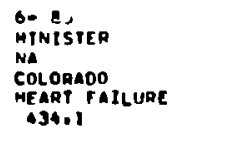 & $\begin{array}{l}\text { SEX N } \\
\text { AGE AO } \\
\text { TEARS NA } \\
\text { YEAR 1971 } \\
\text { KO NA }\end{array}$ & $\begin{array}{l}\text { LYVEA } \\
\text { LUNG } \\
\text { LYMPH } \\
\text { KlONEY } \\
\text { gla }\end{array}$ & $\begin{array}{r}1016.0 \\
970.0 \\
19.5 \\
154,0 \\
123.0\end{array}$ & $\begin{array}{rl}1 & 1000 \\
1000 \\
23 \\
100 \\
100 \\
200\end{array}$ & $\begin{array}{r}250 \\
250 \\
10 \\
10 \\
50\end{array}$ & $\begin{array}{l}.2319 \\
.366 \\
0.000 \\
.013 \\
.263\end{array}$ & 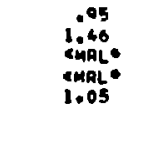 & 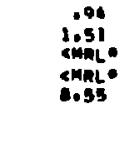 & 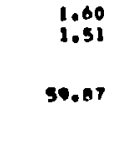 \\
\hline 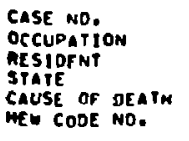 & $\begin{array}{l}\text { 6- AH } \\
\text { LAFOAF, } \\
\text { NA } \\
\text { EOLORAOOO } \\
\text { DNEUMONZA } \\
493.0\end{array}$ & $\begin{array}{l}\text { SEX NA } \\
\text { AGE IA } \\
\text { YEARS NA } \\
\text { YEAR 19T1 } \\
\text { KG WA }\end{array}$ & $\begin{array}{l}\text { LIVER } \\
\text { LIVEG } \\
\text { LUNG } \\
\text { LYJP }\end{array}$ & $\begin{array}{r}1011: 0 \\
1613.0 \\
22.2 \\
132.0\end{array}$ & $\begin{array}{r}1000 \\
1000 \\
25 \\
200\end{array}$ & $\begin{array}{r}250 \\
250 \\
10 \\
50\end{array}$ & $\begin{array}{l}.068 \\
.823 \\
.006 \\
.284\end{array}$ & $\begin{array}{l}1.06 \\
2.069 \\
\text { int. } \\
1.16\end{array}$ & 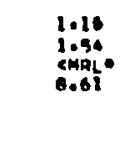 & $\begin{array}{r}1.97 \\
1.54 \\
0.24\end{array}$ \\
\hline 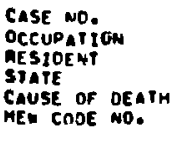 & 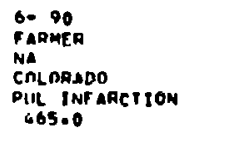 & $\begin{array}{l}\text { SFI M N } \\
\text { AGE 75 } \\
\text { TEARS AA } \\
\text { YEAA 1971 } \\
\text { RG NA }\end{array}$ & 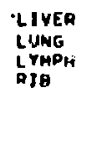 & $\begin{array}{r}2432.0 \\
1085: 0 \\
3.0 \\
+15.0\end{array}$ & $\begin{array}{r}1000 \\
1000 \\
25 \\
200\end{array}$ & $\begin{array}{r}250 \\
250 \\
10 \\
50\end{array}$ & $\begin{array}{l}.497 \\
0.023 \\
0.160 \\
.094\end{array}$ & $\begin{array}{l}1.99 \\
\text { aPRL. } \\
1: 07 \\
1: 08\end{array}$ & 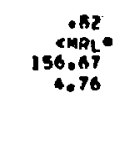 & $\begin{array}{l}1.34 \\
1.57 \\
33.33\end{array}$ \\
\hline $\begin{array}{l}\text { CASE WO. } \\
\text { OSCUPATION } \\
\text { OCSYIOENT } \\
\text { STAYE } \\
\text { CAUSE OF OEATH } \\
\text { MEW COOE NO. }\end{array}$ & 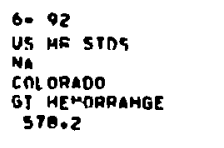 & $\begin{array}{l}\text { GEX M M } \\
\text { AGE AS } \\
\text { VEARS NA } \\
\text { REAR 1971 } \\
\text { KG NA NA }\end{array}$ & 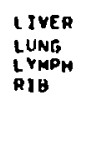 & $\begin{array}{r}2784.0 \\
1119.0 \\
11.7 \\
370.0\end{array}$ & $\begin{array}{r}1000 \\
1000 \\
25 \\
800\end{array}$ & $\begin{array}{l}250 \\
250 \\
10 \\
30\end{array}$ & $\begin{array}{l}.128 \\
0.072 \\
0005 \\
.034\end{array}$ & 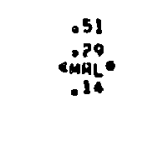 & 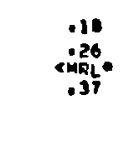 & $\begin{array}{r}.31 \\
.26 \\
2.57\end{array}$ \\
\hline 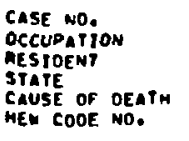 & 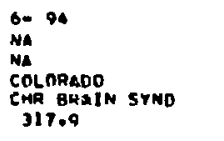 & $\begin{array}{l}\text { SEX F F } \\
\text { AGF T9 } \\
\text { YEARS NR } \\
\text { YEAR 1971 } \\
\text { KG N NA }\end{array}$ & $\begin{array}{l}\text { LIVEA } \\
\text { LLNG } \\
\text { LYMPM } \\
\text { KYPNEY } \\
\text { RIGEY }\end{array}$ & $\begin{array}{l}850.0 \\
045.0 \\
32.0 \\
122: 0 \\
255.0\end{array}$ & $\begin{array}{l}1000 \\
1000 \\
25 \\
100 \\
200\end{array}$ & $\begin{array}{l}250 \\
250 \\
10 \\
10 \\
50\end{array}$ & $\begin{array}{l}.257 \\
.322 \\
0005 \\
0090 \\
0194\end{array}$ & 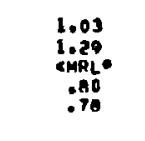 & 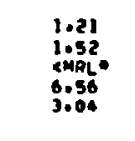 & $\begin{array}{l}2.08 \\
2.52 \\
21.930\end{array}$ \\
\hline 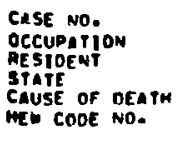 & 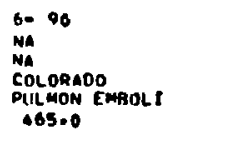 & $\begin{array}{l}\text { SEX F } \\
\text { GEE } 30 \\
\text { YEARS MA } \\
\text { YEAK 1971 } \\
\text { KO NA }\end{array}$ & $\begin{array}{l}\text { LIVEA } \\
\text { LUNG } \\
\text { KIDNEY } \\
\text { RIB }\end{array}$ & $\begin{array}{r}2460.00 \\
1460.00 \\
200.0 \\
205.0\end{array}$ & $\begin{array}{l}1000 \\
1000 \\
100 \\
200\end{array}$ & $\begin{array}{r}250 \\
250 \\
10 \\
30\end{array}$ & $\begin{array}{r}.092 \\
\therefore 076 \\
\therefore 087 \\
.0071\end{array}$ & 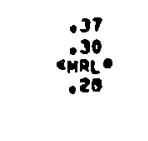 & 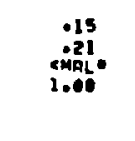 & $\begin{array}{l}.25 \\
.21 \\
. .96\end{array}$ \\
\hline 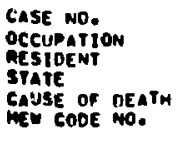 & 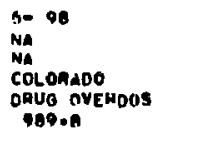 & 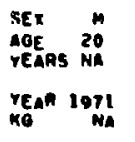 & $\begin{array}{l}\text { LIVER } \\
\text { KIOMEY } \\
\text { AIB } \\
\text { GOMAO }\end{array}$ & $\begin{array}{r}1660.0 \\
170.0 \\
300.0 \\
50.3\end{array}$ & $\begin{array}{l}1000 \\
100 \\
200 \\
300\end{array}$ & $\begin{array}{r}250 \\
30 \\
50 \\
10\end{array}$ & $\begin{array}{l}.026 \\
0010 \\
0110 \\
0110 \\
032\end{array}$ & $\begin{array}{c}\text { CMAL: } \\
\text { SMRL" } \\
: 32 \\
: 34\end{array}$ & 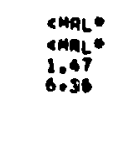 & $\begin{array}{l}10.27 \\
.25\end{array}$ \\
\hline
\end{tabular}




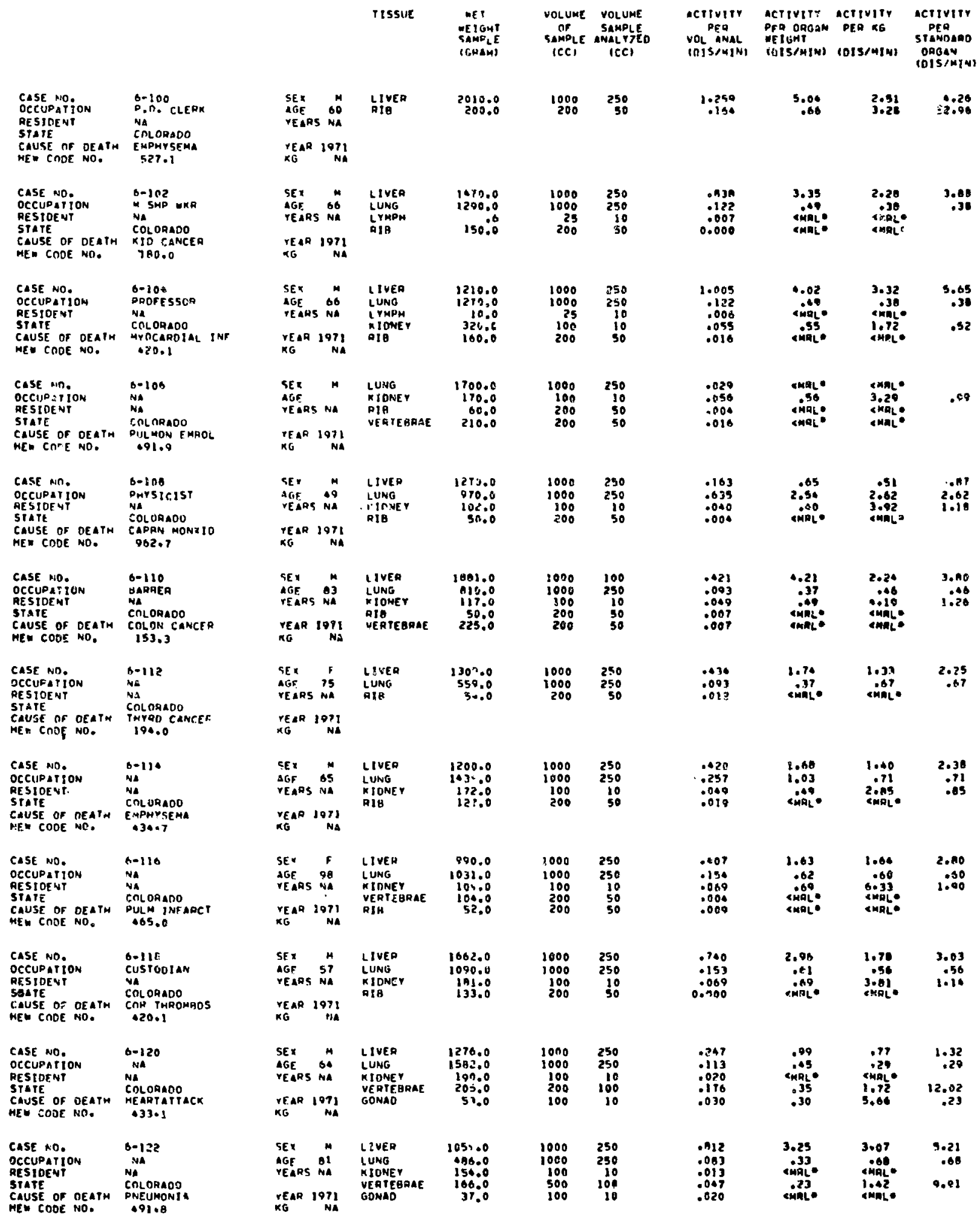




\begin{tabular}{|c|c|c|c|c|c|c|c|c|c|c|}
\hline & & & TISSUE & 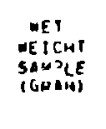 & $\begin{array}{l}\text { VOL UME } \\
\text { Of } \\
\text { SAMPLE } \\
\text { :Ci) }\end{array}$ & $\begin{array}{l}\text { VOLUEE } \\
\text { SAMELE } \\
\text { ANALREO } \\
\text { ICCI }\end{array}$ & 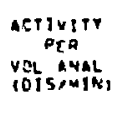 & 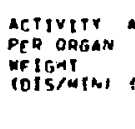 & 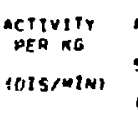 & 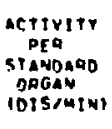 \\
\hline 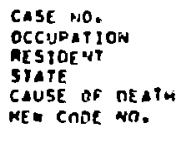 & 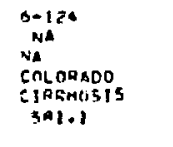 & 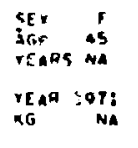 & $\begin{array}{l}\text { LIVER } \\
\text { LUNGG } \\
\text { KIONEY } \\
\text { VEATEBAAE }\end{array}$ & $\begin{array}{r}509.0 \\
1013: 0 \\
127.0 \\
163.0\end{array}$ & $\begin{array}{l}1060 \\
1000 \\
100 \\
200\end{array}$ & $\begin{array}{r}250 \\
250 \\
100 \\
100\end{array}$ & $\begin{array}{l}023 \\
0.023 \\
0.060 \\
0.060 \\
0110\end{array}$ & $\begin{array}{l}\text { SMRL" } \\
.19 \\
.80 \\
.22\end{array}$ & 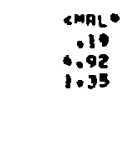 & \begin{tabular}{l}
$: 09$ \\
\hdashline$: 40$
\end{tabular} \\
\hline 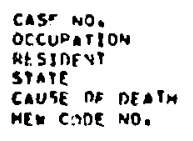 & 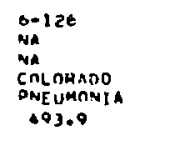 & $\begin{array}{l}\text { SEX M } \\
\text { EEE AEARS NA } \\
\text { TEAA IOTI } \\
\text { KG NA }\end{array}$ & $\begin{array}{l}\text { LIVEA } \\
\text { LUNG } \\
\text { KIONEY } \\
\text { GONAD }\end{array}$ & $\begin{array}{r}1072.0 \\
2512.0 \\
198.0 \\
47.0\end{array}$ & $\begin{array}{l}1000 \\
1000 \\
100 \\
100\end{array}$ & $\begin{array}{l}10 \\
10 \\
10 \\
10\end{array}$ & $\begin{array}{l}.560 \\
: 290 \\
0.026 \\
.043\end{array}$ & $\begin{array}{l}56.00 \\
39.00 \\
2901 . \\
.43 \\
.43\end{array}$ & $\begin{array}{c}52.24 \\
11.94 \\
949 L \bullet \\
9.15\end{array}$ & $\begin{array}{r}89.81 \\
11.36 \\
.37\end{array}$ \\
\hline 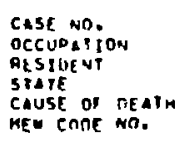 & $\begin{array}{l}\text { G-128 } \\
\text { IND WAKER } \\
\text { NE } \\
\text { CNL NRANO } \\
\text { FOACT SKULL } \\
\text { AOI.0 }\end{array}$ & 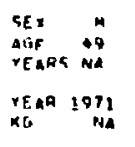 & 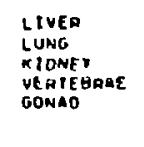 & 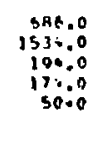 & $\begin{array}{l}1000 \\
1000 \\
100 \\
200 \\
100\end{array}$ & $\begin{array}{l}30 \\
250 \\
10 \\
100 \\
10\end{array}$ & $\begin{array}{l}.610 \\
0.002 \\
0.000 \\
0.073 \\
0004 \\
0.04\end{array}$ & $\begin{aligned} 61.00 \\
: 33 \\
: 00 \\
: 15 \\
: 08\end{aligned}$ & 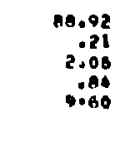 & 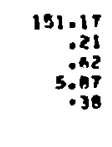 \\
\hline 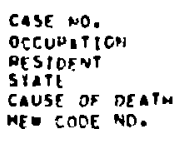 & 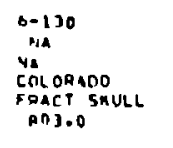 & 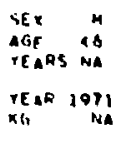 & 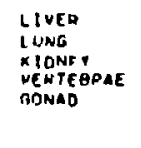 & $\begin{array}{r}222 n, 0 \\
113700 \\
340.00 \\
140.0 \\
7 . .0\end{array}$ & $\begin{array}{l}1000 \\
1000 \\
100 \\
2100 \\
100\end{array}$ & $\begin{array}{l}10 \\
230 \\
10 \\
100 \\
10\end{array}$ & $\begin{array}{l}.150 \\
0071 \\
-010 \\
-0091 \\
.090\end{array}$ & 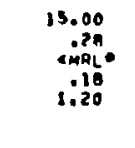 & 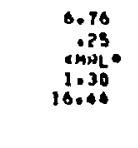 & $\begin{array}{l}11.00 \\
.25 \\
9.10 \\
0.68\end{array}$ \\
\hline 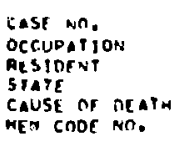 & 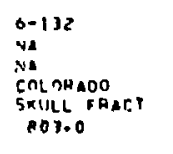 & 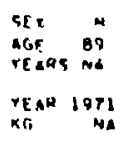 & $\begin{array}{l}\text { LIVER } \\
\text { LUNG } \\
\text { KIONEY } \\
\text { GONAD }\end{array}$ & $\begin{array}{r}137 ? .0 \\
828.0 \\
231.0 \\
20.0\end{array}$ & $\begin{array}{l}1000 \\
1000 \\
100 \\
100\end{array}$ & $\begin{array}{r}10 \\
250 \\
10 \\
10\end{array}$ & $\begin{array}{l}.210 \\
0.185 \\
0.040 \\
0040\end{array}$ & $\begin{array}{r}91.00 \\
: 14 \\
.00 \\
.20\end{array}$ & $\begin{array}{l}06.33 \\
890 \\
28.08\end{array}$ & $\begin{array}{r}112.70 \\
.90 \\
.51 \\
.910\end{array}$ \\
\hline 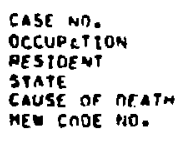 & 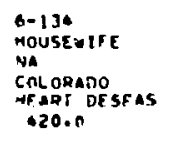 & $\begin{array}{l}\text { SEX } \\
\text { AGF SA } \\
\text { VEAAS NA } \\
\text { YEAR IOYI } \\
\text { KG NE NE }\end{array}$ & $\begin{array}{l}\text { LIVEP } \\
\text { LUNG } \\
\text { LYMPH } \\
\text { KIONEY }\end{array}$ & $\begin{array}{l}152.0 \\
53.0 \\
0.0 \\
31.2 \\
113.0\end{array}$ & $\begin{array}{r}1000 \\
1000 \\
25 \\
100\end{array}$ & $\begin{array}{r}250 \\
250 \\
10 \\
10\end{array}$ & $\begin{array}{l}.298 \\
.113 \\
.030 \\
.010\end{array}$ & $\begin{array}{l}1.18 \\
.45 \\
.07 \\
.00\end{array}$ & $\begin{array}{r}1.57 \\
3.50 \\
39.08 \\
1.00\end{array}$ & $\begin{array}{l}2.68 \\
.50 \\
2.38 \\
2.12\end{array}$ \\
\hline 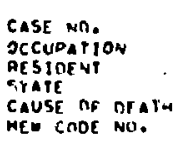 & 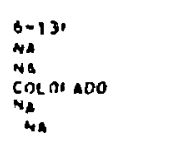 & 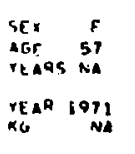 & $\begin{array}{l}\text { LUNG } \\
\text { LPHPW } \\
\text { KIONEY } \\
\text { KERTERAAE }\end{array}$ & $\begin{array}{r}1101.0 \\
08.8 \\
138.00\end{array}$ & $\begin{array}{r}1000 \\
25 \\
190 \\
530\end{array}$ & $\begin{array}{r}250 \\
10 \\
10 \\
100\end{array}$ & $\begin{array}{l}.331 \\
: 190 \\
0.000 \\
0.089\end{array}$ & $\begin{array}{l}1.35 \\
.45 \\
\text { sipL- } \\
.36\end{array}$ & $\begin{array}{c}1.23 \\
93.75 \\
2401 . \\
2.56\end{array}$ & $\begin{array}{r}1.23 \\
.96 \\
17.76\end{array}$ \\
\hline 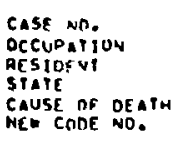 & 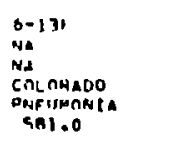 & 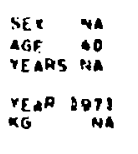 & 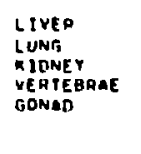 & $\begin{array}{r}791.0 \\
1119.0 \\
228: 0 \\
2550 \\
20.0\end{array}$ & $\begin{array}{l}1000 \\
1000 \\
100 \\
500 \\
100\end{array}$ & $\begin{array}{l}250 \\
250 \\
10 \\
10 \\
10 \\
10\end{array}$ & $\begin{array}{l}.206 \\
.257 \\
-255 \\
0.253 \\
.0250\end{array}$ & 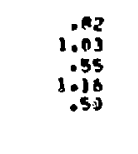 & $\begin{array}{l}1.03 \\
2.97 \\
2.07 \\
29.51 \\
29.08\end{array}$ & $\begin{array}{r}1.75 \\
792 \\
793 \\
31 ; 98 \\
1,00\end{array}$ \\
\hline 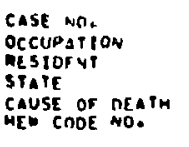 & 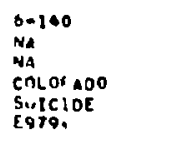 & 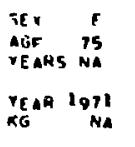 & $\begin{array}{l}\text { GIVER } \\
\text { LUNG } \\
\text { KIONEY } \\
\text { YEATEGAAE }\end{array}$ & $\begin{array}{l}585.0 \\
39.0 \\
38: 0 \\
98: 0 \\
7 j .0\end{array}$ & $\begin{array}{l}1000 \\
1000 \\
100 \\
200\end{array}$ & $\begin{array}{l}250 \\
250 \\
100 \\
100\end{array}$ & $\begin{array}{l}.286 \\
.13 n \\
0076 \\
.012\end{array}$ & 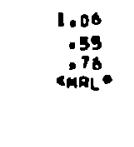 & 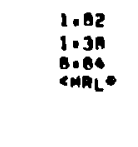 & $\begin{array}{l}3.00 \\
0.00 \\
0.36 \\
2.05\end{array}$ \\
\hline 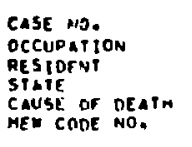 & 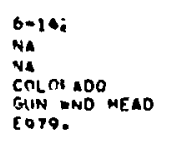 & $\begin{array}{l}\text { SER MA } \\
\text { AGF } 21 \\
\text { VEAOS NA } \\
\text { REAR } 1971 \\
\text { RG NA }\end{array}$ & $\begin{array}{l}\text { IIVEA } \\
\text { LUNG } \\
\text { LYMPH } \\
\text { MIONEY } \\
\text { VENTEBAAE } \\
\text { GONAD }\end{array}$ & $\begin{array}{r}530.0 \\
1000.0 \\
10.6 \\
1050 \\
1050 \\
26.0\end{array}$ & $\begin{array}{l}1000 \\
1000 \\
25 \\
100 \\
200 \\
100\end{array}$ & $\begin{array}{r}250 \\
250 \\
10 \\
10 \\
109 \\
10\end{array}$ & $\begin{array}{l}.060 \\
.0133 \\
.184 \\
.069 \\
.041 \\
-0.000\end{array}$ & $\begin{array}{c}1.87 \\
.33 \\
.82 \\
.68 \\
0.06 \\
\text { MRL. }\end{array}$ & $\begin{array}{r}3.51 \\
0.32 \\
262.30 \\
8.40 \\
.77 \\
m a 6\end{array}$ & $\begin{array}{l}5.90 \\
.32 \\
2.02 \\
2.05 \\
5.03\end{array}$ \\
\hline 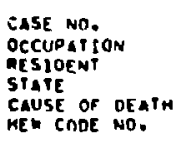 & 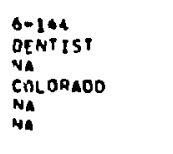 & $\begin{array}{l}\text { SEX NA } \\
\text { AGE MA } \\
\text { YEADS MR } \\
\text { YEAA 1971 } \\
\text { KG NA NA }\end{array}$ & $\begin{array}{l}\text { LYVEA } \\
\text { LONG } \\
\text { GONAD }\end{array}$ & $\begin{array}{l}1510.0 \\
1037.0 \\
12.0\end{array}$ & $\begin{array}{l}1000 \\
1000 \\
100\end{array}$ & $\begin{array}{l}250 \\
250 \\
10\end{array}$ & $\begin{array}{r}1.27 \\
: 118 \\
0100\end{array}$ & $\begin{array}{l}3.08 \\
1.07 \\
1.00\end{array}$ & $\begin{array}{r}3.35 \\
13.068 \\
13.89\end{array}$ & $\begin{array}{r}5.09 \\
.068 \\
.36\end{array}$ \\
\hline 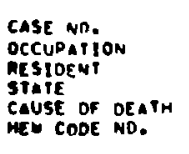 & 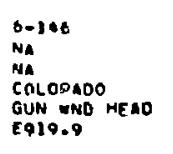 & 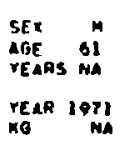 & $\begin{array}{l}\text { LUYEA } \\
\text { LUNO } \\
\text { LYMPH } \\
\text { YEATEBAAE } \\
\text { GOMAO }\end{array}$ & $\begin{array}{r}1860.0 \\
1650.01 \\
120.07 \\
37.0\end{array}$ & $\begin{array}{r}1000 \\
1000 \\
25 \\
200 \\
100\end{array}$ & $\begin{array}{l}250 \\
250 \\
10 \\
100 \\
10\end{array}$ & $\begin{array}{l}.580 \\
0.137 \\
0.035 \\
0132 \\
.051\end{array}$ & $\begin{array}{r}2.32 \\
.55 \\
.21 \\
.26 \\
.31\end{array}$ & 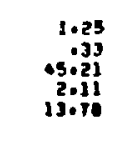 & $\begin{array}{r}2.12 \\
.33 \\
.05 \\
10.05 \\
.98\end{array}$ \\
\hline
\end{tabular}




\begin{tabular}{|c|c|c|c|}
\hline PISSUE & $\begin{array}{l}\text { DET } \\
\text { WEIGHT } \\
\text { SAMPLE } \\
\text { (GPAM) }\end{array}$ & $\begin{array}{l}\text { YOLUAE } \\
\text { OF } \\
\text { SAHPLE } \\
\text { ICE J }\end{array}$ & $\begin{array}{l}\text { VOLUME } \\
\text { SAMPLE } \\
\text { ANALYZEO } \\
\text { ICCY }\end{array}$ \\
\hline
\end{tabular}

\begin{tabular}{|c|c|}
\hline $\begin{array}{l}\text { CASE NO, } \\
\text { OCCUFATION } \\
\text { AESIDENT } \\
\text { STATE } \\
\text { CAUSE OF DEAIH } \\
\text { HEL CADE NO. }\end{array}$ & $\begin{array}{l}\text { O-140 } \\
\text { NA } \\
\text { NA } \\
\text { COLOFADO } \\
\text { PNEUMONIA } \\
\text { SEI.O }\end{array}$ \\
\hline $\begin{array}{l}\text { CASE NOE } \\
\text { OCCUPAIION } \\
\text { AESTOENT } \\
\text { STETE } \\
\text { CAUSE OF OEATH } \\
\text { ME COOE NO. }\end{array}$ & $\begin{array}{l}\text { Gelse } \\
\text { NA } \\
\text { NA } \\
\text { COLOAADD } \\
\text { NA } \\
\text { NA }\end{array}$ \\
\hline
\end{tabular}

\begin{tabular}{|c|c|c|c|c|c|}
\hline & $3 t$ & $\begin{array}{l}\text { LUMG } \\
\text { LYMPH }\end{array}$ & $\begin{array}{r}1242.0 \\
5.1\end{array}$ & $\begin{array}{r}1000 \\
25\end{array}$ & $\begin{array}{r}250 \\
10\end{array}$ \\
\hline $\begin{array}{l}\text { YEARS } \\
\text { YEAR } \\
\text { KG }\end{array}$ & $\begin{array}{r}\text { S NA } \\
1971 \\
\text { NA }\end{array}$ & $\begin{array}{l}\text { K IONEY } \\
\text { VEHTEBARE } \\
\text { GONAO }\end{array}$ & $\begin{array}{r}235.0 \\
99.0 \\
34.0\end{array}$ & $\begin{array}{l}100 \\
200 \\
100\end{array}$ & $\begin{array}{r}10 \\
100 \\
10\end{array}$ \\
\hline $\begin{array}{l}\text { SEX } \\
\text { AGE } \\
\text { YEAAS } \\
\text { YEAR } \\
\text { KG }\end{array}$ & $\begin{array}{r}\text { M } \\
55 \\
\text { NA } \\
19 ? 1 \\
\text { NA }\end{array}$ & $\begin{array}{l}\text { LUNG } \\
\text { LYMPA } \\
\text { KIONEY } \\
\text { YERYEBALE } \\
\text { GONAS }\end{array}$ & $\begin{array}{r}1370.0 \\
2.0 \\
201.0 \\
202.0 \\
35.0\end{array}$ & $\begin{array}{r}1000 \\
25 \\
100 \\
500 \\
100\end{array}$ & $\begin{array}{r}250 \\
10 \\
10 \\
100 \\
10\end{array}$ \\
\hline
\end{tabular}

\begin{tabular}{|c|c|c|c|}
\hline $\begin{array}{l}\text { ACIIYITY } \\
\text { PEA } \\
\text { YOL ANAL } \\
\text { TOIS/MINI }\end{array}$ & $\begin{array}{l}\text { ACTIVITY } \\
\text { PFA OAgAN } \\
\text { I IGNT } \\
\text { CoISTMINI }\end{array}$ & $\begin{array}{l}\text { ACTIVITY } \\
\text { PER KG } \\
\text { lots/mIN) }\end{array}$ & $\begin{array}{l}\text { ACTIVITY } \\
\text { OER } \\
\text { STANDARO } \\
\text { OROAN } \\
\text { IDIS/MINI }\end{array}$ \\
\hline
\end{tabular}

\begin{tabular}{|c|c|c|c|}
\hline $\begin{array}{r}.101 \\
.068 \\
=073 \\
.067 \\
.044\end{array}$ & $\begin{array}{l}.64 \\
.17 \\
.179 \\
.13 \\
.46\end{array}$ & $\begin{array}{r}033 \\
33.33 \\
6496 \cdot \\
1.35 \\
12.94\end{array}$ & $\begin{array}{r}.33 \\
.33 \\
9.47 \\
.52\end{array}$ \\
\hline $\begin{array}{l}.434 \\
.157 \\
.061 \\
.096 \\
.104\end{array}$ & $\begin{array}{r}1.74 \\
.39 \\
.61 \\
.06\end{array}$ & $\begin{array}{r}1.27 \\
196.25 \\
2.17 \\
1.70 \\
29.71\end{array}$ & $\begin{array}{r}1.27 \\
1.96 \\
.05 \\
13.91 \\
1.19\end{array}$ \\
\hline
\end{tabular}




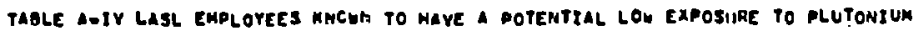

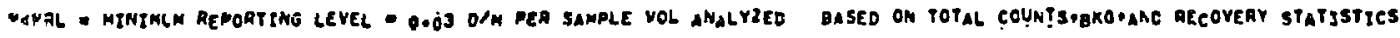

11s5uE

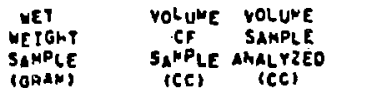

ACIIYITY ACTIVITY ACTIYITY
PER A PER CFGAN PER KO

VOL WHAL WELGH

WE PER

(OISIMIN) (CISIMEN) COIS/MBH) OORGA

CoIs/min:

\begin{tabular}{|c|c|}
\hline $\begin{array}{l}\text { CASE NO, } \\
\text { OCCUOATIOA } \\
\text { RESIOENT } \\
\text { STATE } \\
\text { CAUSE OF OEATH } \\
\text { HE CODE AO. }\end{array}$ & 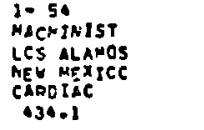 \\
\hline $\begin{array}{l}\text { CASE NO. } \\
\text { OCCLPATION } \\
\text { RESIDENT } \\
\text { STAIE } \\
\text { CAUSE OF OEATH } \\
\text { MEY CODE NC. }\end{array}$ & 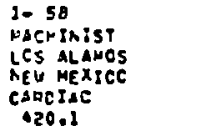 \\
\hline $\begin{array}{l}\text { CASE NO, } \\
\text { DECUPATION } \\
\text { AESITENT } \\
\text { SIAZE } \\
\text { CAUSE OF DEATH } \\
\text { HEN CODE MOA }\end{array}$ & 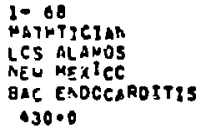 \\
\hline $\begin{array}{l}\text { CASE NO. } \\
\text { OECLDATION } \\
\text { ATSIOENT } \\
\text { STATE. }\end{array}$ & $\begin{array}{l}\text { I- TA } \\
\text { HCCIMIST } \\
\text { LCS ALAMOS } \\
\text { NEA HEXIEC }\end{array}$ \\
\hline $\begin{array}{l}\text { ChUSE OF OEATH } \\
\text { HEW CCOE RO. }\end{array}$ & $\begin{array}{l}\text { Ctafmosis } \\
\text { ise.0 }\end{array}$ \\
\hline $\begin{array}{l}\text { CASE HO. } \\
\text { OCCUPATION } \\
\text { AFSIOENT } \\
\text { STATE }\end{array}$ & $\begin{array}{l}\text { I- CO } \\
\text { ACCCUNTANT } \\
\text { LCS ALAWOS } \\
\text { REW MEXICC }\end{array}$ \\
\hline
\end{tabular}

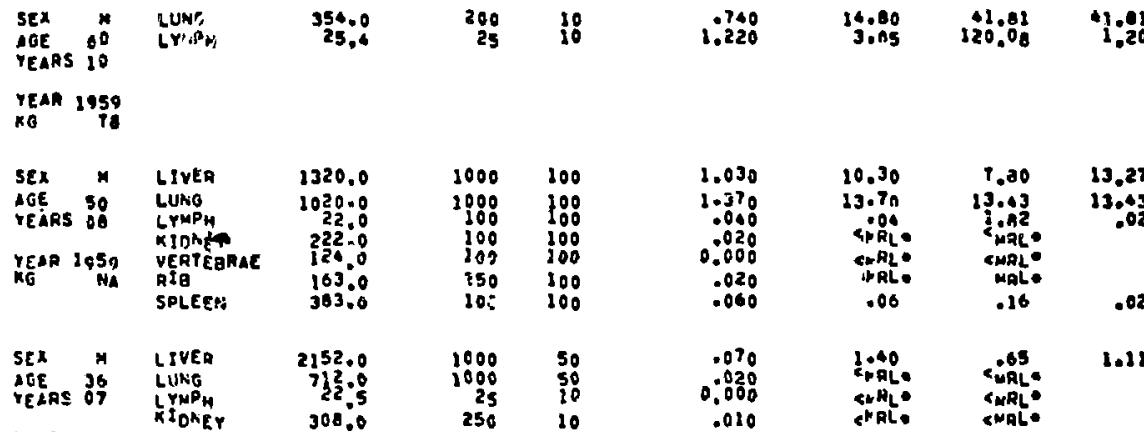

TEAA 1960

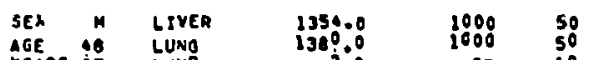

AGE $Y$ AAS OP

YEAA
KO

LYMPM

207.0

$\begin{array}{rr}1000 & 50 \\ 25 & 10 \\ 100 & 10\end{array}$

.030
$=200$
.030
$=020$

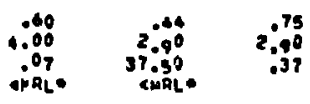

MEE ins it

YEAR 1460
MG

$\begin{array}{lrrr}\text { LIVEA } & 1720.0 & 1000 & 50 \\ \text { LUNG } & 736.0 & 1000 & 50 \\ \text { LYMPM } & 9.0 & 50 & 10\end{array}$

CAUSE OF OEATH MULTJPLE YYELOMA

KIOAEY 30$\}$

$160^{\circ}$

.040
.210
2.020
2.070

$\begin{array}{rrr}.80 & .47 & .79 \\ 4.20 & 5.71 & 3.71 \\ 20.70 & .2 .72 & 24.81\end{array}$

SEX

CASE nO.

OCCLPAIION

1. 0.

Destcrnt

CLEKK

LCS ALANOS

CAUSE OF DEATH CERCNARY ECCLUST

HEW COOE ND.

CASE NO. I-i26

OCCUPATION TECHHICRAA
RESTOENT

RESIOENTT LCS ALAROS

STATE
CAUSE OF OEATH SEWLL FRACTUAE

MEU COOE NO, 103.0

YEAAS if

YEAR 1960

LIVER 1529.0

KG $\mathrm{HA}$

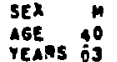

YEAR 196)

MO HA

case no.

occlopition

1-i26

RESInENT

STAIE
CAUSE OF OEATM AEY OEXICIA

Trennician

los alamos

NEW NeXIC

MEW COOE NO, 962.7

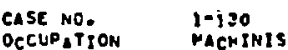

RESIDENT

STAlE or OFitM REU HEXICC

CAUSE OF OEATH LLNG CANCEI

$\begin{array}{ll}\text { CASE NO. } & \text { I-132 } \\ \text { OCCUPATION } & \text { DRAFTSMAN }\end{array}$

$\begin{array}{ll}\text { OFSTOENT } & \text { DRAFTSMAN } \\ \text { LOS ALAMOS }\end{array}$

STATE OF DEAYH CORCHARY ECE

SER M

AEE 31
YEARS OS

TEAP 25S1

$\begin{array}{lr}\text { LUNG } & 1529.0 \\ \text { LYMPH } & 52.0 \\ \text { KIOTER } & 19.0\end{array}$

1000

50
50
10
10

2.200

LIVER $2745.9 \quad 1000 \quad 50$

LUNB $\quad 10,3.0$

KIOREY 296.8

380

10

.070

.070
0.000
0.000

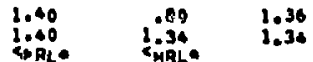

KEW COOE HOE $120 \% 1$

CASE No.

OCCLPATION TECHNICIAA
RESIOENT L LE ALAMGS

1*i36

SYATE HEW HEXICC

CaUSE OF DEATH CCRCNARY GEC
MEN CODE NO.

SEX H
YGE SEA

YEAN 1961

LIVEH $\quad 2776.0 \quad 1000$

LUNO

$\operatorname{lrmPH}_{\text {TOR }}$

15.0

1008

50
50
10
10

.240

.230
.030

$\begin{array}{rrr}2.08 & 1.58 & 2.60 \\ 4.60 & 5.74 & 5.74 \\ \text { i.i5 } & 10.00 & .10\end{array}$

LIVEA $\quad 2134.4 \quad 1000$

000
50
100

50
50
10
10

$\begin{array}{lrr}2.00 & 1.31 & 2.23 \\ 5.80 & 5.20 & 5.20 \\ 130 & 15.00 & .15 \\ \text { PRLL } & \text { MRL } & \end{array}$

CL TE NO.

ORTIPATION CLEKK

RESIJEN

STA?

CLEAK

CAUSE OF DEATM PLL INFARCTIOM

$\begin{array}{ll}\text { SEE } & 32 \\ \text { YEÂAS OS }\end{array}$

YEAA 1961

LUNG

MIONEY

$\begin{array}{rrr}2179.0 & 1000 & 50 \\ 923.0 & 1000 & 50\end{array}$

923.0
3.0
410.0

180

50
10

.060
.090

.090
0.000

$\begin{array}{ll}1.20 & .55 \\ 1.80 \\ \text { STALE } \\ \text { SWRL }\end{array}$

sex

LIVE:

1761.0

TEE 34

YEAA IPOI

LUNG

1761.00
900.0
15000

1000

50
50
10
10

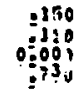

2.00
$3.20 \quad 2.72 \quad 2.93$

$\begin{array}{lll}2.20 & 2.44 \\ 7.3^{\circ} & 25.69 & 7.77\end{array}$

.

Liveg

$\begin{array}{rrr}2326.0 & 2000 & 50 \\ 921.0 & 1300 & 50 \\ 9.0 & 50 & 10\end{array}$

50
50
10
10

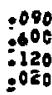

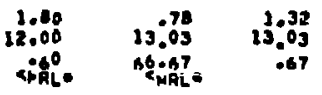




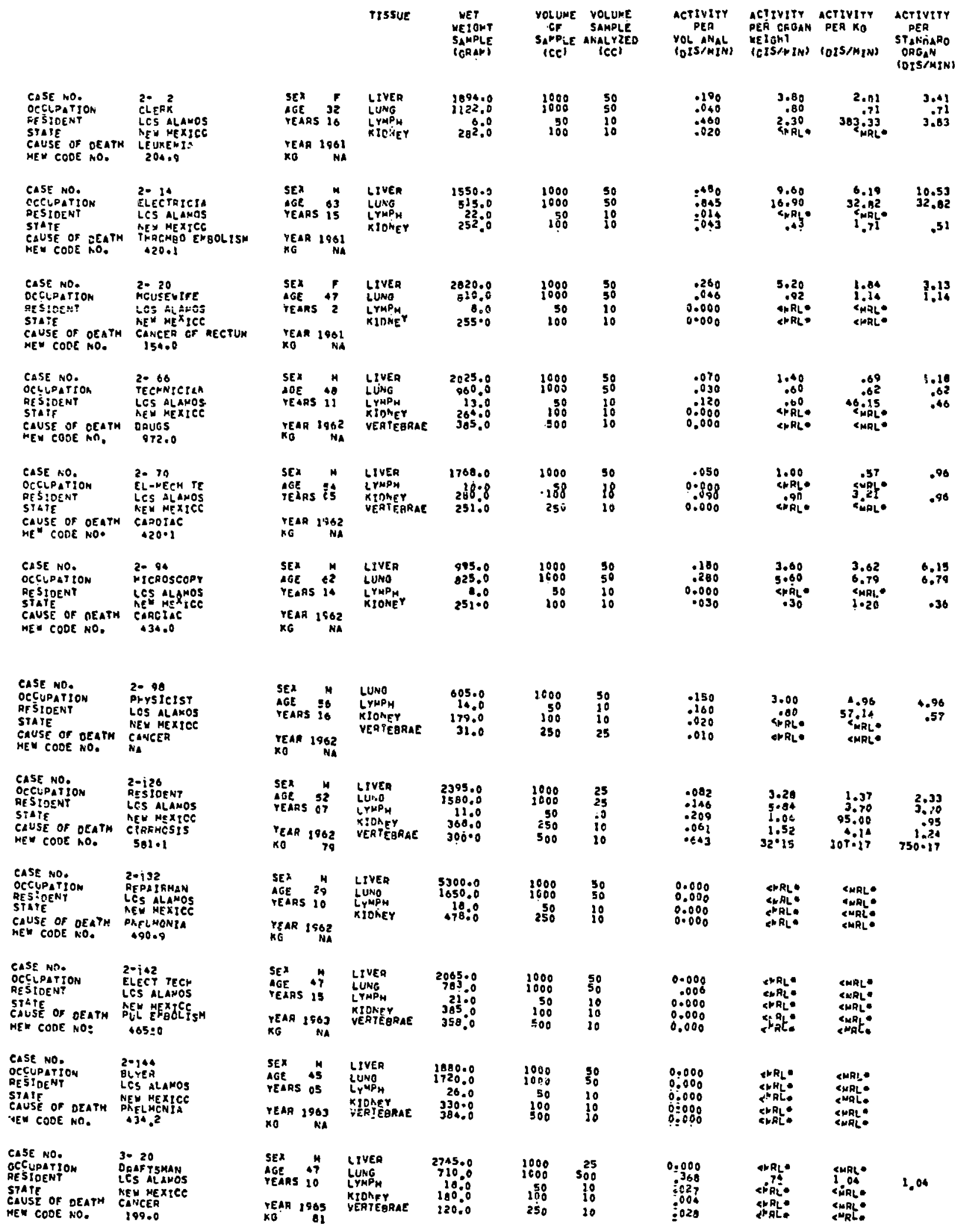


VOLUME VOLUME
CF SAMPLE
SAPPLE AAALTTEEO SAPPLE AAÁLTZEO
ICCI ICC)

ACTYYTPT
POL ANAL
(DISIMIN)

ACTIVITY ACTIVITY
PER OFGAN PER KO
WEIGHT
IOISTRINT (DISAKINI

activith

DER

ORGAN

$\begin{array}{ll}\text { CASE NOE } & 9 \text { 9E } \\ \text { OCEUPATION } & \text { AEC PRO FRE } \\ \text { RESTOENT } & \text { LCS ALANOS } \\ \text { STATE } & \text { AEU NEXICE }\end{array}$

CAUSE OF DERTH CCFCNARY THRONB

HE CODE NO.

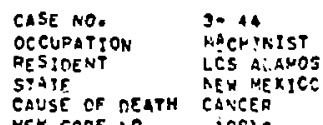

HEW coOr AO

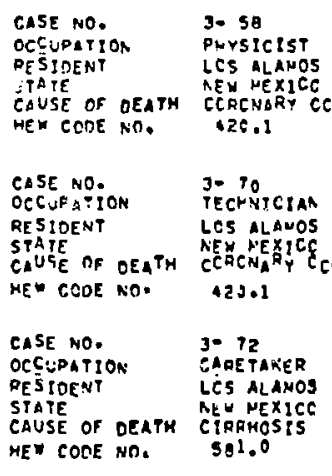

case no.

3- et

OCCUPATION TLERK
RESTCENT

STATE RE RLW MEXTCC

CAUSE OF DEATH CERCNARY CEC
SEX M
AGE 11
YeARS 10
YEAR 1986
KG NA

$\begin{array}{llll}\text { LUER } & 1150.0 & 1000 & 25 \\ \text { LUN: } & 1250.0 & 1000 & 500\end{array}$

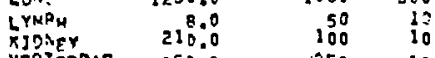

SEX IN
AGE 5 I
YEASS 13

YEAR 1967

$\begin{array}{lr}\text { YEAR } & 1967 \\ & 70\end{array}$

$\begin{array}{lllll}\text { SEX } & \text { LIVE } & 1720.0 & 1000 & 25 \\ \text { AGE A } & \text { LUNO } & 1130.0 & 1000 & 25\end{array}$

YEARS it

TEAR 1967 YERTEGRAE

330.0

30.0

160

100

SEX

YEARS 21

LIVER

no Na

KETTEYRAE

1728.0

330.0

1000
1000

50
100

100

AGE 43

YEAR 2968

KO BO

LUNG

KEONEY

1375.0

1000

$50 \quad 20$

$\begin{array}{ll}100 & 10 \\ 100 & 10\end{array}$

25
25
10
10

.021
.001
0.000

0.000

4.36
1.71
4.81

C.RL.

AHRL $\quad$ \&MRL:

6.45

0.000

.020
.005

3.:

2.54

254.

2,54

.025
.127
.029
.194
.041
.148

$2 \% R L$
5.08
$19 R L$
1.94
11.02
1.48

5 HRL
+50

$4.50 \quad 4.50$

$5.08 \quad 1.76$

$103.75 \quad 1288.25$

:250

.017

10.26

$5.93 \quad 10.07$

$C P_{L}$

4.96

CNRL:

3.920

$\begin{array}{lll}5.92 & 0.31 & 7.32\end{array}$

SuR

6.06

SMRL:

60.23
SEX F

YEARS 21

YERR 1968

LIVEA $\$ 350.0$

LUNO 1055.0

$\begin{array}{lr}\text { KIONEY } & 255.0 \\ \text { LYMPM } & 7.0\end{array}$

1000

25

10

0.000
.151

.042
.032

.032
.002

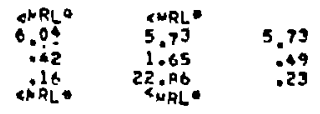

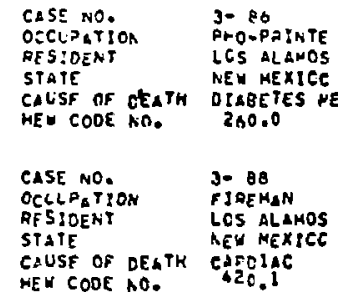

MEW CODE hO.

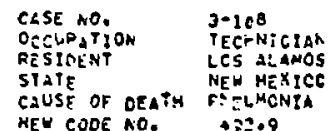

HEY COOE NO.

$\begin{array}{ll}\text { CASE NO. } & \text { 3-iA2 } \\ \text { OCCOPSTION } & \text { ENGINEEF } \\ \text { RESINENT } & \text { LCS ALENOS } \\ \text { STATE } & \text { NEW MEXIOC } \\ \text { CALSE OF OEATH CAREIAC AFAEST } \\ \text { MEW COOE RO. }\end{array}$

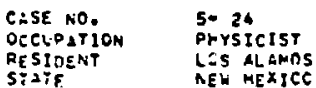

CaUSE, OF OEATH MEAa: ATTACK

HEW COOC A.

CASE NO.

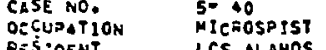

RESTOENT LCS HLANOS

CAUSE OF DEATH MUEAAGIAL INF

HEX COOE NOS.
YEA 1967

LUNG

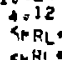

SEA $F$

IGE 34

YEAB 1968
KO 52

$\begin{array}{lr}\text { LIVER } & 1710.0 \\ \text { LUNG } & 920.0 \\ \text { LYMPH } & 5.0 \\ \text { KIONEY } & 425.0 \\ \text { VERIEBRAE } & 40.0\end{array}$

$\begin{array}{ll}1000 & 25 \\ 1000 & 25 \\ 50 & 10 \\ 200 & 10 \\ 100 & 10\end{array}$

.030

.091

118

.003
.022

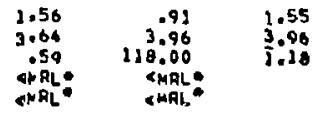

SEA
AEE
TESTS 19

YEAR 1968

LIVER

1000

25
25
10
10
10

KG NA

LUNG $\quad 1710.0$

$\begin{array}{lr}\text { LYMPH } & 8.0 \\ \text { KIORंEY } & 350.0\end{array}$

VERTEBAAE

55.0

2000

100

.156
.093
.038
.030

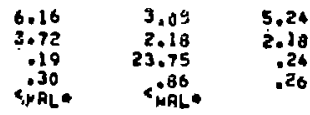

SEX HA LUNG

MEE EA 24

YEAR 1959

LUNO
LYMPH
KIONEY

KIOAEY
VERTERAA

970.0

$\begin{array}{rr}2000 & 250 \\ 50 & 10 \\ 100 & 10 \\ 250 & 100\end{array}$

.004

22.340

.340
.230
.336
.071

49.36

$9.36 \quad 59.89 \quad 50.89$

$\begin{array}{rrr}3.36 & 198.33 & 1.98 \\ & 13.44 & 4.03\end{array}$

250.0

6.900

.189

$\begin{array}{rr}1000 & 250 \\ 50 & 10 \\ 100 & 10 \\ 250 & 200\end{array}$

$.1+2$

$\begin{array}{rrr}23.96 & 23.76 \\ 896 & 236.25 & 2.36\end{array}$

$.35 \quad 2.73 \quad 29.12$

KEAR ITE:
KG.

$\begin{array}{ll}\text { KIDAEY } & 350.0 \\ \text { VERTEGAAE } & 130.0\end{array}$

$\begin{array}{rr}1000 & 250 \\ 50 & 10 \\ 100 & 10 \\ 100 & 50\end{array}$

.000

.000
.370
1.173
.145

.24
1.85
11.73
.20

.38
462.50
33.51

.38
.62

TEAAS OS

YEAA
$K G$

KIOAEY

$350 . \%$

2.955

$\begin{array}{lllll}\text { SEX } & \text { LUNO } & 1364.0 & 1000 & 500 \\ \text { AGE S5 LIVER } & 1089.0 & 1000 & 500\end{array}$

3.93

$\begin{array}{ll}2.87 & 2.87 \\ 3.95 & 6.72\end{array}$ 
Tissue

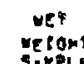

veign
sippLE
TGRAFI
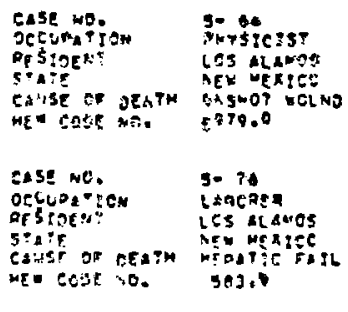

case no.

eccuosition

aesione w

los singes

CSese

$\mathrm{HE}=$ cese A.G. 020.1

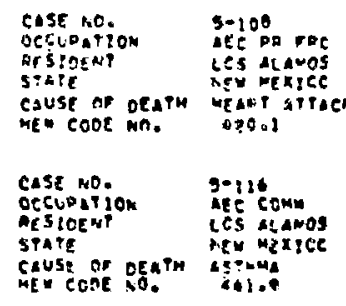

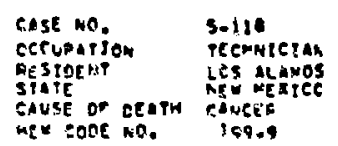

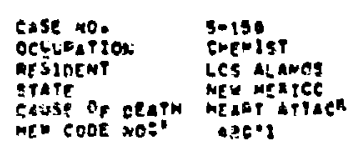

nesuration

OTSIOENT LEN RLANOS

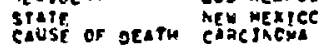

ME" CONE ka. 194.0

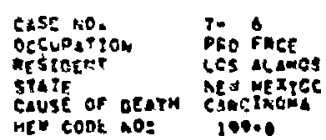

\begin{tabular}{|c|c|c|c|c|c|c|c|c|c|}
\hline 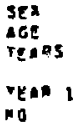 & is? & 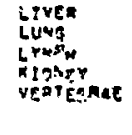 & $\begin{array}{r}1298.06 \\
892.0 \\
26.0 \\
265.0 \\
100.0\end{array}$ & $\begin{array}{l}590 \\
980 \\
250 \\
250 \\
200\end{array}$ & $\begin{array}{r}250 \\
250 \\
\text { is } \\
19 \\
10\end{array}$ & 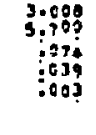 & $\begin{array}{r}0.82 \\
11: 48 \\
\vdots 18 \\
\text { simL. }\end{array}$ & $\begin{array}{c}17.70 \\
17.49 \\
46.25 \\
3.40 \\
\text { ind. }\end{array}$ & 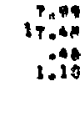 \\
\hline $\begin{array}{l}\text { sex } \\
\text { dege } \\
\text { reges } \\
\text { yess } \\
\text { ag }\end{array}$ & $\begin{array}{l}64 \\
64 \\
1859 \\
40\end{array}$ & 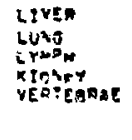 & $\begin{array}{r}1724.8 \\
1069.5 \\
20.8 \\
100.0 \\
99.0\end{array}$ & $\begin{array}{l}300 \\
980 \\
25 \\
105 \\
105\end{array}$ & $\begin{array}{r}10 \\
250 \\
10 \\
90 \\
90\end{array}$ & $\begin{array}{r}.090 \\
10.930 \\
0.202 \\
0.990 \\
.690\end{array}$ & $\begin{array}{r}0.08 \\
21.92 \\
i \neq 9.9 \\
1.40\end{array}$ & 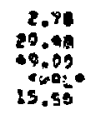 & $\begin{array}{r}4.73 \\
24.99 \\
123.40\end{array}$ \\
\hline 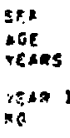 & 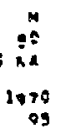 & 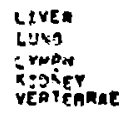 & $\begin{array}{r}2013 \times 0 \\
397.0 \\
8.7 \\
323,8\end{array}$ & $\begin{array}{l}500 \\
905 \\
25 \\
108\end{array}$ & $\begin{array}{r}10 \\
256 \\
20 \\
263\end{array}$ & $\begin{array}{r}.260 \\
+.610 \\
.186 \\
.914\end{array}$ & 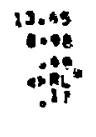 & $\begin{array}{r}0.44 \\
23.30 \\
03.25 \\
2401 \\
1.34\end{array}$ & $\begin{array}{r}11.30 \\
19.56 \\
.61 \\
9.90\end{array}$ \\
\hline $\begin{array}{l}\text { sca } \\
\text { iefe } \\
\text { rejus } \\
\text { vean } \\
\text { ret }\end{array}$ & 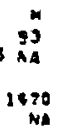 & 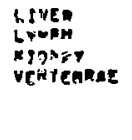 & 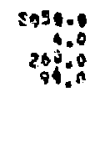 & $\begin{array}{l}909 \\
29 \\
200 \\
200\end{array}$ & $\begin{array}{r}33 \\
10 \\
100\end{array}$ & 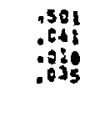 & 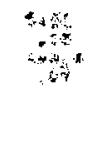 & 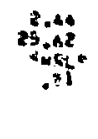 & $\begin{array}{r}. .15 \\
.14 \\
.145\end{array}$ \\
\hline $\begin{array}{l}\text { sex } \\
\text { sef } \\
\text { veding } \\
\text { reat } \\
\text { nete }\end{array}$ & $\begin{array}{l}m \\
85 \\
154 \\
170\end{array}$ & 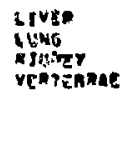 & $\begin{array}{r}503.0 \\
1220: 0 \\
390.0 \\
90.0\end{array}$ & $\begin{array}{r}340 \\
2406 \\
190 \\
206\end{array}$ & $\begin{array}{l}208 \\
256 \\
160\end{array}$ & 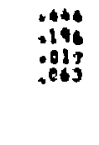 & $\begin{array}{l}2.32 \\
\text { afto } \\
.15\end{array}$ & $\begin{array}{l}1.19 \\
\text { ing. } \\
3.45\end{array}$ & $\begin{array}{r}2.61 \\
15,15\end{array}$ \\
\hline $\begin{array}{l}\text { se: } \\
\text { Age } \\
\text { eins } \\
\text { Tese } \\
\text { se }\end{array}$ & $\begin{array}{l}1 \\
82 \\
20 \\
192\end{array}$ & 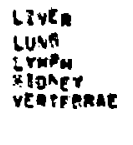 & $\begin{array}{r}1263.0 \\
049.8 \\
295: 8 \\
126.0\end{array}$ & $\begin{array}{r}500 \\
1000 \\
186 \\
800\end{array}$ & $\begin{array}{l}100 \\
100 \\
18 \\
10\end{array}$ & $\begin{array}{l}.016 \\
.814 \\
.831 \\
.126\end{array}$ & $\begin{array}{r}0.07 \\
070 \\
0.70 \\
2.56\end{array}$ & $\begin{array}{l}3.22 \\
1.10 . \\
30.96 \\
20.92\end{array}$ & $\begin{array}{r}1.00 \\
102,08\end{array}$ \\
\hline $\begin{array}{l}\text { sed } \\
\text { deE } \\
\text { vesas } \\
\text { resin } \\
\text { no }\end{array}$ & in & 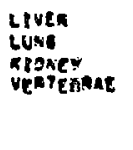 & $\begin{aligned} 1040.0 \\
1900: 0 \\
3050 \\
50: 0\end{aligned}$ & $\begin{array}{l}r .900 \\
100 \\
100\end{array}$ & $\begin{array}{l}250 \\
150 \\
100 \\
100\end{array}$ & $\begin{array}{l}1.009 \\
2.368 \\
0.098\end{array}$ & 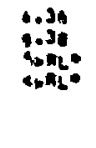 & 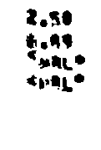 & $\begin{array}{l}5.30 \\
0.10\end{array}$ \\
\hline $\begin{array}{l}\text { SER } \\
\text { igE } \\
\text { YeAOS } \\
\text { YeAn } \\
\text { ro }\end{array}$ & $\begin{array}{l}m \\
34 \\
361 \\
\text { Na }\end{array}$ & 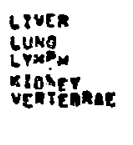 & $\begin{array}{r}3820.0 \\
500: 0 \\
2089 \\
10098\end{array}$ & $\begin{array}{l}1069 \\
20.65 \\
215 \\
215\end{array}$ & $\begin{array}{r}230 \\
258 \\
19 \\
108\end{array}$ & $\begin{array}{r}.496 \\
1.793 \\
1.025 \\
.098 \\
.127\end{array}$ & $\begin{array}{l}1.90 \\
2.82 \\
3.58 \\
3.50\end{array}$ & sos: & $\begin{array}{r}2.80 \\
8.89 \\
21.39\end{array}$ \\
\hline $\begin{array}{l}\text { SER } \\
\text { afe } \\
\text { Yedas } \\
\text { resa } \\
\text { mo }\end{array}$ & 5 & 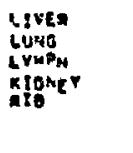 & $\begin{array}{r}1840.0 \\
1320.0 \\
368: 6 \\
103.0\end{array}$ & $\begin{array}{r}1190 \\
7000 \\
25 \\
250 \\
250\end{array}$ & $\begin{array}{r}256 \\
250 \\
10 \\
200\end{array}$ & $\begin{array}{r}1.191 \\
.100 \\
0.085 \\
.137\end{array}$ & 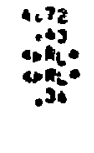 & 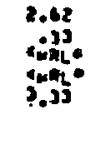 & נ, "4." \\
\hline
\end{tabular}




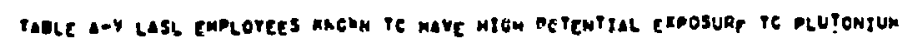

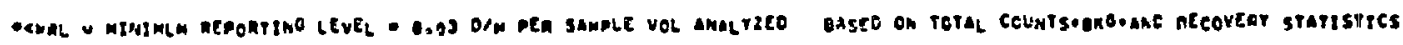

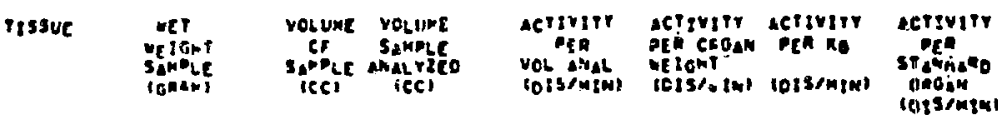

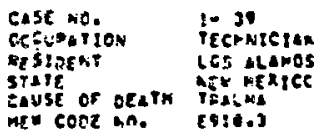

Case no.

ogthation moerthist

arsineki les alatos

cevse or oestm gadeist

af. eite an, ajs.l

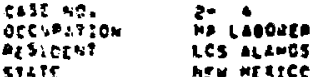

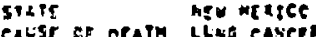

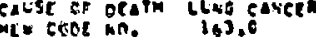

Cast ne.

otthortion io Jonlto

eestacni les dicuos

civef or ecarm conctioc

afe chit ag

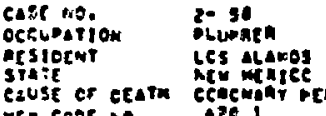

we $\mathrm{C}$ cane

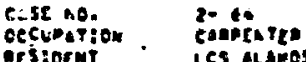

ofsinewt " tes alpios

caust of ceatm giosida

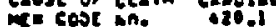

case $x$.

occupatso

ecsjoch

cause of efarm ceatus

mo cone in.

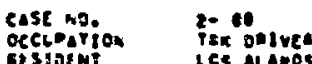

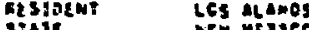

siat

me ean ant iso.e

case no.

occusifion 2-100

otsinew

LCS allues

caust of otart octirenter

wL c coos no.

Cóse no.

ectingitio

ces at inos

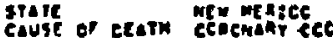

ne $=$ eed so. $\quad 20.1$

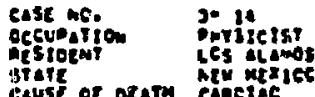

lavs or oratm canciec

ne ceas we.

ate.t

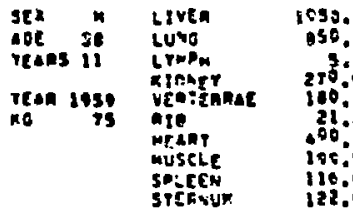

$\begin{array}{ll}1000 & 100 \\ 1000 & 100 \\ 100 & 10 \\ 100 & 10 \\ 100 & 10 \\ 100 & 10 \\ 200 & 10 \\ 100 & 10 \\ 109 & 10 \\ 100 & 10\end{array}$

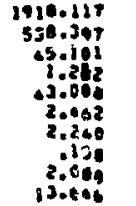

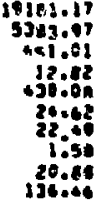

$4634.50 \quad 1672 \% .83$

$\begin{array}{ll}550.0 & 1608 \quad 100 \\ 50.0 & 1000\end{array}$

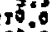

00.0

6.0

Sex bive t7it.

ictas of

ture

$171 \%$

2604100

3.463

30.935

3⿻.43

rean 295

nioner 332.0

30 if

.210

Th.

6334.31 433\%.61

45096.23 ise.0.

47.46 1*.25

290.

11..3 120.25

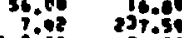

I19.0

gra.se

29.4

acs on ctuen lus ist

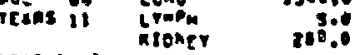

1690 ife
1806
306

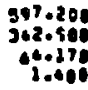

sort.06

193.50

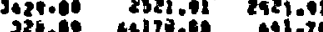

itios

tolp.es ot.7e

IEA Io6!

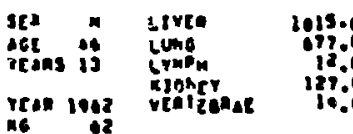

1989
itfo
so:
si

290.925

$57 \% .03$

I.7:

3ิำ

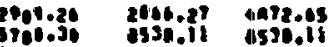

ain.7s iseses.es 1530.1

i.7 70.4 ige

b.s7 sis.se arer.se

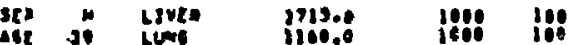

reass is

reas inet

229.8

1680 if
so is
ise

3.417

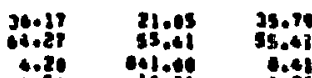

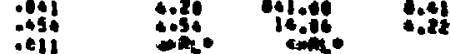

10

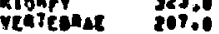

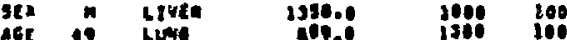

reass in trum its

rean 10:2

verarceses

16.

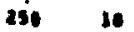

1.315
2.318

istit

.04

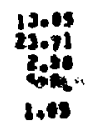

2.9129 .31

catis

(2)

4. 4 at

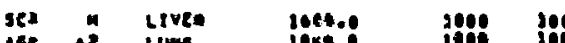

ist ins is

icen tous

lowg iostio

rengerter

909 iff
50
100

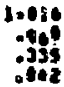

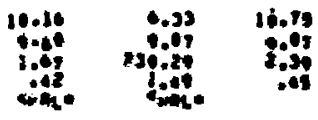

tiven 3113.0 s000 toe

-122

.21
.798
.987

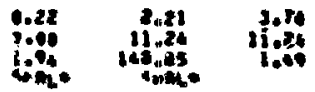

rean ists

Lioker

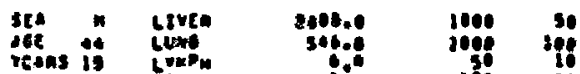

Tean toe?

tian?

rentedinas 30 :0

sea
get ans i?

ran sos?

Live:

croping

Sex atre

get ans

vean 14has $\lim _{x}$
ationet

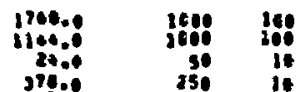

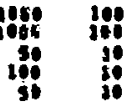

Iso it

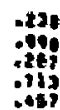

2.24
$16: 13$
10.98
10.94

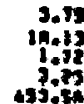

H.A3

$1+010$

i.t.

4.50
sto.t.
7.0

202.41 1064

tre.n atpen

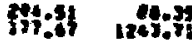




\begin{tabular}{|c|c|c|c|c|c|c|c|c|c|c|}
\hline 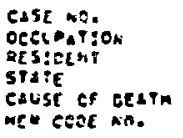 & 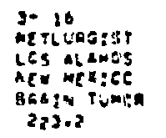 & 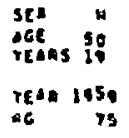 & 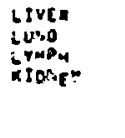 & $\begin{array}{r}1003.0 \\
623.0 \\
27.0 \\
27 \% .0\end{array}$ & $\begin{array}{r}2000 \\
1600 \\
58 \\
100\end{array}$ & $\begin{array}{l}100 \\
198 \\
10\end{array}$ & $\begin{array}{r}70.015 \\
23.351 \\
10.93 \\
.021\end{array}$ & $\begin{array}{r}7,6.15 \\
225.31 \\
53.45 \\
7 . R_{L}\end{array}$ & 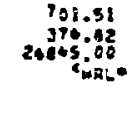 & $\begin{array}{r}1192.34 \\
376.02 \\
208.45\end{array}$ \\
\hline 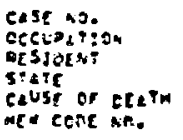 & 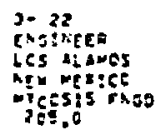 & 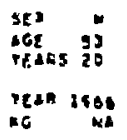 & 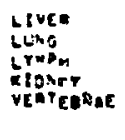 & $\begin{array}{r}2720.0 \\
1180.0 \\
20.0 \\
155.0 \\
105.0\end{array}$ & $\begin{array}{r}1600 \\
1060 \\
50 \\
100 \\
250\end{array}$ & $\begin{array}{l}100 \\
500 \\
10 \\
10 \\
10\end{array}$ & $\begin{array}{l}.200 \\
2.564 \\
.063 \\
.156 \\
.017\end{array}$ & $\begin{array}{l}2.00 \\
3.83 \\
.45 \\
3.50\end{array}$ & $\begin{array}{l}1.10 \\
3.38 \\
10.91 \\
30.96 \\
\text {.016. }\end{array}$ & $\begin{array}{r}1.08 \\
3.30 \\
3.02\end{array}$ \\
\hline 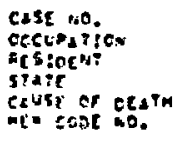 & 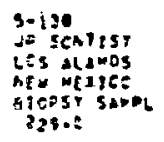 & 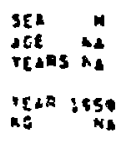 & 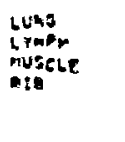 & $\begin{array}{r}11.0 \\
1.0 \\
1.0 \\
2=0\end{array}$ & $\begin{array}{r}100 \\
25 \\
25 \\
160\end{array}$ & $i$ & $\begin{array}{r}1.010 \\
22.550 \\
.230 \\
.110\end{array}$ & $\begin{array}{r}601.00 \\
561.75 \\
51.75 \\
71.00\end{array}$ & $\begin{array}{r}964.78 \\
563150.06 \\
5750.08 \\
3550.00 \\
175\end{array}$ & $\begin{array}{r}0600.70 \\
3037.50 \\
172509.08 \\
24 \times 59.00\end{array}$ \\
\hline 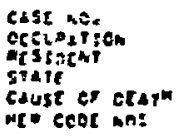 & 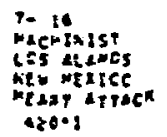 & 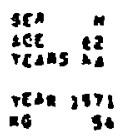 & 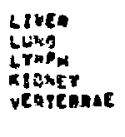 & $\begin{array}{r}2002.0 \\
1019.0 \\
221.8 \\
0.90\end{array}$ & $\begin{array}{r}2,00 \\
1000 \\
25 \\
100 \\
200\end{array}$ & $\begin{array}{l}250 \\
250 \\
10 \\
10 \\
200\end{array}$ & $\begin{array}{l}3.313 \\
7.551 \\
.901 \\
0.096 \\
.213\end{array}$ & $\begin{array}{l}19.25 \\
30.20 \\
1.25 \\
4.26 \\
.40\end{array}$ & $\begin{array}{r}6.02 \\
24.47 \\
262,02 \\
4 \times 18 \\
0.47\end{array}$ & $\begin{array}{r}21.29 \\
29.47 \\
2.02 \\
32.27\end{array}$ \\
\hline
\end{tabular}

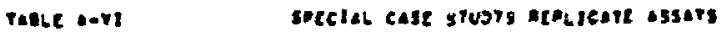

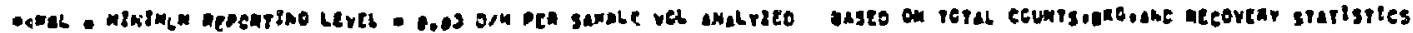

Tissur

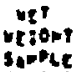

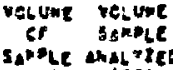

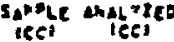

actigit
ors
vot chis

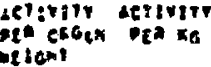

itgas

cosstaini activitit starnat stiknimb isistutx

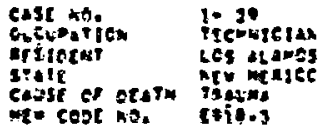

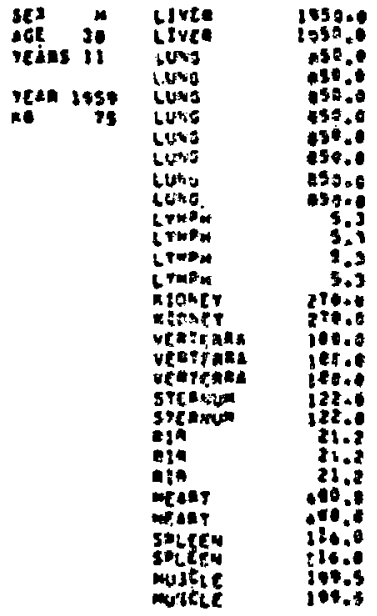

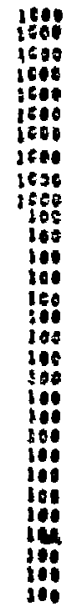

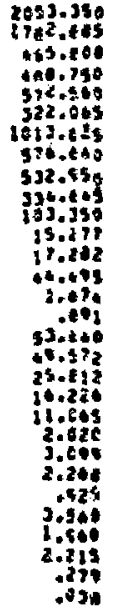

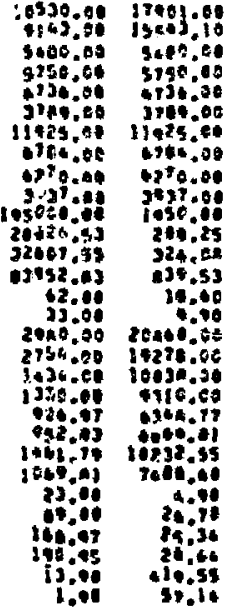




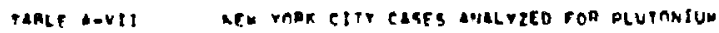

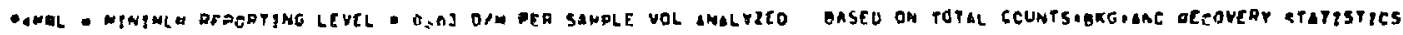

pesur.

.

siwple
Volume voluer SAP 5 CHALC GPLE ANALTTED
ICCI activit yol ana ints mint

activitr activito -ea gcasar eca xa idisoni

inIsomplat

ACTTVTT STEพñano ones isisfoges!

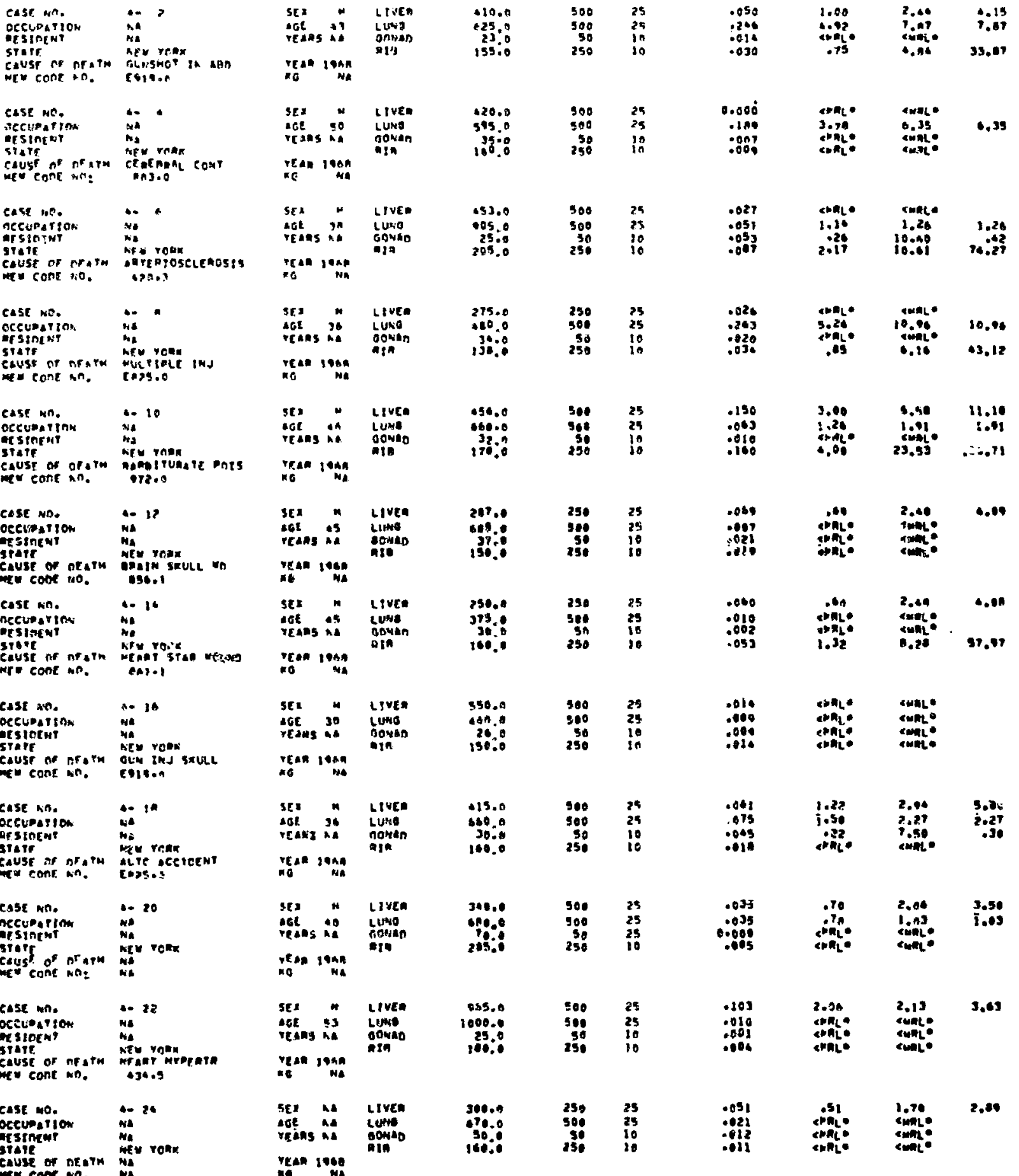




\begin{tabular}{|c|c|c|c|c|c|c|c|c|c|c|}
\hline & & & TISSUE & $\begin{array}{l}\text { WET } \\
\text { WEIBNT } \\
\text { SEMPEE } \\
\text { CGRENI }\end{array}$ & $\begin{array}{l}\text { YOLUNE } \\
\text { AFF } \\
\text { SAPPLE } \\
\text { ISCI }\end{array}$ & $\begin{array}{l}\text { VOLUME } \\
\text { SAMPLC } \\
\text { ANALYIEO } \\
\text { TEC) }\end{array}$ & $\begin{array}{l}\text { ACTIVITY } \\
\text { PEA } \\
\text { YOL ANAL } \\
\text { OOISIMINI }\end{array}$ & $\begin{array}{l}\text { ACTIVITY } \\
\text { OFR OEOAN } \\
\text { MEIGMT } \\
\text { IEISIOINI }\end{array}$ & $\begin{array}{l}\text { ACPIYITY } \\
\text { PEA Ka } \\
\text { TOESAHTNI }\end{array}$ & $\begin{array}{l}\text { ACTIYTTY } \\
\text { PER } \\
\text { SPANMARD } \\
\text { OROAN } \\
\text { (OOSTMINI }\end{array}$ \\
\hline 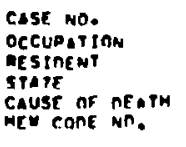 & 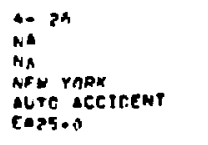 & $\begin{array}{l}\text { SEX M } \\
\text { LOE } \\
\text { VEAAS NA } \\
\text { YEAA ITAA } \\
\text { NG NA }\end{array}$ & $\begin{array}{l}\text { LIVER } \\
\text { LUNO } \\
\text { OONAn } \\
\text { RIA }\end{array}$ & $\begin{array}{r}435.0 \\
390.0 \\
190.0 \\
190.0\end{array}$ & $\begin{array}{r}250 \\
500 \\
50 \\
250\end{array}$ & $\begin{array}{l}25 \\
25 \\
10 \\
10\end{array}$ & $\begin{array}{l}.060 \\
01017 \\
.011 \\
.019\end{array}$ & $\begin{array}{l}-60 \\
\Leftrightarrow A_{L}= \\
\Leftrightarrow P_{L}= \\
\Leftrightarrow R_{L}\end{array}$ & $\begin{array}{l}1.38 \\
\text { CMALL: } \\
\text { CMAL: } \\
\text { S }\end{array}$ & 2.34 \\
\hline $\begin{array}{l}\text { Case no. } \\
\text { occuparion } \\
\text { ofsinewt } \\
\text { sfate } \\
\text { cause or neavh } \\
\text { ne cone no. }\end{array}$ & $\begin{array}{l}\text { A- } 2 A \\
\text { NA } \\
\text { NE } \\
\text { HEY YORK } \\
\text { ALTC ACCIOENT } \\
\text { ER2S on }\end{array}$ & 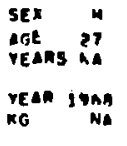 & $\begin{array}{l}\text { LIVEA } \\
\text { LUNB } \\
\text { oONAB } \\
\text { PIn }\end{array}$ & $\begin{array}{l}310.0 \\
600.0 \\
40.0 \\
215.0\end{array}$ & $\begin{array}{r}250 \\
500 \\
50 \\
250\end{array}$ & $\begin{array}{l}25 \\
25 \\
1 n \\
10\end{array}$ & $\begin{array}{l}.140 \\
.011 \\
0.000 \\
0.000\end{array}$ & 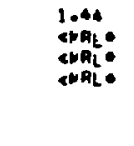 & 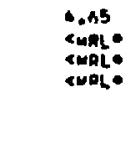 & 7.70 \\
\hline 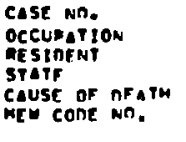 & 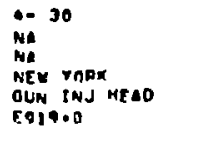 & 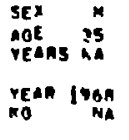 & $\begin{array}{l}\text { LIVEA } \\
\text { LINO } \\
\text { OONAn } \\
\text { Dgh }\end{array}$ & $\begin{array}{r}170.0 \\
435.0 \\
300 \\
180.0\end{array}$ & $\begin{array}{r}250 \\
500 \\
50 \\
250\end{array}$ & $\begin{array}{l}25 \\
25 \\
10 \\
10\end{array}$ & $\begin{array}{l}.028 \\
.041 \\
008 \\
.141\end{array}$ & 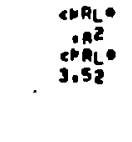 & $\begin{array}{l}\text { EMAL" } \\
1.09 \\
\text { LARL } \\
19.58\end{array}$ & $\begin{array}{r}1.00 \\
i 37.00\end{array}$ \\
\hline 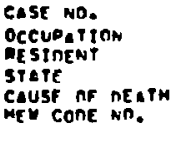 & 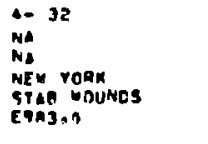 & 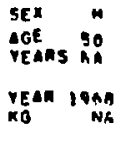 & $\begin{array}{l}\text { CIVEA } \\
\text { LUNG } \\
\text { OONAO } \\
\text { nIA }\end{array}$ & $\begin{array}{r}485.0 \\
550.0 \\
30.0 \\
+35.0\end{array}$ & $\begin{array}{l}250 \\
500 \\
50 \\
500\end{array}$ & $\begin{array}{l}25 \\
25 \\
10 \\
10\end{array}$ & $\begin{array}{r}.050 \\
.014 \\
.005 \\
0.000\end{array}$ & 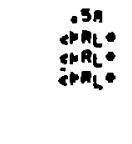 & $\begin{array}{l}2.20 \\
\angle M A L \\
\text { CMAL: } \\
\text { CHAL: }\end{array}$ & 2.03 \\
\hline 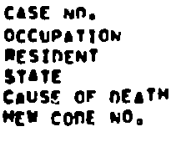 & $\begin{array}{l}\text { A- } 34 \\
\text { NA } \\
\text { KA } \\
\text { NEY YOPE } \\
\text { CNEST STAB WO } \\
\text { OSI - }\end{array}$ & 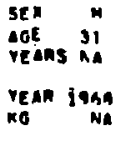 & $\begin{array}{l}\text { Live: } \\
\text { LUNG } \\
\text { oONho } \\
\text { nin }\end{array}$ & $\begin{array}{r}365=0 \\
705: 0 \\
42=0 \\
155=0\end{array}$ & $\begin{array}{r}250 \\
900 \\
50 \\
250\end{array}$ & $\begin{array}{l}25 \\
25 \\
10 \\
10\end{array}$ & $\begin{array}{l}.033 \\
.028 \\
.008 \\
.002\end{array}$ & 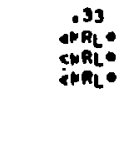 & 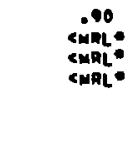 & 1.54 \\
\hline 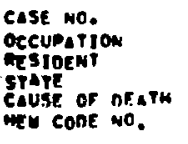 & 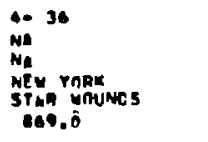 & $\begin{array}{l}\text { sex } \\
\text { ige } 37 \\
\text { reans ha } \\
\text { rean gose } \\
\text { ne na }\end{array}$ & $\begin{array}{l}\text { LIVEA } \\
\text { LUNO } \\
\text { oONAn } \\
\text { Ris }\end{array}$ & $\begin{array}{r}350.0 \\
3400 \\
2040\end{array}$ & $\begin{array}{r}250 \\
250 \\
50 \\
250\end{array}$ & $\begin{array}{l}25 \\
25 \\
10 \\
10\end{array}$ & $\begin{array}{l}.042 \\
.028 \\
.020 \\
.095\end{array}$ & 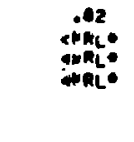 & 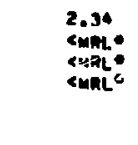 & 3.90 \\
\hline 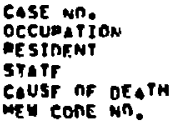 & $\begin{array}{l}\text { A- Jn } \\
\text { NA } \\
\text { NA } \\
\text { NEW YORK } \\
\text { ALTO ACC TEENT } \\
\text { EEPS: } 0\end{array}$ & 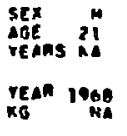 & $\begin{array}{l}\text { LIVEn } \\
\text { LUNB } \\
\text { oONAD } \\
\text { nte }\end{array}$ & $\begin{array}{r}205.0 \\
630: 0 \\
49: 1 \\
220.0\end{array}$ & $\begin{array}{r}100 \\
500 \\
500 \\
250\end{array}$ & $\begin{array}{l}25 \\
25 \\
10 \\
10\end{array}$ & $\begin{array}{r}.709 \\
.005 \\
0.000 \\
.031\end{array}$ & $\underset{: 7 \%}{.04}$ & $\begin{array}{l}2+93 \\
<\in R L= \\
<\rightarrow R L \\
3.52\end{array}$ & $\begin{array}{l}4.09 \\
24.64\end{array}$ \\
\hline 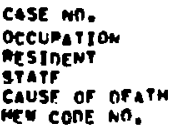 & 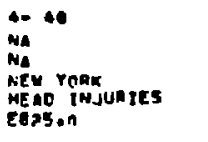 & 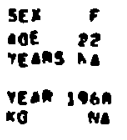 & $\begin{array}{l}\text { LiYeA } \\
\text { LUNO } \\
\text { AONAS } \\
\text { ATh }\end{array}$ & $\begin{array}{r}270.0 \\
4+0.0 \\
15.0 \\
20100\end{array}$ & $\begin{array}{l}100 \\
500 \\
50 \\
290\end{array}$ & $\begin{array}{l}25 \\
28 \\
10 \\
10\end{array}$ & $\begin{array}{r}.042 \\
.011 \\
0.007 \\
.010\end{array}$ & 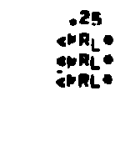 & $\begin{array}{l}\text { P2 } \\
\text { SMAL: } \\
\text { SMRL: }\end{array}$ & i. .58 \\
\hline 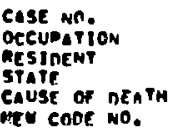 & 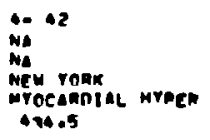 & 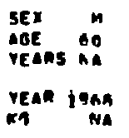 & $\begin{array}{l}\text { LIVEA } \\
\text { LUNA } \\
\text { GONAN } \\
\text { aIS }\end{array}$ & $\begin{array}{r}50: 0 \\
500 \% 0 \\
32: 0 \\
270.0\end{array}$ & $\begin{array}{l}250 \\
500 \\
58 \\
256\end{array}$ & $\begin{array}{l}25 \\
25 \\
10 \\
50\end{array}$ & $\begin{array}{l}.077 \\
.012 \\
.003 \\
.052\end{array}$ & cimco & $\begin{array}{l}2.71 \\
\text { cmile } \\
\text { cmeit. } \\
6.01\end{array}$ & $\begin{array}{r}2.91 \\
33.70\end{array}$ \\
\hline $\begin{array}{l}\text { Case no. } \\
\text { oecubarion } \\
\text { nesinent } \\
\text { stafe } \\
\text { Causf nF ntair } \\
\text { my cone mo. }\end{array}$ & 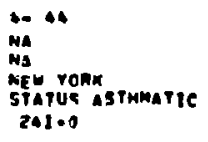 & $\begin{array}{l}\text { SEX } \\
\text { AGE } 22 \\
\text { VEAnS RA } \\
\text { VEAR IOAn } \\
\text { no }\end{array}$ & $\begin{array}{l}\text { LIVEE } \\
\text { LuNe } \\
\text { erinad } \\
\text { RiA }\end{array}$ & $\begin{array}{r}46.0 \\
177.0 \\
15.0 \\
295.0\end{array}$ & $\begin{array}{r}250 \\
500 \\
50 \\
250\end{array}$ & $\begin{array}{l}25 \\
25 \\
10 \\
10\end{array}$ & $\begin{array}{l}.118 \\
.034 \\
.057 \\
.040\end{array}$ & $\begin{array}{r}1.18 \\
.68 \\
1.28\end{array}$ & $\begin{array}{r}2.57 \\
1.00 \\
19.00 \\
3.92\end{array}$ & $\begin{array}{r}4.36 \\
1.00 \\
27.76\end{array}$ \\
\hline 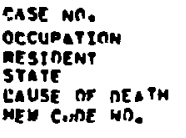 & $\begin{array}{l}\text { AO AS } \\
\text { MA } \\
\text { HA YOAK } \\
\text { NEU TIPLE INS } \\
\text { CELS.0 } \\
\text { CEZS }\end{array}$ & 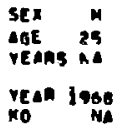 & $\begin{array}{l}\text { LIVEA } \\
\text { LUNO } \\
\text { ONNAD } \\
\text { RIO }\end{array}$ & $\begin{array}{r}540.0 \\
345: 0 \\
30 \% 0 \\
242.0\end{array}$ & $\begin{array}{l}250 \\
500 \\
50 \\
250\end{array}$ & $\begin{array}{l}25 \\
25 \\
10 \\
10\end{array}$ & $\begin{array}{l}.005 \\
.003 \\
.011 \\
.105\end{array}$ & 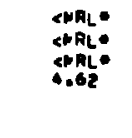 & $\begin{array}{l}\text { supl: } \\
\text { sent: } \\
\text { sori: } \\
19.12\end{array}$ & 133.70 \\
\hline 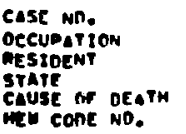 & 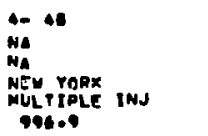 & $\begin{array}{l}\text { sex m } \\
\text { ade } 17 \\
\text { veans in } \\
\text { vean ioba } \\
\text { ne ma }\end{array}$ & $\begin{array}{l}\text { LIVEA } \\
\text { LUNB } \\
\text { gONAD } \\
\text { DIA }\end{array}$ & $\begin{array}{r}380.0 \\
795.0 \\
35.0 \\
230.0\end{array}$ & $\begin{array}{l}250 \\
500 \\
58 \\
250\end{array}$ & $\begin{array}{l}25 \\
25 \\
10 \\
20\end{array}$ & $\begin{array}{l}.057 \\
.025 \\
.018 \\
.227\end{array}$ & $\begin{array}{l}.57 \\
\text { eWGL: } \\
2,5 R_{L}^{\circ} \\
2,52\end{array}$ & $\begin{array}{c}1.59 \\
\text { cminte } \\
12.72\end{array}$ & $\begin{array}{r}2.53 \\
09.02\end{array}$ \\
\hline
\end{tabular}


ITSSUE

CASE NO.

occupation

AESINENT

STATE

MEU CODE NO.

\begin{abstract}
SEX H LIVER
IGE AI LUNG

YEARS AA GONAD

YEAA 1960
TO
\end{abstract}

996.9
ACTIVITY

PF

VOL INAL

ACTiVitY ACTIVITY
PER OAGAN PEN Ka

TEIOH 1

(OISININ) (DIS/MIN)

activiti

PEA

WEIGHT CF SAMPLE
SAMPLE

(CC) $\langle C E\rangle$

340.0

680.0

$\begin{array}{ll}250 & 25 \\ 500 & 25 \\ 50 & 10\end{array}$

.05

cirl.

1.42

SHAL:

eMRL:

250.0

.008

CWRLE

ORBAN

(OD:5/MIN)

2.41 


\section{APPENDIX B}

\section{CUMULATIVE FREQUENCY DISTRIBUTIONS}
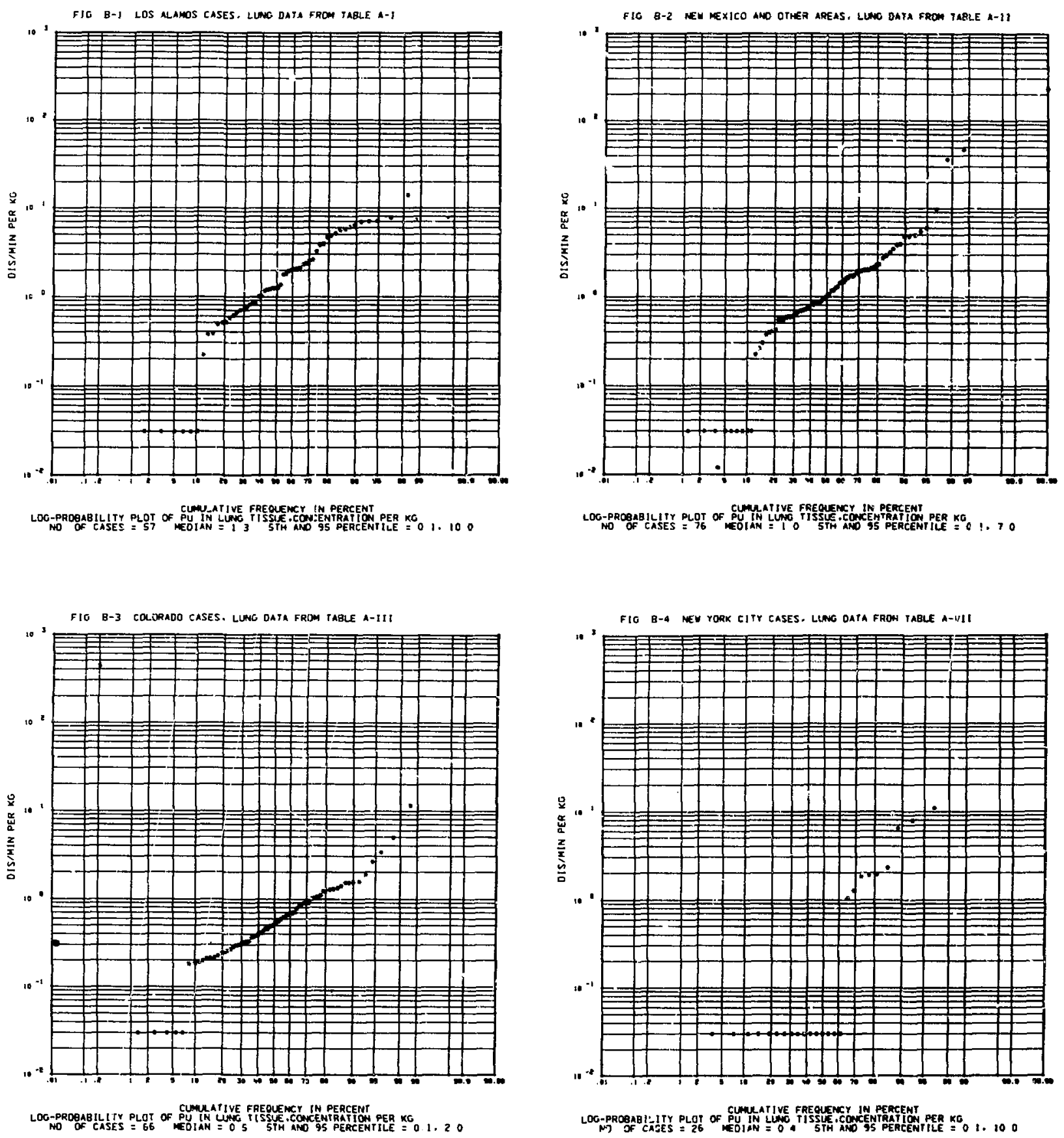

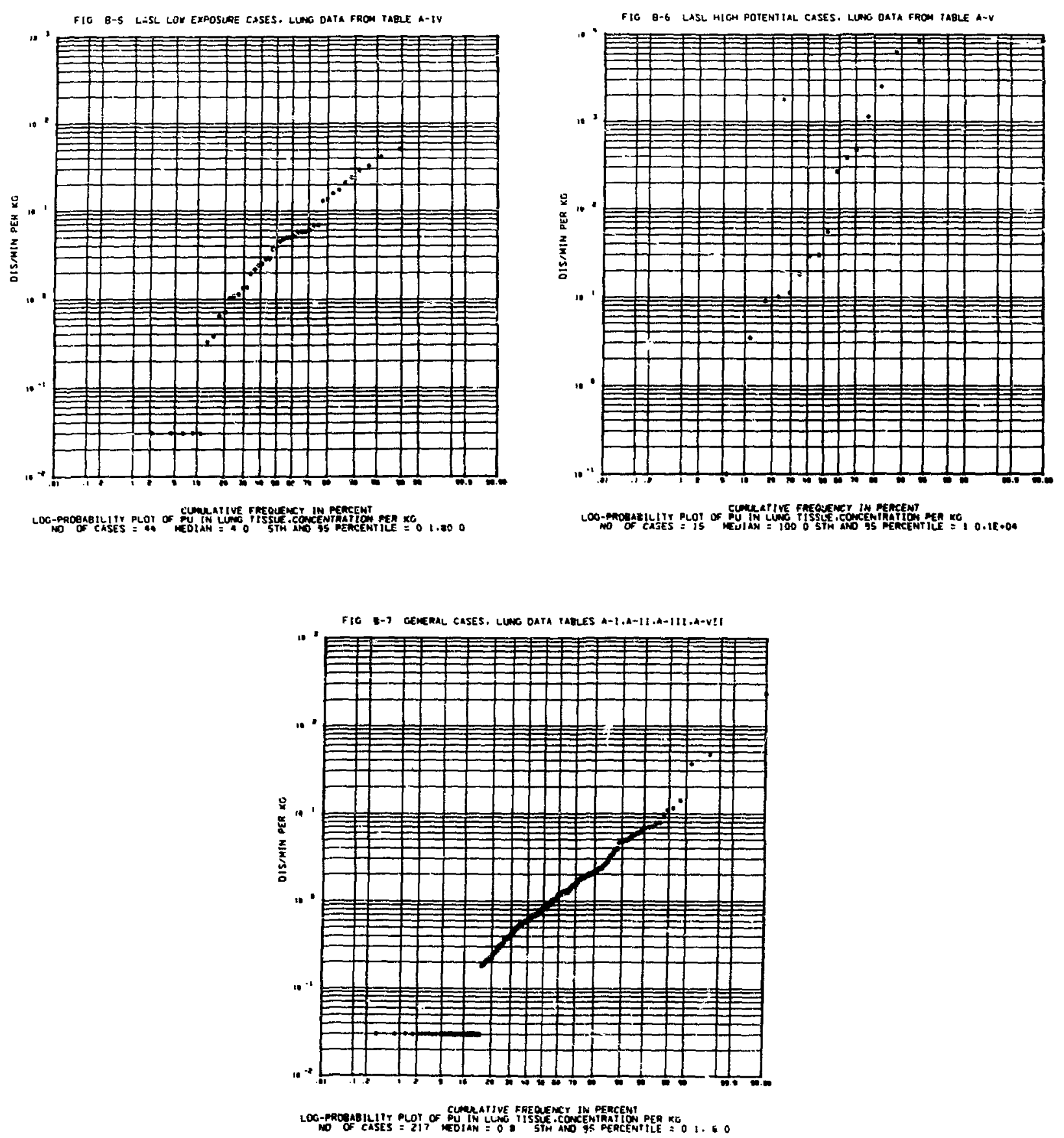

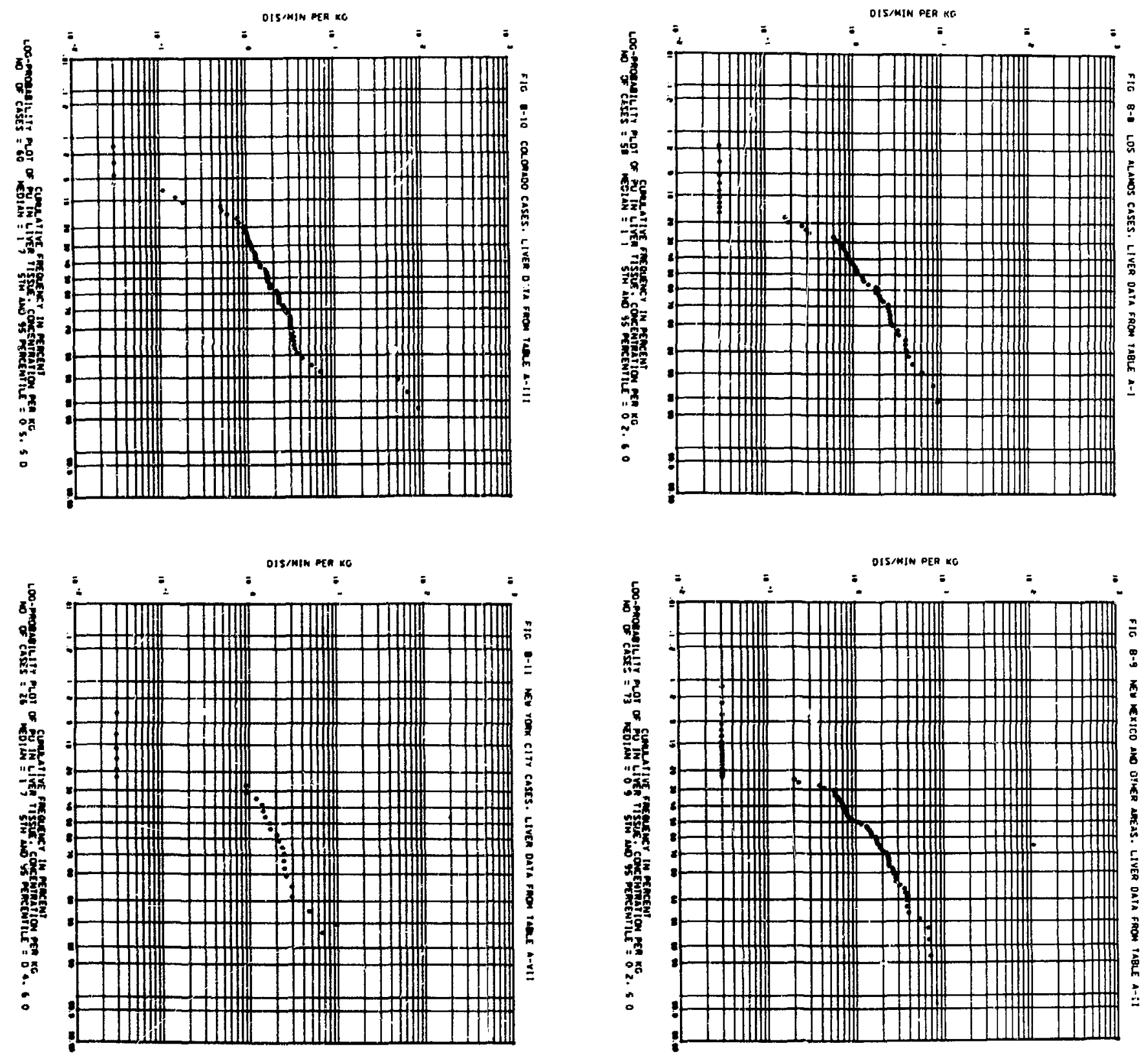

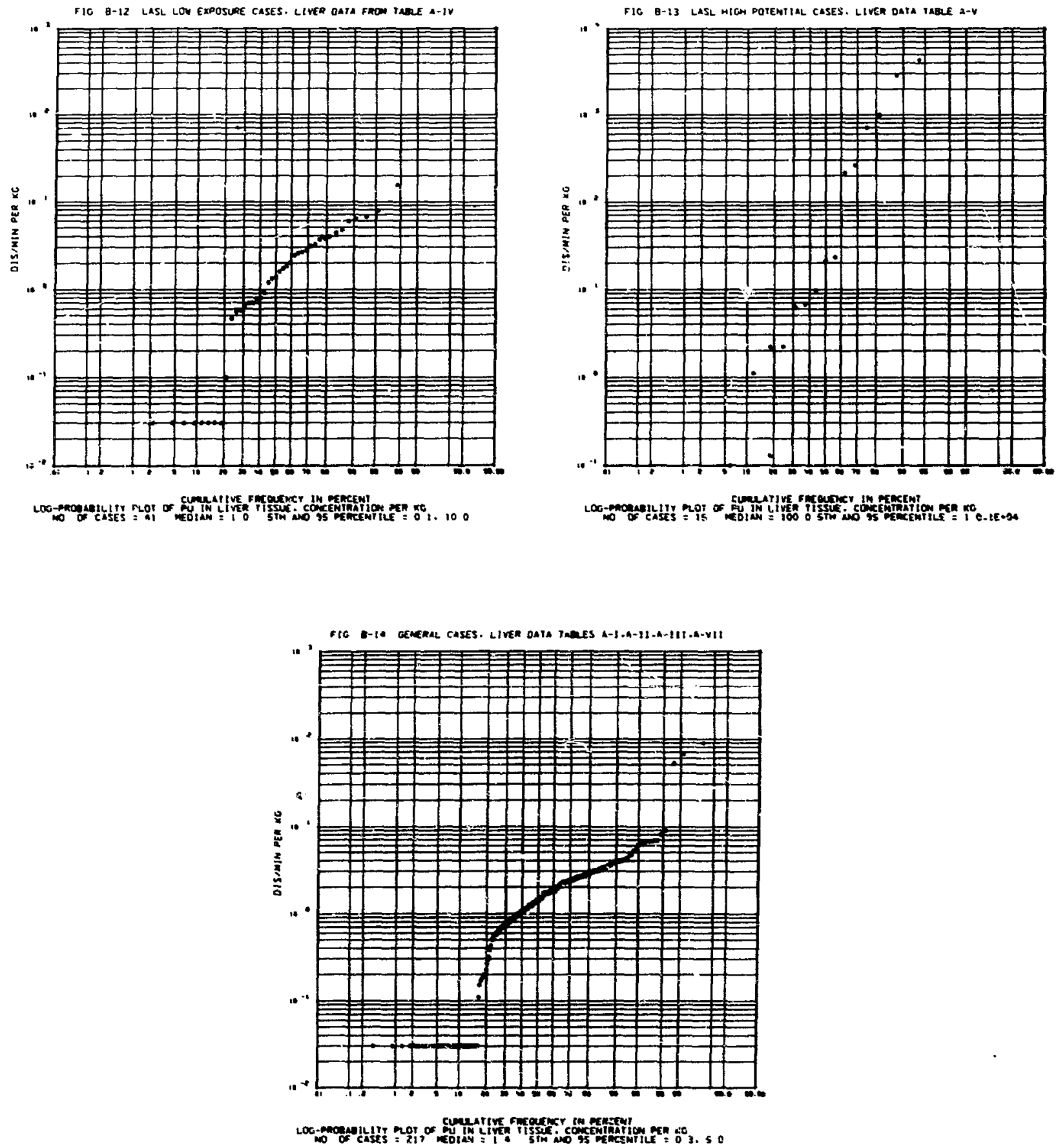

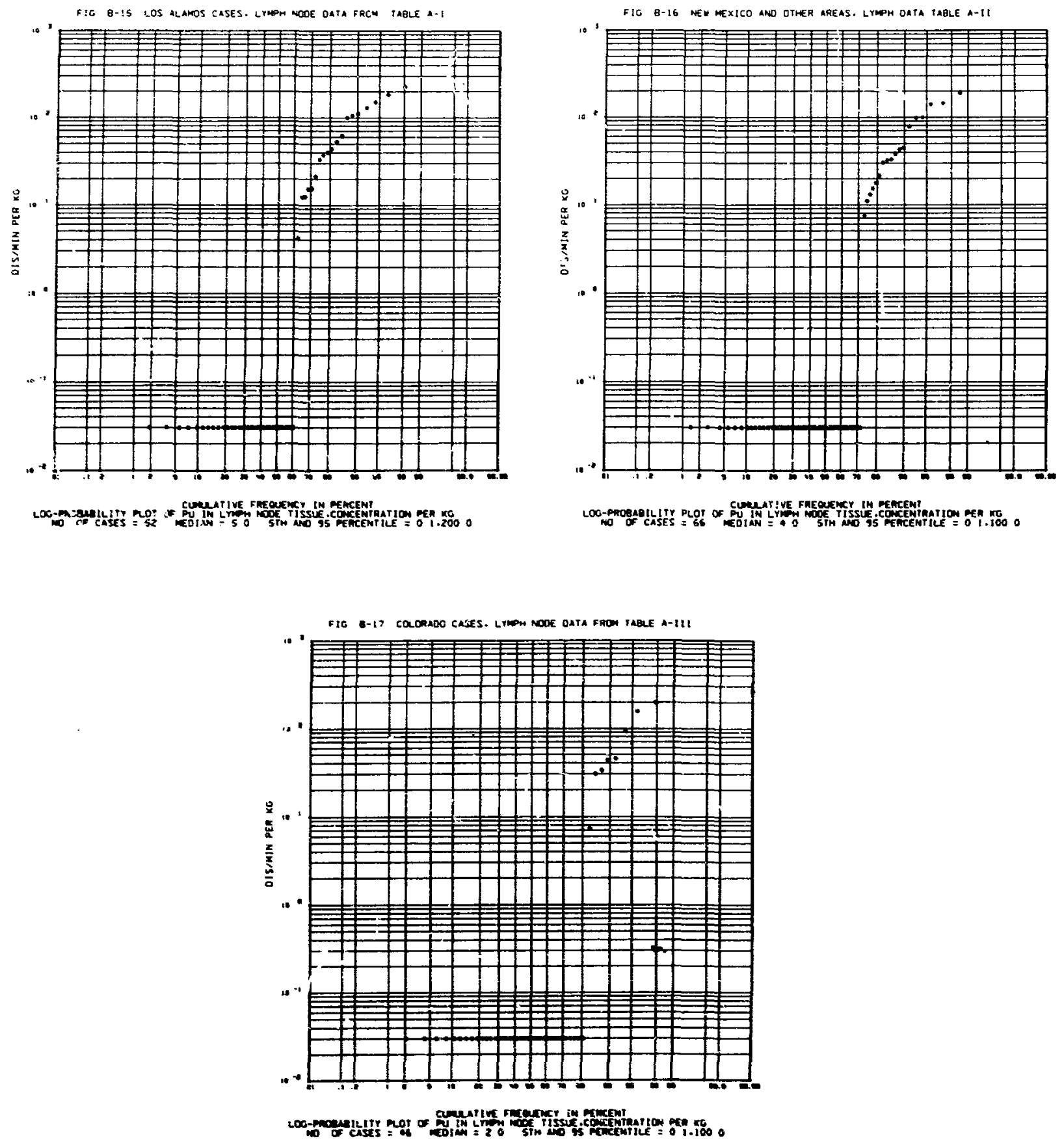

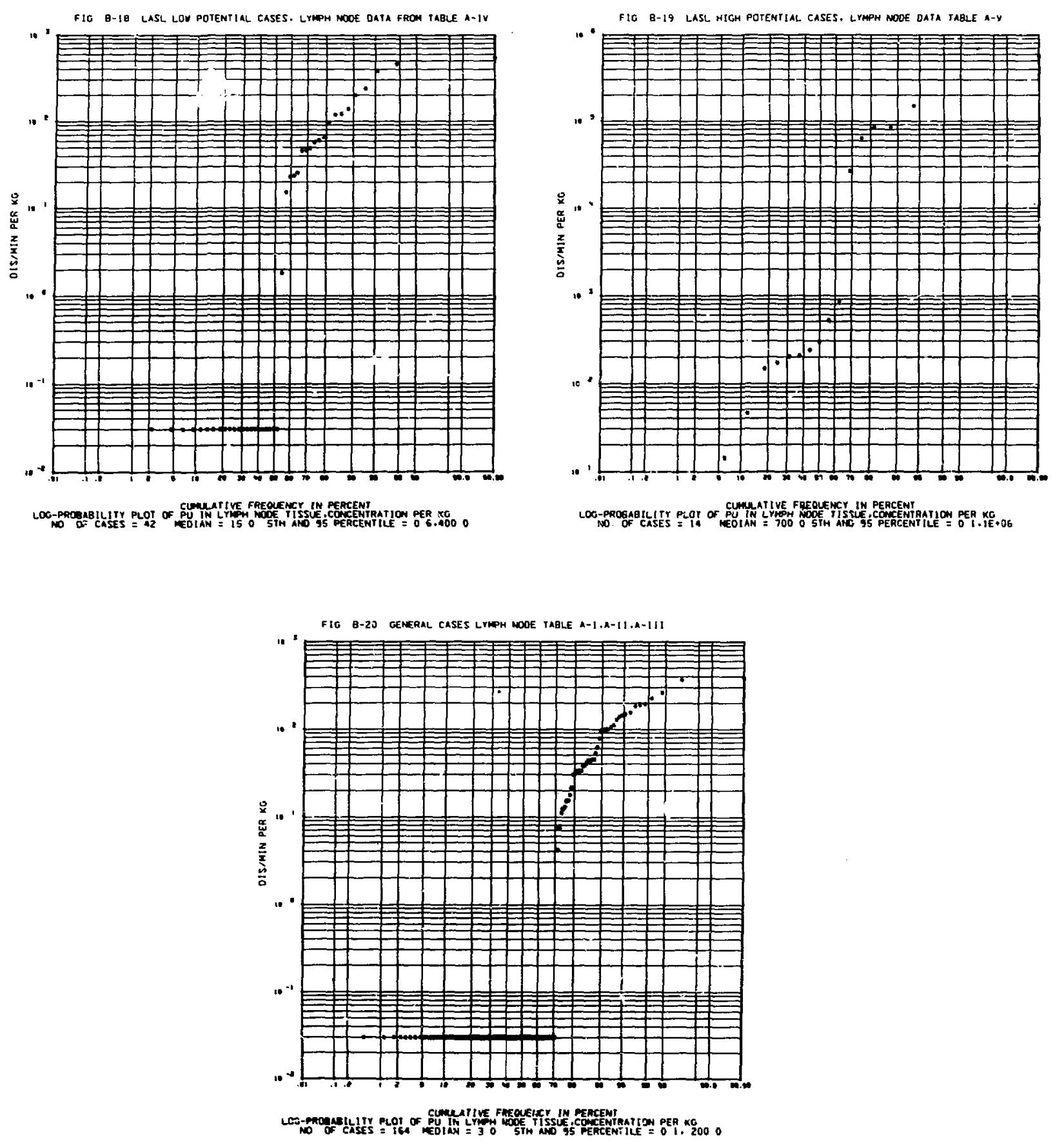

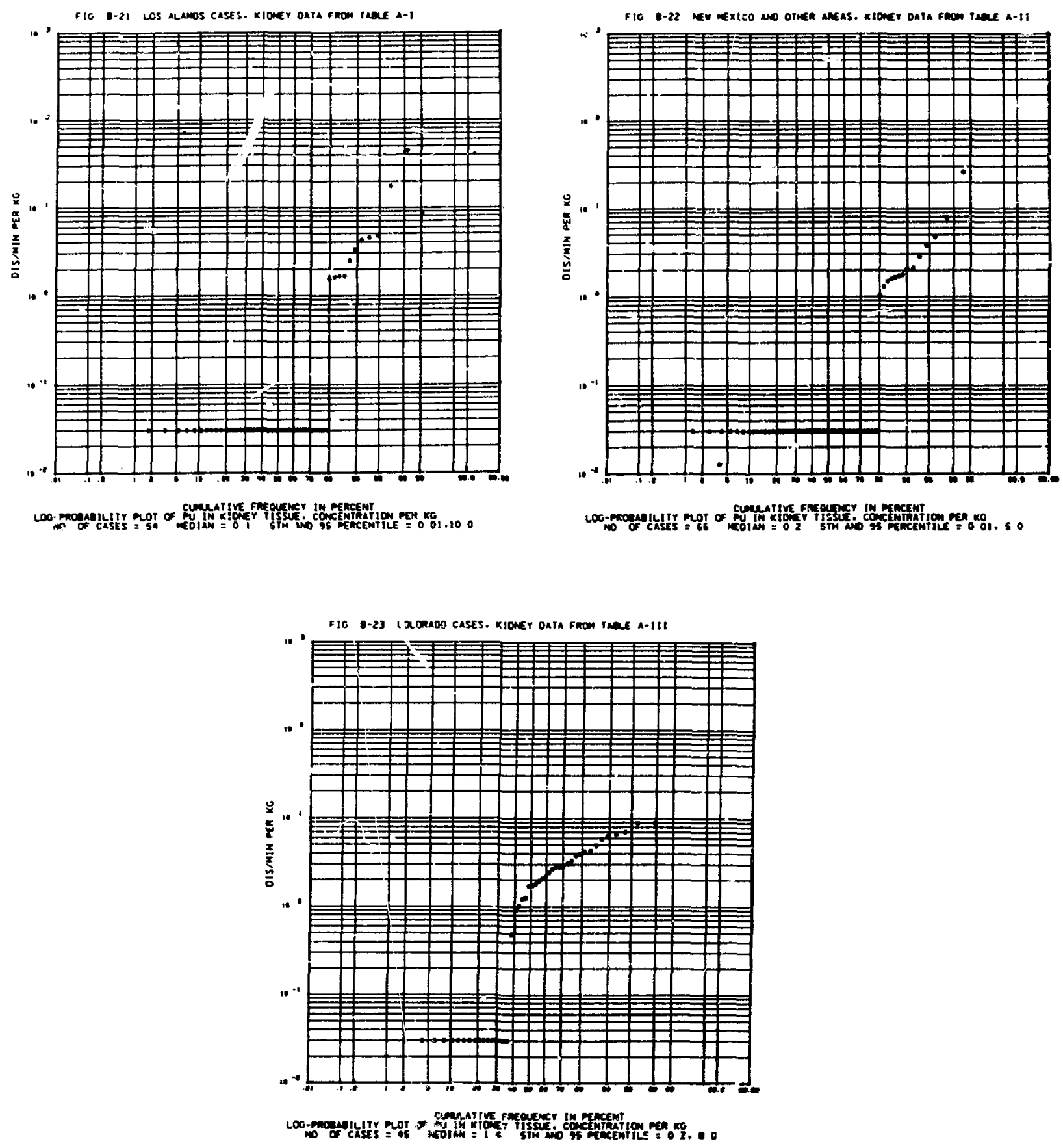


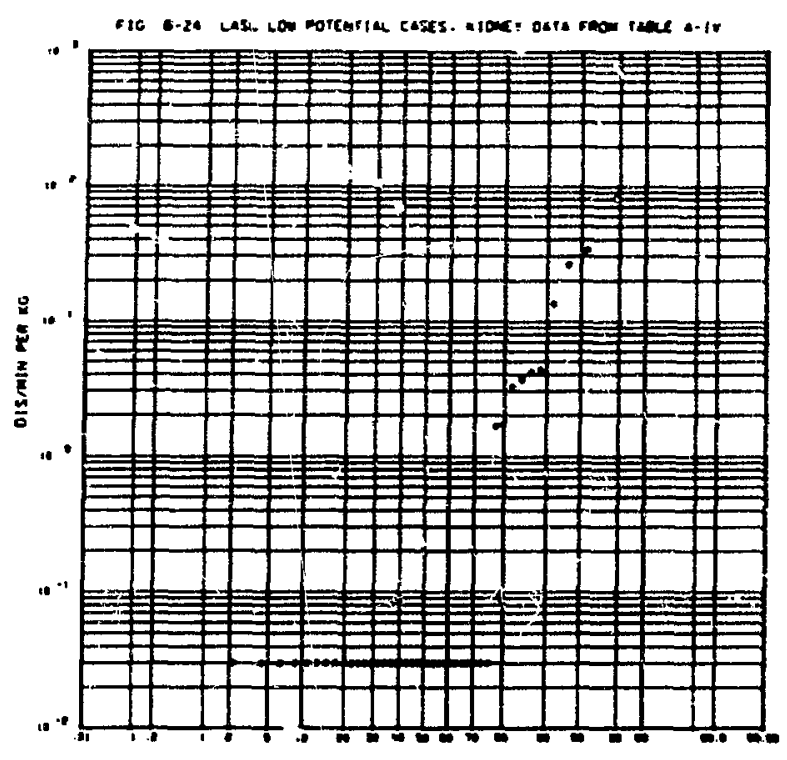

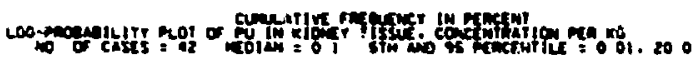

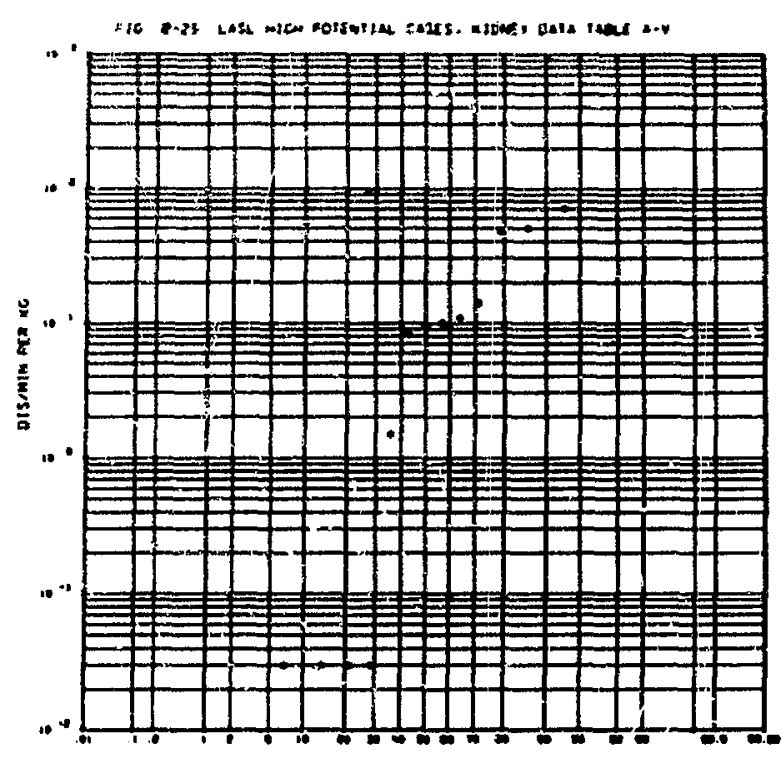

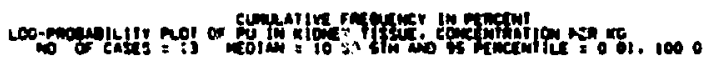

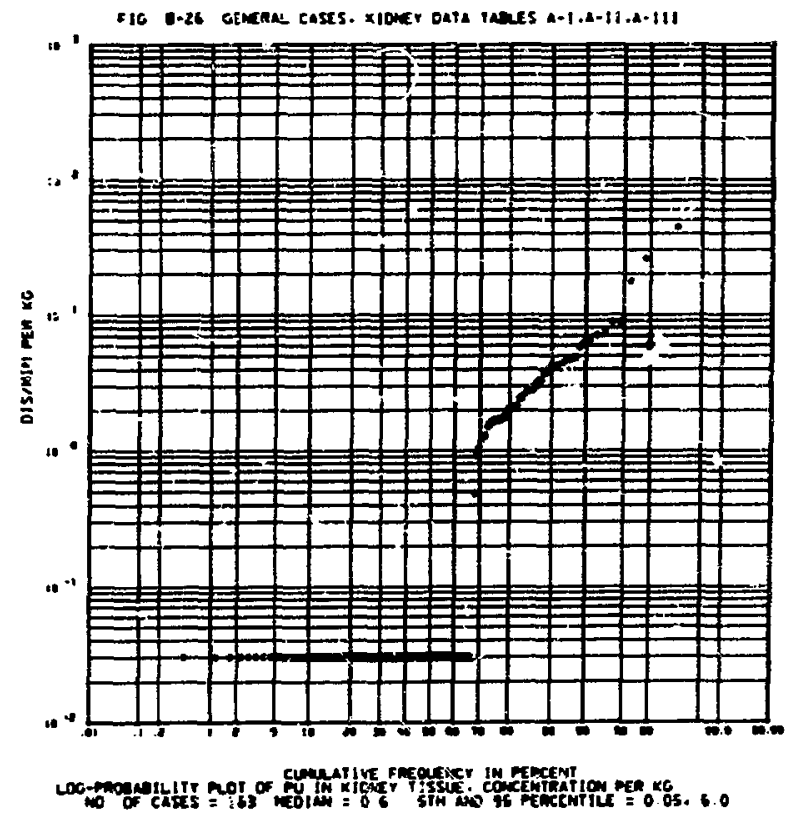




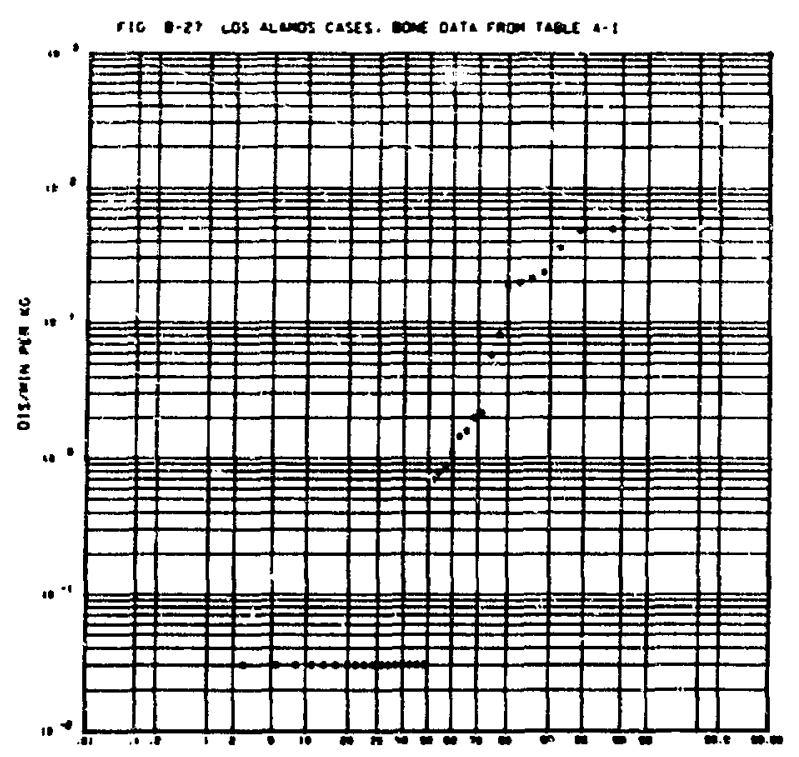

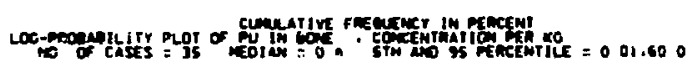

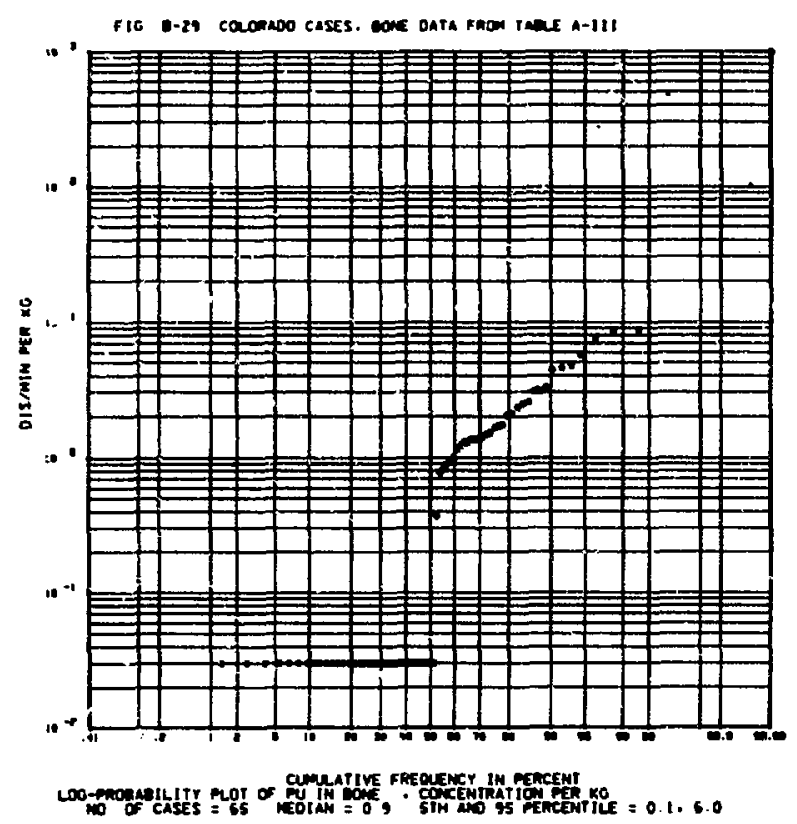

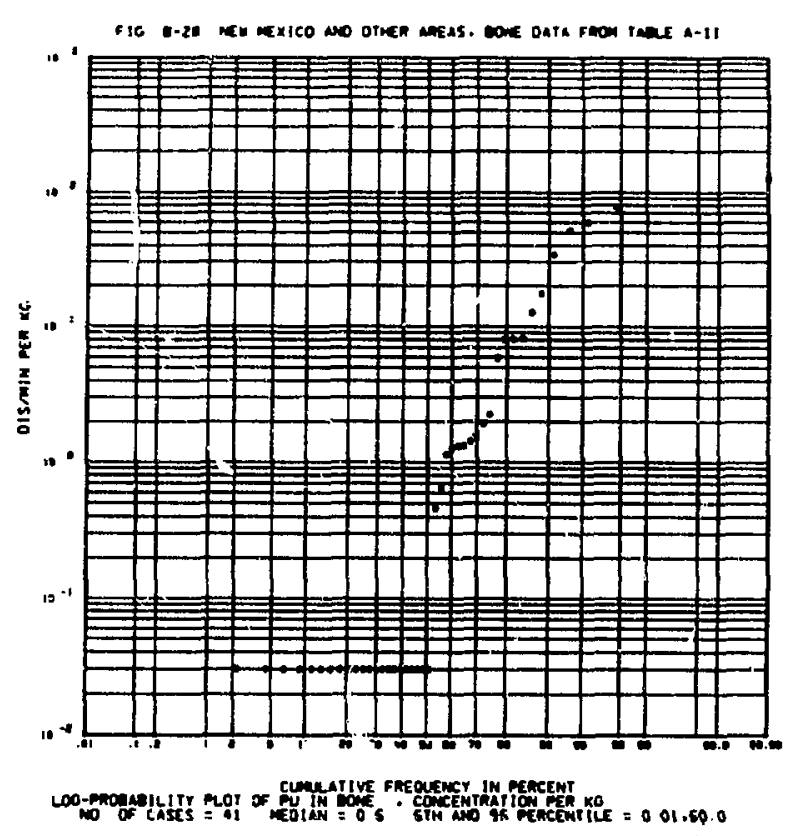

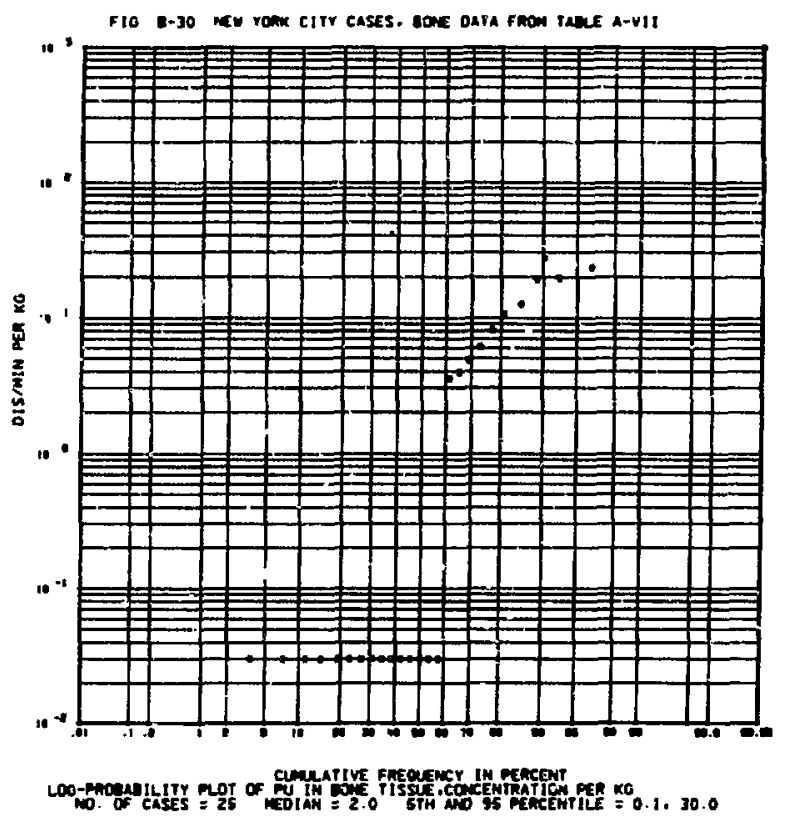



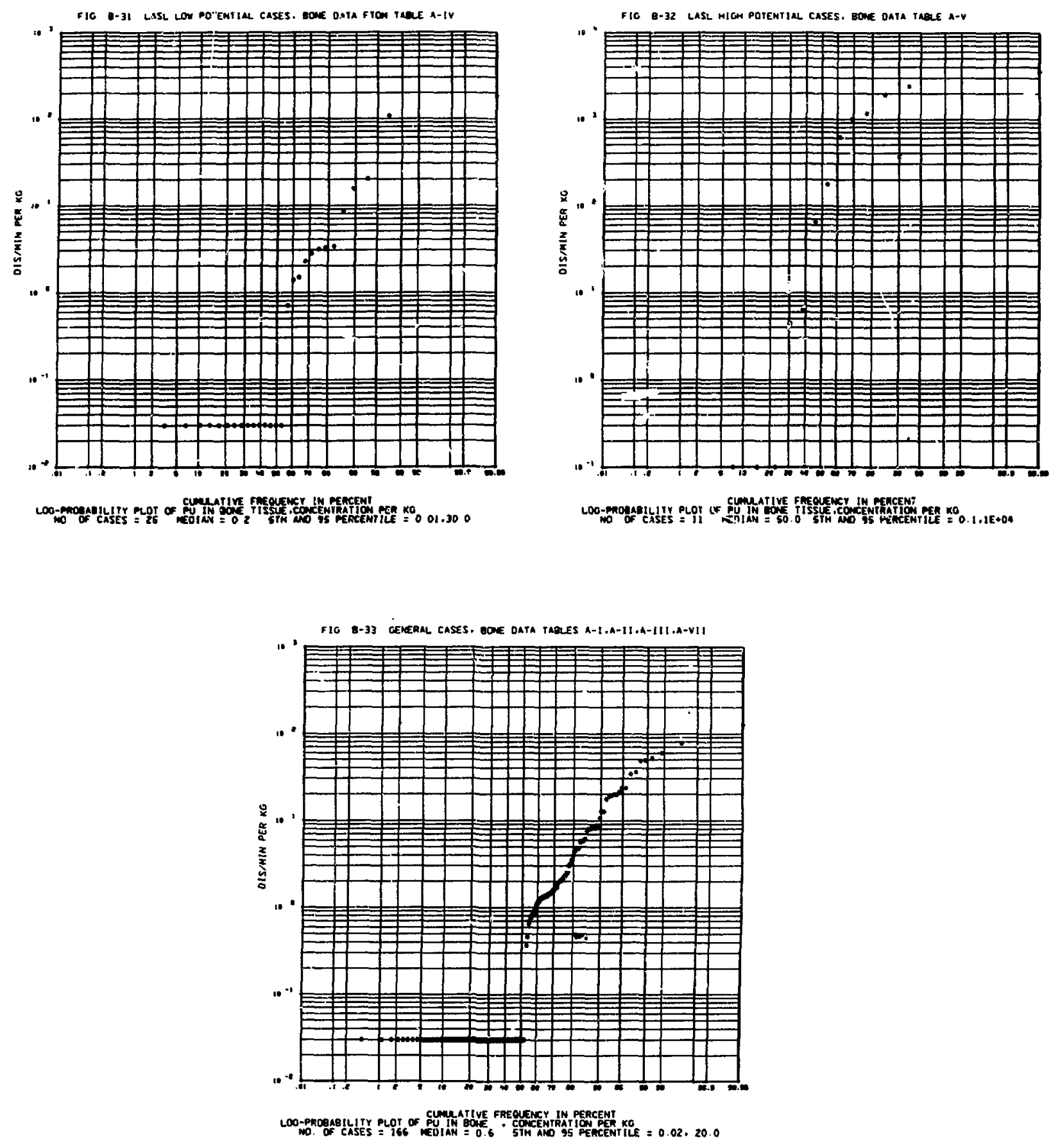


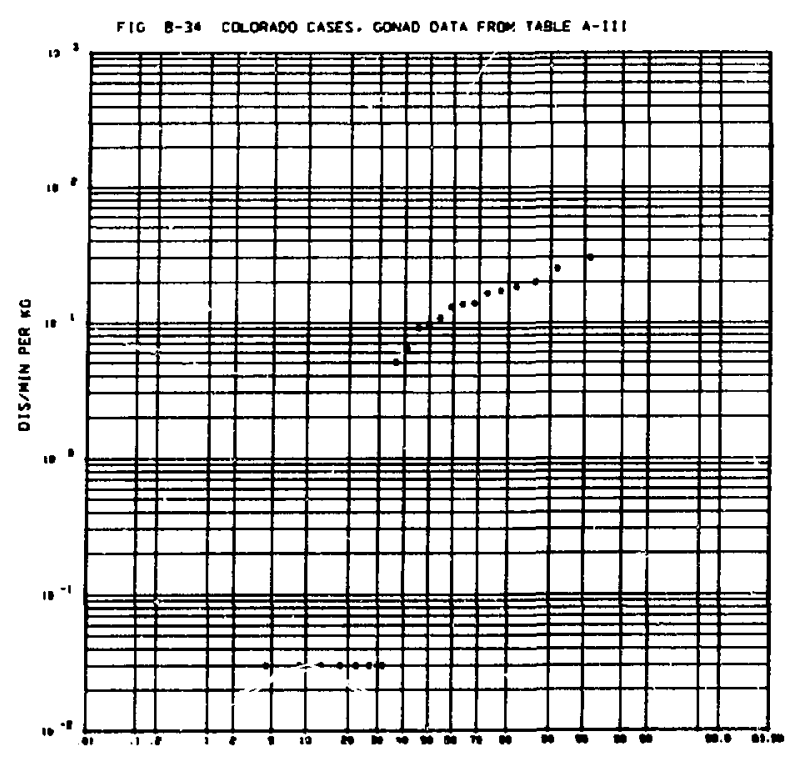

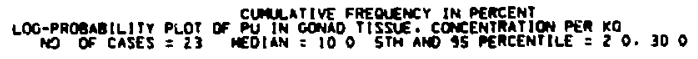

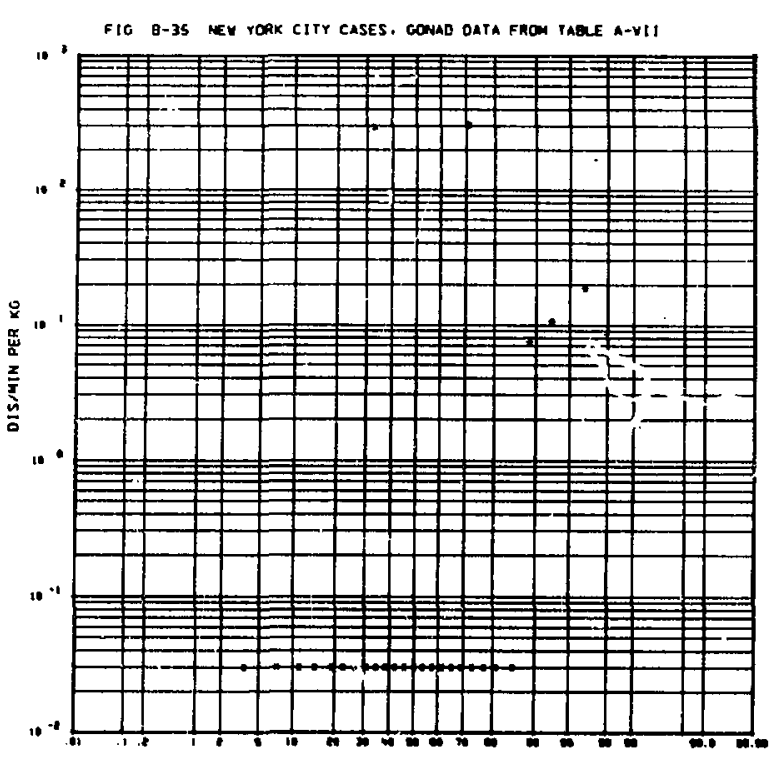

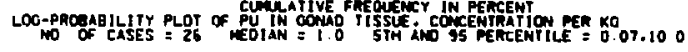




\section{APPENDIIX C}

SUMMARY TABLES

TABLE C-I

SOTH PERCENTILE DISTRIBUTION OF PLUTONIUM IN HEMAN TISSUE

\section{Nonoccupationally Exposed}

\section{Los Alamos}

New Mexico \& U.S.

Colorado

New York

Al: Populations
Plutonium Disintegrations per Minute per Kilogram

\begin{tabular}{|c|c|c|c|c|c|}
\hline \multirow[b]{2}{*}{ Lung } & \multicolumn{3}{|c|}{ Lymph } & \multirow[b]{2}{*}{ Bone } & \multirow[b]{2}{*}{ Gonad } \\
\hline & Liver & Node & Kidney & & \\
\hline $1.3(57)^{2}$ & $1.1(58)$ & $5.0(52)$ & $0.1(54)$ & $0.4(35)$ & $\mathbf{b}$ \\
\hline $1.0(76)$ & $0.9(73)$ & $4.0(66)$ & $0.2(66)$ & $0.5(41)$ & $\mathbf{b}$ \\
\hline $0.5(66)$ & $1.7(60)$ & $2.0(46)$ & $1.4(45)$ & $0.9(65)$ & $10.0(23)$ \\
\hline $0.4(26)$ & $1.7(26)$ & b & b & $2.0(25)$ & $1.0(26)$ \\
\hline $0.8(217)$ & $1.4(2 ! 7)$ & $3.0(164)$ & $0.6(163)$ & $0.6(166)$ & b \\
\hline
\end{tabular}

\section{C'ccupationally Exposed}

$\begin{array}{lrrrrrr}\text { Potential } & 4.0(44) & 1.0(41) & 15.0(42) & 0.1(42) & 0.3(25) & b \\ \text { High Potential } & 100.0(15) & 100.0(15) & 700.0(14) & 10.0(13) & 50.0(11) & b\end{array}$

(a) number of samples.

bsamples not requested.

CData cannot be compared as a group because of differences in type and duration of exposure.

\section{TABLE C-II}

SUMMARY OF PLUTONIUM IN HUMAN TISSUE ESTIMATED FROM LOG-PROR,ARILITY FLOTS OF CONCENTRATION PER kg OF TISSUE

\begin{tabular}{|c|c|c|c|c|}
\hline \multirow{2}{*}{$\frac{\text { Population }}{\text { General }}$} & \multirow{2}{*}{$\frac{\text { Tissue }}{\text { Lung }}$} & \multirow{2}{*}{$\frac{\begin{array}{c}\text { Median } \\
\text { (dis/min/kg) }\end{array}}{0.8}$} & \multicolumn{2}{|c|}{$\begin{array}{l}\text { 5th to } 95 \text { th } \\
\text { Percentile } \\
\text { of Results } \\
\text { (dis/min } / \mathrm{kg} \text { ) }\end{array}$} \\
\hline & & & 0.1 & to 8.0 \\
\hline Low-Potential & & 4.0 & 0.1 & to 80.0 \\
\hline High-Potential & & 100.0 & 1.0 & to $1 \times 10^{4}$ \\
\hline General & Liver & 1.4 & 0.3 & to 5.0 \\
\hline Low-Potential & & 1.0 & 0.1 & to 10.0 \\
\hline High Potential & & 100.0 & 0.1 & to $1 \times 10^{4}$ \\
\hline \multirow[t]{2}{*}{ General } & Lymph & & & \\
\hline & Node & 3.0 & 0.1 & to 200.0 \\
\hline Low-Potential & & 15.0 & 0.6 & to 400.0 \\
\hline High-Potential & & 700.0 & 0.1 & to $1 \times 10^{6}$ \\
\hline General & Kidney & 0.6 & 0.05 & $5: 06.0$ \\
\hline Low-Potentia! & & 0.1 & 0.01 & to 20.0 \\
\hline High-Potential & & 1.0 & 0.01 & to 100.0 \\
\hline General & Bone & 0.6 & 0.02 & to 20.0 \\
\hline Low-Potential & & 0.2 & 0.03 & to 30.0 \\
\hline High-Potential & & 30.0 & 0.6 & to $1 \times 10^{4}$ \\
\hline
\end{tabular}

